\title{
ABORDAGEM QUANTITATIVA NA PREDIÇÃO ESPACIAL DE ATRIBUTOS DO SOLO E GERAÇÃO DE ZONAS DE MANEJO AGRÍCOLA
}

\author{
MARCIA FREIRE MACHADO SÁ \\ Engenheira Agrônoma
}

Orientador: Prof. Dr. KLAUS REICHARDT

Tese apresentada à Escola Superior de Agricultura "Luiz de Queiroz", Universidade de São Paulo, para obtenção do título de Doutor em Agronomia, Área de Concentração: Solos e Nutrição de Plantas.

PIRACICABA

Estado de São Paulo - Brasil

Janeiro - 2001 


\title{
Dados Internacionais de Catalogação na Publicação (CIP) DIVISÃO DE BIBLIOTECA E DOCUMENTAÇÃO - Campus "Luiz de Queiroz"/USP
}

\author{
Sá, Marcia Freire Machado \\ Abordagem quantitativa na predição espacial de atributos do solo e geração de zonas de \\ manejo agricola / Marcia Freire Machado Sá. - - Piracicaba, 2001. \\ $117 \mathrm{p}$. \\ Tese (doutorado) - Escola Superior de Agricultura Luiz de Queiroz, 2001. \\ Bibliografia. \\ 1. Agricultura de precisão 2. Análise de regressão 3. Fertilidade do solo 4. Manejo solo \\ 5. Propriedade fisico-química do solo 6. Relação solo-paisagem 7. Variabilidade espacial I. \\ Título
}

CDD 631.4 
Dedico este trabalho

a meus pais, José e Leda, pelo seu amor e constante incentivo, ao meu esposo Juca, por seu companheirismo e confiança e aos meus filhos Cássia e Daniel, fonte de inspiração e força para abraçar os desafios 


\section{Agradecimentos}

Meus sinceros agradecimentos às pessoas e instituições que tornaram possível a realização deste trabalho:

Ao Prof. Dr Klaus Reichardt pela orientação, confiança e amizade;

Ao Prof. Dr. Brian K. Slater, pela orientação durante o período que permaneci

na The Ohio State University desenvolvendo habilidades em softwares que possibilitaram a conclusão deste trabalho;

À Empresa Lucio Miranda Empreendimentos Agropecuários, e particularmente ao Sr. Lúcio, pelo apoio e suporte irrestrito durante a fase de coleta das amostras de solo na Fazenda Santa Branca. Agradecimento extendido ao Eng. Agrônomo Paulo Sérgio Assumpção e, especialmente, ao Eng. Agrônomo Jorge do Rocio Ferreira e toda a equipe de campo da fazenda por me acompanharem na árdua tarefa de amostragem dos solos;

Ao proprietário da Fazenda Pousada dos Gaúchos, Sr. Ivo Arnt Filho pela permissão de acesso e coleta de amostras de solo nos campos nativos de sua propriedade;

Ao Prof. Dr. José Alexandre Melo Demattê pela colaboração durante a etapa de elaboração do projeto inicial deste trabalho;

À equipe técnica dos laboratórios de Física e Mineralogia dos Solos da ESALQUSP (Bete, Wladmir e Luciano) e Física dos Solos do CENA-USP (Dudu e Ademir) pela amizade e companheirismo;

À Universidade Estadual de Ponta Grossa e à Escola Superior de Agricultura Luiz de Queiroz, pela oportunidade de realização do curso de doutorado;

À The Ohio State University, School of Natural Researches, pela oportunidade de realização do "doutorado sandwich";

À CAPES, pelo suporte através de concessão de bolsa de estudo "doutorado sandwich";

À FAPESP, pela concessão de auxílio financeiro à execução do projeto; 
Aos colegas do Depto de Ciência do Solo e Engenharia Agrícola da UEPG pelo suporte durante o período de minha ausência. Agradecimentos especiais ao Prof. Dr. Altair Justino por se encarregar de meus negócios pessoais durante o tempo de permanência no exterior;

Ao amigo, colega e esposo João Carlos (Juca) pela imensurável ajuda, força e compreensão, em cada passo da realização deste trabalho. 


\section{SUMÁRIO}

Página

RESUMO xii

SUMMARY ix

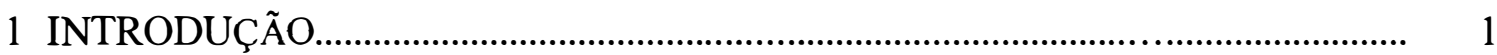

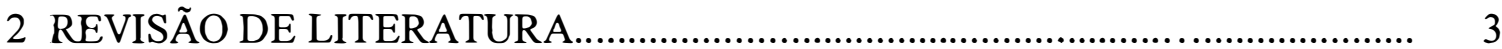

2.1 Paradigmas e Pedologia............................................................ 3

2.2 Em direção à modelagem quantitativa da diversidade dos solos.................. 5

2.2.1 Estruturas de classificação............................................... 5

2.2.2 Modelos de organização do continuum solo-paisagem............................. 6

2.3 Indivíduos, entidades, e corpos de solos.......................................... 8

2.4. Relações solo-paisagem e modelagem................................................ 9

2.4.1 Perspectiva histórica................................................... 9

2.4.2 Modelos de solo-paisagem.......................................... 10

2.4.3 Uma de uma nova estrutura espacial para modelar a diversidade dos solos... 11

2.5 Predição de propriedades dos solos a partir de modelos contínuos da relação solo-paisagem.................................................................... 12

2.5.1 Modelo de Elevação Digital (DEM)..................................... 12

2.5.2 Atributos Topográficos....................................... 13

2.6 Uso da classificação contínua na pedologia................................ 15

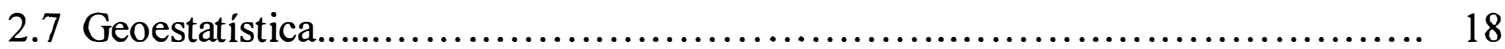

2.8 Agricultura de precisão............................................... 18

3 PREDIÇÃO DE ATRIBUTOS DE SOLOS ATRAVÉS DE ANÁLISES TOPOGRÁFICAS EM TOPOSSEQUÊNCIAS DA REGIÃO DOS “CAMPOS

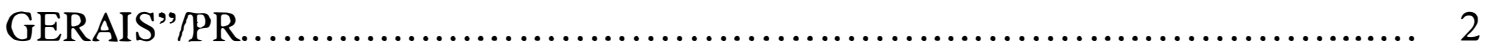

3.1 RESUMO............................................................. 21

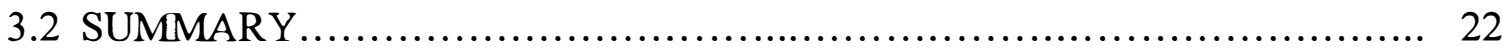

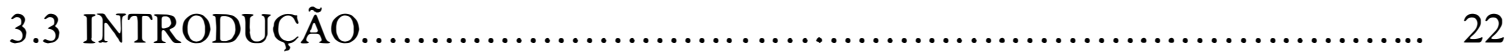

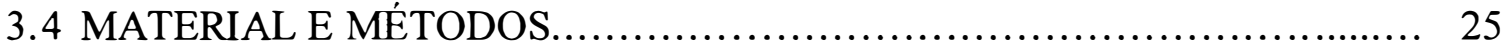


3.4.1 Caracterização geral da área............................................. 25

3.4.2 Modelo de Elevação Digital (DEM) e Atributos Topográficos................. 27

3.4.3 Metodologia de amostragem e análise de solo e plantas .................... 28

3.4.4 Análises Estatísticas e Obtenção de Curvas de Isolinhas de Atributos do Solo 30

3.4.5 Relações entre atributos dos solos e topográficos ........................ 31

3.4.6 Classificação contínua ou fuzzy...................................... 31

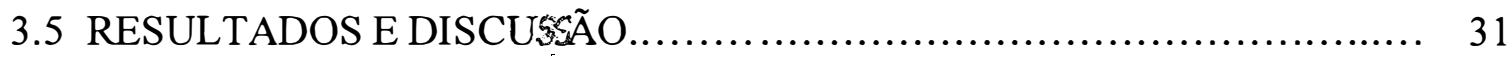

3.6 CONCLUSÕES..................................................... 52

4 VARIABILIDADE DA FERTILIDADE DO SOLO EM TOPOSSEQUÊNCIAS DA REGIÃO DOS “CAMPOS GERAIS”-PR: AVALIANDO O POTENCIAL PARA O GERENCIAMENTO LOCALIZADO DE FERTILIZANTES............. 53

4.1 RESUMO.......................................................... 53

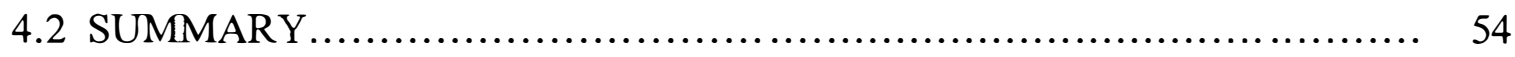

4.3 INTRODUÇÃO....................................................... 54

4.4 MATERIAL E MÉTODOS................................................ 57

4.5 RESULTADOS E DISCUSSÃO........................................... 60

4.5.1 Perfis de solos.......................................................... 60

4.5.2 Estatística clássica.................................................... 61

4.5.3 Recomendação de fertilizantes......................................... 65

4.5 .4 Rendimento do trigo .............................................. 69

4.5.5 Geoestatística..................................................... 70

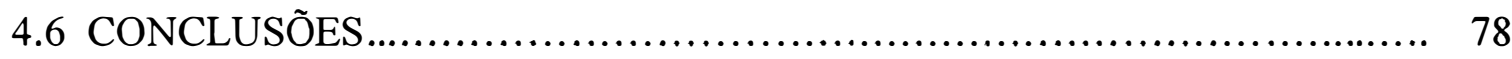

5 CONCLUSÕES GERAIS........................................................................... 79

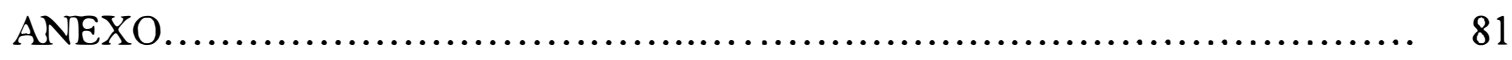

REFERÊNCIAS BIBLIOGRÁFICAS.................................... 101 


\title{
ABORDAGEM QUANTITATIVA NA PREDIÇÃO ESPACIAL DE ATRIBUTOS DO SOLO E GERAÇÃO DE ZONAS DE MANEJO AGRÍCOLA
}

\author{
Autora: MARCIA FREIRE MACHADO SÁ \\ Orientador: Prof. KLAUS REICHARDT
}

\section{RESUMO}

Uma combinação de ferramentas relativamente novas foi usada para identificar e caracterizar a variabilidade espacial de atributos do solo e para criar zonas de manejo agrícola. Foram selecionadas quatro topossequências representativas da região dos “Campos Gerais"-PR de acordo com o material de origem dos solos e do tempo de adoção do sistema Plantio Direto (PD) no município de Tibagi (50 $20^{\circ} \mathrm{W} ; 24^{\circ} 26^{\prime} \mathrm{S}$ ). As áreas escolhidas compreendem um campo nativo e três áreas adjacentes cultivadas no sistema PD nos últimos 10 e 20 anos. Os solos foram amostrados em grades de 50,0 $\mathrm{m}$ de espaçamento nas profundidades $0-0,10 ; 0,10-0,20 \mathrm{~m}$. Os dados utilizados na análise incluíram: altitude, $\mathrm{pH}, \mathrm{MO}, \mathrm{Ca}, \mathrm{Mg}, \mathrm{K}$ trocáveis, $\mathrm{P}, \mathrm{CTC}$, densidade do solo, argila, silte, areia e rendimento do trigo. A análise de regressão linear múltipla foi utilizada para explorar as relações entre os atributos topográficos derivados dos Modelos de Elevação Digital e atributos dos solos. Relações significativas foram encontradas entre os atributos topográficos estudados e alguns indicadores chave da fertilidade dos solos, tais como MO, CTC, conteúdo de argila e densidade do solo. A técnica "Fuzzy k-means" foi usada para agrupar valores de atributos de solos e 
topográficos. Os resultados revelaram a possibilidade de definir zonas de fertilidade dos solos nas topossequências estudadas.

A fertilidade do solo foi altamente variável e muito estratificada nas três áreas estudadas. Os teores de $\mathrm{MO}, \mathrm{Ca}$ e $\mathrm{Mg}$ trocáveis aumentaram de acordo com o teor de argila dos solos. Em geral, a maior variabilidade espacial foi observada na área PD20. O rendimento do trigo apresentou variações, porém, neste ano agrícola, houve baixa correlação desta variável com a fertilidade do solo.

Os atributos dos solos mostraram diferenças na dependência espacial. Modelos geoestatísticos anisotrópicos lineares foram definidos para a maioria das variáveis estudadas. O conteúdo de $\mathrm{MO}$ foi a variável que apresentou maior dependência espacial, seguida pelo $\mathrm{K}$ e Ca trocáveis. A quantidade de fertilizantes recomendada seria similar na aplicação uniforme (convencional) e no manejo localizado de fertilizantes, mas a distribuição de fertilizantes nas áreas seria espacialmente diferente. 


\title{
QUANTITATIVE APPROACH ON SPATIAL PREDICTION OF SOIL ATTRIBUTES AND CROP MANAGEMENT ZONE GENERATION
}

\author{
Author: MARCIA FREIRE MACHADO SÁ \\ Adviser: Prof. KLAUS REICHARDT
}

\section{SUMMARY}

A combination of relatively recent tools was used to identify and characterize the soil spatial variability and to create crop management zones. Four representative toposequences of the "Campos Gerais" region were selected according to parent material and no-tillage management period in the Santa Branca farm $\left(50^{\circ} 20^{\prime} \mathrm{W}\right.$; $24^{\circ} 26^{\prime} \mathrm{S}$ ), southern of Brazil. Chosen areas consisted of an undisturbed native field and three adjacent sites cultivated under no-tillage system for the past 10 and 20 years. Surface soil samples of the $0-0,10 ; 0,10-0,20 \mathrm{~m}$ depths were sampled in a 50,0 m grid. Data used in this analysis included: altitude, $\mathrm{pH}, \mathrm{OM}, \mathrm{Ca}, \mathrm{Mg}, \mathrm{P}, \mathrm{K}$ soil tests, soil bulk density, clay, silt and sand contents and wheat yield. Multiple linear regression analysis was performed to explore the relationship between topographic attributes derived from Digital Elevation Model and soil attributes. Significant relationships were found between terrain attributes and some key indicators of soil fertility such as OM, CEC, clay and bulk density. The fuzzy k-means technique was used as a method of grouping selected soil and terrain attributes. The results defined useful clusters of soil potential fertility. 
Soil fertility was highly variable and very stratified for three studied sites. The values of $\mathrm{OM}$ content and exchangeable $\mathrm{Ca}$ and $\mathrm{Mg}$ increased according to the clay content of the sites. In general the highest spatial variation was observed in the NT20 site. Wheat yield was highly variable but there was little correlation with soil fertility.

The soil properties displayed differences in spatial dependence. Linear anisotropic geostatistical models were defined for most of the soil variables measured for all sites. OM was the variable with more spatial dependence, followed by $\mathrm{K}$ and $\mathrm{Ca}$. Total fertilizer recommendation was similar for uniform versus soil specific management, but the distribution of fertilizer within the field would be spatially different. 


\section{INTRODUCÃO}

O solo é um dos principais fatores a ser considerado em relação à sustentabilidade agro-ecológica por ser a base da produção de alimentos para a humanidade, principalmente quando os prognósticos apontam para a duplicação da população mundial e uma demanda triplicada de produção de alimentos nos próximos cinquenta anos.

Partindo-se do princípio de que o solo é um recurso natural não renovável à curto prazo e que se encontra disponível em quantidade limitada, esforços devem ser feitos no sentido de sua preservação e maximização da produtividade agrícola à nível econômico para o produtor.

A introdução do sistema plantio direto (PD) no Brasil, no início da década de 1970 foi um grande avanço em direção à sustentabilidade do sistema agrícola, melhorando a qualidade do solo e aumentando o potencial produtivo. O processo de produção no sistema PD envolve o não revolvimento do solo, a manutenção dos resíduos culturais na superfície e a rotação de culturas, contribuindo para a quase eliminação das perdas por erosão e para o aumento do conteúdo da matéria orgânica dos solos (Mondardo, 1978; Sidiras \& Pavan,1985; Derpsch et al., 1986; Blevins et al., 1997; Thomas, 1990; Sá, 1997; Kinsela, 1997).

Um novo desafio da agricultura neste novo milênio, que traz promessas de aumento de rentabilidade e benefícios ao meio ambiente emergiu nas últimas duas décadas com a Agricultura de precisão (AP) ou gerenciamento localizado da produção agrícola. Um dos requisitos para o sucesso da AP é o conhecimento da variabilidade do solo para o manejo eficiente das aplicações de fertilizantes. Hoje estão disponíveis ferramentas que possibilitam a coleta, armazenamento e análise de variadas classes de dados e informação viabilizando estudos desta natureza. Uma das maiores limitações do 
gerenciamento localizado dos solos é o alto custo de obtenção de informação adequada sobre as propriedades do solo na escala adequada. Há necessidade de desenvolver-se modelos para predição de propriedades dos solos que façam o melhor uso de informações subordinadas, particularmente as de custo de obtenção relativamente baixo, tal como a topografia (Moore et al., 1991; Lark, 1999).

Assumindo-se que as relações solo-paisagem sejam preditas em processo comum, técnicas geomorfométricas podem ser usadas para derivar atributos topográficos e segmentar a paisagem em unidades de relevo. Análises de modelos de elevação digital contidas em programas de sistemas de informação geográfica permitem acurácia e agilização deste processo. Por outro lado, análises de regressão linear múltipla podem ser empregadas para explorar as relações entre os atributos do solo e topográficos, gerando modelos de predição de atributos do solo (Moore et al., 1993a).

Com o intuito de utilizar estas novas abordagens e ferramentas foi escolhida uma área representativa dos solos da região dos “Campos Gerais”, Estado do Paraná, a longo período cultivada sob o sistema PD. Este trabalho foi realizado como um passo inicial na identificação dos processos contribuintes para a variabilidade espacial de solos desta região, com distinção de material de origem e com diferenças quanto ao tempo de adoção do sistema PD.

Os objetivos deste trabalho foram: 1) verificar as alterações nos atributos do solo ao longo de topossequências com o tempo de adoção do sistema PD; 2) testar a hipótese de que as variações na paisagem, representadas por variáveis topográficas, estejam relacionadas com a variabilidade espacial de propriedades do solo; e 3) verificar o potencial de métodos de classificação contínua ou "fuzzy"como ferramenta na geração de zonas de manejo agrícola. 


\section{REVISÃO DE LITERATURA}

\section{1 Paradigmas e Pedologia}

Desde o final do século passado, quando a ciência do solo foi considerada uma disciplina independente, os pedólogos tem procurado mapear, classificar e desvendar a história do recurso solo. Como o conhecimento sobre os solos tem evoluído, modelos e idéias têm surgido as quais por seu turno têm influenciado os métodos de estudo e a estrutura organizacional da disciplina.

O solo é um sistema complexo, espacialmente e temporalmente variável. Sistemas convencionais de classificação de solos frequentemente empregam classes taxonômicas hierárquicas, onde cada indivíduo-solo pertence a uma única classe em determinado nível categórico. O pedólogo de campo determina o tipo de solo e o delineamento das unidades de mapeamento. Por necessidade, seu trabalho é baseado em limitado número de observações de perfis de solos e em sua interpretação pessoal das feições da paisagem. Este procedimento tem portanto um carater subjetivo .

As unidades de mapeamento incluem solos que não se ajustam às descrições da legenda, os quais são tratados como impurezas. Além disso, as propriedades do solo geralmente variam também dentro da "parte pura" da unidade de mapeamento. Sendo assim, a precisão na predição dos valores dos atributos em pontos não amostrados depende da variância dentro das unidades (Trangmar et al., 1985).

Os levantamentos de solos são largamente utilizados para auxiliar na determinação da aptidão dos solos para uma variedade de usos dentro de uma região, (Kuilenburg et al., 1982). No entanto, nas últimas duas décadas tem crescido o questionamento quanto a adequação destas unidades para fornecer informações para o manejo de práticas agrícolas na escala de campo. Os paradigmas que governam o estudo 
dos solos estão evoluindo para refletir o avanço do conhecimento e a aplicação de ferramentas quantitativas mais sofisticadas tem sido explorada pelos pedólogos (Nielsen \& Alemi, 1989; McBratney \& Gruijter, 1992; Odeh et al., 1992; Slater, 1994; Irvin et al., 1997).

Geralmente o indivíduo solo tem uma distribuição mais contínua (são mais fracamente agrupados) no espaço do que o implícito no sistema hierárquico e de classes rígidas (McBratney \& Gruijter, 1992). Os cientistas de solos frequentemente referem-se a pedosfera como um continuum (McBratney et al., 1992). Técnicas quantitativas de classificação têm sido empregadas baseadas na análise de grupos de solos, porém lidando com classes descontínuas (Webster, 1977). Desenvolvimentos recentes com classificação contínua e mapeamento parecem promissores no ordenamento de dados espaciais de solos (McBratney \& Gruijter, 1992; Irvin et al., 1997; Lark, 1999).

Outros avanços como os estudos quantitativos da variabilidade dos solos baseados na teoria das variáveis regionalizadas e métodos geoestatísticos, têm sido discutidos e aplicados na ciência do solo para auxiliar na compreensão da dependência espacial das propriedades dos solo (Burgess \& Webster, 1980; Vieira et al., 1981; Yost et al., 1982; McBratney \& Webster, 1981; Reichardt et al., 1986; Cahn et al., 1994; Cambardella et al., 1994).

O solo é um material vivo, que se desenvolve na interface da atmosfera, biosfera, hidrosfera e geosfera (Jenny, 1980). Sendo assim, a superfície da terra, os sistemas hidrológicos de superfície, e as comunidades biológicas têm co-evoluido. Os sistemas são produtos de processos históricos comuns e funcionam de uma maneira integrada (Christophersen \& Neal, 1990).

Uma integração de modelos descrevendo processos contínuos entre o sistema solo e o ambiente circunvizinho, ligando processos pedológicos, geomorfológicos, hidrológicos e ecológicos se faz necessária. Esta integração é essencial no entendimento de processos históricos, tais como a evolução da paisagem e a gênese dos solos, como também na predição e manejo de atributos do solo, em escala regional e local. 


\subsection{Em direção à modelagem quantitativa da diversidade dos solos}

\subsubsection{Estruturas de classificação}

Todo modelo pedológico pode ser caracterizado com respeito ao grau computacional, complexidade e nível de organização. Estas três características são usadas como estrutura para classificar os tipos de modelos que têm sido desenvolvidos (Hoosbeek \& Bryant, 1992). A primeira característica, grau de computação aplicada no modelo, distingue os modelos entre qualitativos e quantitativos (Fig. 1)

\begin{tabular}{|l|l|}
\hline Qualitativo & Quantitativo \\
\hline Mental/Verbal & Matemático \\
\hline Descritivo & Determinístico/Estocástico \\
\hline
\end{tabular}

\section{Grau de computação}

Figura 1. Classificação baseada no grau de computação. Fonte: Hoosbeek \& Bryant (1992).

Modelos mentais e verbais são descritivos e qualitativos. Modelos matemáticos expressam abstrações, na forma de algorítmos, usando tanto a abordagem determinística quanto estocástica. Modelos determinísticos presumem que um sistema simulado terá ao final apenas um resultado definido para uma entrada de dados. Já a resultante de um modelo estocástico não é uma solução determinada, mas sim uma distribuição ao redor da média. O modelo estocástico pressupõe que o resultado seja incerto e, portanto, usa a estrutura de simulação para levar a incerteza em conta (Addiscott \& Wagenet, 1985). $\mathrm{Na}$ verdade, muitos modelos que têm sido desenvolvidos se enquadram em alguma posição intermediária entre esses dois extremos.

A segunda característica, complexidade da estrutura usada no modelo, faz distinção entre modelos funcionais e mecanísticos. Modelos funcionais usam uma relação simplificada ou empírica entre dados observados e simulados. Modelos 
mecanísticos incorporam mecanismos fundamentais dos processos envolvidos com grau de complexidade correspondente ao estado presente do conhecimento científico (Addiscott \& Wagenet, 1985).

A terceira distinção é baseada na hierarquia organizacional, a qual descreve a que nível um modelo objetiva simular um sistema natural. A variabilidade espacial do sistema solo necessita ser investigada no nível de resolução apropriado à escala que o modelo objetiva simular o sistema. A variabilidade espacial dos solos forma um continuum desde o nível de resolução megascópico ao microscópico (Wilding, 1985).

Os modelos qualitativos serviram bem ao propósito dos levantamentos de solos para descrever a distribuição dos solos na paisagem, e continuam tendo seu papel no cumprimento deste propósito. O desenvolvimento de modelos quantitativos contribuirá para o entendimento da gênese dos solos e m áreas onde os levantamentos de solos não estão completos (Hoosbeek \& Bryant, 1992). Os pedólogos são desafiados a adotar ferramentas de simulação e modelagem e começam a árdua tarefa de colecionar dados para construir e testar modelos pedogenéticos quantitativos (Hoosbeek \& Bryant, 1992).

\subsubsection{Modelos de organização do continuum solo-paisagem}

Os levantamentos de solos convencionais são baseados num modelo de organização do continuum solo-paisagem que pressupõe a dominância de blocos de solos similares com variação brusca ocorrendo nos limites (Burrough, 1993). Estudos da variabilidade dos solos têm gerado outros modelos de estrutura espacial. Uma variedade de modelos espaciais conceituais pode ser ilustrada plotando uma variável hipotética (atributo) $z$ contra uma variável espacial $x$ (Burrough et al., 1994) (Fig. 2). Este modelo conceitual ilustra abrupta, contínua ou irregular (noisy) variação no espaço.

A Fig. 2a mostra o modelo convencional o qual é também chamado de modelo discreto, ou mapa de polígono. O solo muda abruptamente nos limites mapeados e é relativamente homogêneo dentro da classe. Pressupõe-se que ocorram fortes correlações entre as propriedades dos solos, além de sensíveis expressões dos limites da vizinhança; tais como mudanças de vegetação, formas de relevo e padrões de imagens de 
sensoriamento remoto. A Fig. $2 \mathrm{~b}$ apresenta um modelo contínuo, baseado na suposição de variabilidade espacial gradual, a qual pode ser modelada como uma superficie matemática .

$\mathrm{Na}$ realidade, modelos menos extremos de variabilidade são frequentemente mais apropriados. Modificações dos modelos discretos e contínuos permitem algum "ruido" ou pequenas oscilações de variações dentro das divisões geográficas discretas (Fig. 2c) ou dentro da paisagem variando continuamente (Fig. 2d). Estas formas de variação podem estar todas presentes em uma única área (Fig. 2e), onde: - variações não estacionárias geram uma tendência, mudanças abruptas em atributos particulares podem estar presentes, e as variações dentro da unidade podem ser grandes. Em alguns casos, predominam as variações em curta distancia (Fig. 2f) e nenhum modelo ordenado é apropriado. Onde nenhuma ordem geográfica pode ser decifrada, o mapeamento não é útil. (Burrough et al., 1994).
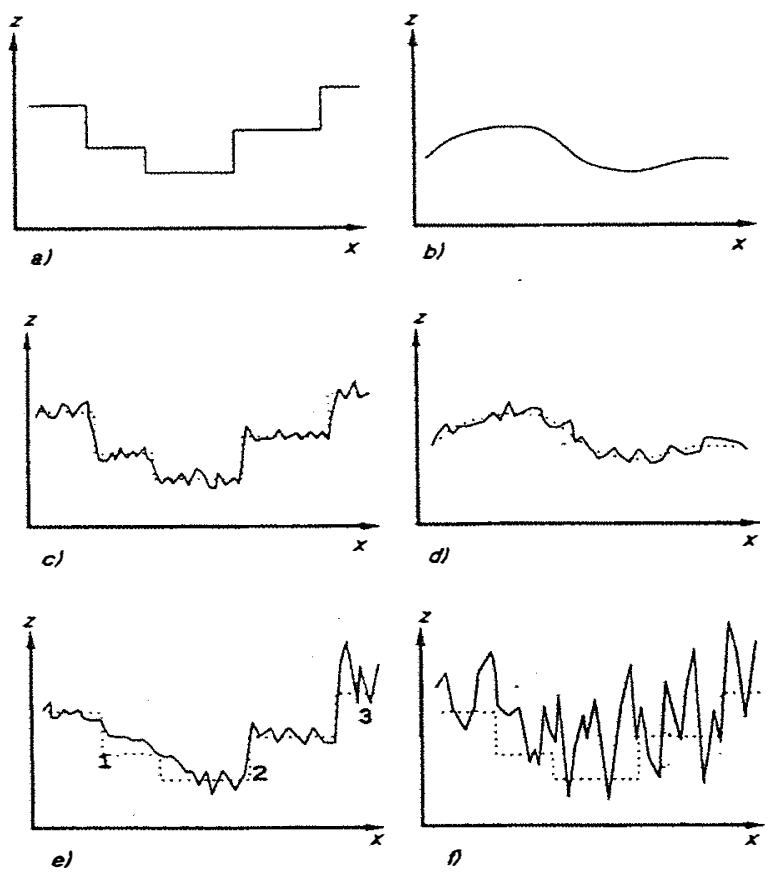

Figura 2. Modelos de distribuição dos solos no espaço geográfico Fonte: Burrough (1993). 


\subsection{Indivíduos, entidades e corpos de solos}

A despeito da ênfase em rigidamente definidas entidades na classificação e levantamentos dos solos, os cientistas de solos tem frequentemente referido-se a seus objetos de estudo como um continuum (Simonson \& Gardner, 1960; Knox, 1965; Davies \& Gamm, 1970). Considerável desacordo existe com relação ao objeto solo como indivíduo. A literatura debate se o papel da classificação é o de agregar indivíduos ou de dividir um continuum (Simonson, 1968). Na prática, entretanto, a classificação de solos não lida com indivíduos, nem com segmentos do continuum, mas com dados derivados de amostragem. No desenvolvimento de uma classificação, as classes podem ser construidas com base no conceito modal, mas são muitas vezes definidas em termos de critérios limitados (Cline, 1949).

A busca do indivíduo solo está relacionada ao desejo de conciliar unidades taxonômicas e de mapeamento, e à necessidade de estabelecer-se um denominador comum para a comunicação e correlação com outros sistemas. Um indivíduo ideal seria, de acordo com Johnson (1963):

- observável, mensurável e completo,

- delimitado por claros limites naturais,

- de conveniente tamanho para estudo,

- precisamente definido.

Como o solo geralmente não é um universo particular, nenhum indivíduo solo natural satisfatório, deste tipo, é reconhecido (Knox, 1965; Schelling, 1970). Como uma alternativa, indivíduos artificiais têm sido propostos (Knox, 1965). Indivíduos artificiais são construções conceituais, vindas do universo contínuo, criadas arbitrariamente e por conveniência (Knox, 1965).

Se os indivíduos não são facilmente reconhecidos, corpos de solos (soil body), podem ser considerados. Corpos de solos são divisões do continuum, os quais não precisam necessáriamente preencher o critério de indivisibilidade, necessário para indivíduos. Para um corpo de solo ser considerado um indivíduo solo, ele deve ser 
completo em si mesmo e também incluir toda a sequência vertical de horizontes do solo (Knox, 1965).

Várias outras entidades têm sido propostas. A tessera (Jenny, 1980) é um prisma vertical, tri-dimensional, ou cilíndrico de solo. A tessera é geralmente considerada como uma unidade operacional, a qual é examinada, descrita e amostrada no campo. Tesserae são, portanto, corpos artificiais similares em conceito aos "perfis de solos tomados como corpos" (Knox, 1965) e similares aos pedons, embora frequentemente menores do que estes. Na prática, os pedólogos e cartógrafos lidam principalmente com dados oriundos de amostras representativas de perfis ou tessera. A despeito das muitas discussões relativas à objetos, entidades e corpos no universo solo, a maior parte destas construções não são realmente utilizadas. Webster (1968) comentou que neste sentido, o pedon é irrelevante na Soil Taxonomy.

Os horizontes podem ser examinados localmente, na face dos perfis, onde eles são tradicionalmente considerados como sub-unidades do perfil ou pedon, mas podem também servir como unidades geográficas dentro da paisagem (FitzPatrick, 1980).

Huggett (1975) descreveu solo-paisagem como um sistema aberto tridimensional, no qual os limites são definidos como: - divisões de drenagem, superfĩcie da terra, e o front de intemperismo na base do perfil do solo.

\subsection{Relações solo-paisagem e modelagem}

\subsubsection{Perspectiva histórica}

A pedologia se desenvolveu do conceito revolucionário do solo como um corpo natural organizado e independente (Cline, 1961) que evoluiu da concepção nascida na Rússia, na década de 1870 (desenvolvida por Dokuchaev e outros), do solo como material alterado do substrato geológico e variando de acordo com influências do ambiente. 
A formalização por Jenny (1941) dos fatores de formação do solo e a incorporação do relevo como um dos fatores, promoveu uma interligação entre geomorfologia e pedologia.

Na década de 1950, emergiu uma estrutura sistemática para investigação das relações solo-paisagem (Ruhe, 1956) que influenciou fortemente muitos estudos subsequentes e melhorou o conhecimento qualitativo do solo, das feições de relevo e relações estratigráficas (Wambeke,1962; Walker, 1966; Ruhe, 1975; Daniels \& Gamble, 1978; Lepsch et al., 1977, Vidal Torrado, 1989; Sá, 1995). Este tipo de abordagem estabeleceu prioridade na emergência de ferramentas e técnicas para análises espaciais mais sofisticadas.

\subsubsection{Modelos de solo-paisagem}

Os modelos de solo-paisagem descrevem o padrão natural dos solos e sua relação com outros elementos e processos da paisagem. Desta forma formalizam as relações entre solos, relevo e hidrologia, resultantes de correntes comuns de gênese. A modelagem do solo-paisagem é baseada na predizibilidade hipotética das relações entre componentes e da presença de variações sistemáticas na paisagem (Hall \& Olson, 1991).

Para estabelecer correlações entre os componentes do solo-paisagem, os mesmos devem ser definidos e reconhecidos. Tradicionalmente, correlações entre solos e unidades do relevo (landform) têm sido estudadas usando-se pontos e dados de transectos, ou generalizações tais como unidades de mapeamento de solo e subdivisões geomórficas da paisagem (McSweeney et al., 1994).

Milne (1935) reconheceu as relações entre variações dos atributos do solo e a posição na paisagem e estabeleceu o conceito de catena, o qual, simplificadamente pode ser definido como uma sequência adjacente de solos diferenciados ao longo de uma vertente (Retallack, 1992).

Ruhe \& Walker (1968) propuseram um modelo de cinco segmentos para dividir as vertentes em unidades geomórficas e correlaciona-las com as propriedades dos solos. 
Um modelo mais complexo, de divisão da catena em nove unidades geomórficas (estendendo-se do centro do interflúvio até o fundo do vale e da base do solo até a interface solo-atmosfera) foi desenvolvido por Conacher \& Dalrymple (1977).

Vários estudos de solo-paisagem procuraram relacionar a forma da vertente (concavidade, convexidade, curvaturas planas e de perfil), além da declividade, com atributos do solo (Troeh, 1964; Huggett, 1975). Pennock et al., (1987) definiram elementos topográficos pela combinação da declividade, das curvaturas planas e de perfil e relacionou-os com o conteúdo de água do solo.

\subsubsection{Uma nova estrutura espacial para modelar a diversidade dos solos}

A hipótese básica de uma nova estrutura para modelagem dos solos é que modelos realísticos do continuum solo-paisagem no tempo e espaço possam ser sintetisados pela união de modelos hidrológicos de superfície e geomorfométricos (Moore et al., 1991) e integração da estratigrafia tridimensional dos materiais da superficie da terra (McSweeney et al., 1994; Slater, 1994; Irvin et al., 1997).

Três princípios gerais governam o modelo (Kirkby, 1985):

- Coleta racional de dados para definir a escala e estrutura da diversidade local. Preferencialmente ao uso de unidades ou indivíduos, a abordagem admite que os dados sejam derivados de amostras que possam ser flexivelmente arranjadas e classificadas;

- Estrutura flexível de dados para estocagem, análise e integração de informações. A estrutura de dados requerida deve incorporar a realidade da continuidade e variação 3-D do manto de solo.

- Modelos que relacionem os componentes do sistema. Os componentes da paisagem devem ser correlacionados para auxiliar no desenvolvimento de modelos de interpolação entre locais de amostragem, como também para predizer a distribuição de atributos desejados a partir de dados associados. A estimativa de erro e validação do modelo devem ser integradas. 


\subsection{Predição de propriedades dos solos a partir de modelos contínuos da relação solo-paisagem}

O solo e o relevo são fenômenos contínuos e embora limites possam ser frequentemente reconhecidos e usados com bom efeito, eles são essencialmente artificiais. É provável que as relações mais frutíferas para estimar-se propriedades do solo sejam funções contínuas dos atributos do relevo (Lark, 1999). Diferentes modelos têm sido propostos que resumam as relações entre as condições do solo e a topografia.

Os modelos mais antigos eram descontínuos, baseados na estratificação da paisagem em unidades tais como feições do relevo. Estes fornecem uma estrutura de amostragem e valores médios das propriedades do solo para cada uma das feições do relevo, que são então usados em predições, geralmente em escalas cartográficas pequenas.

Mais recentemente, vários modelos contínuos da relação solo-relevo foram desenvolvidos, nos quais assume-se que as condições do solo mudem continuamente com as propriedades topográficas. Estes modelos oscilam entre os que possuem um componente mecanístico significante (Moore et al., 1993a) para os puramente empíricos e estatísticos (Odeh et al., 1994).

\subsubsection{Modelo de Elevação Digital (DEM).}

Métodos modernos tais como levantamentos de campo realizados com GPS, análises automatizadas de fotografias aéreas e sensoriamento remoto permitem gerar rapidamente modelos de elevação digital (DEMs), com muito boa resolução espacial.

DEM é um caso especial de uma superfície contínua, interpolada, que tem muito uso em GIS. As medidas de altitude, que também podem ser obtidas com uso de teodolitos, são interpoladas usando-se diversos tipos de interpoladores (por exemplo spline ou kriging) contidos em programas de sistemas de informação geográfica (GIS), gerando representações tridimensionais da paisagem. Os programas GIS permitem sobrepor informações temáticas, tais como, por exemplo, mapas de isolinhas de 
atributos dos solos aos DEMs permitindo melhor visualização da ocorrência de alterações de características do solo na paisagem.

\subsubsection{Atributos Topográficos}

Algorítmos têm sido desenvolvidos para estimar-se atributos topográficos primários e secundários (Moore et al., 1993b) a partir de DEMs usando-se análises espaciais de programas GIS, baseadas em estrutura raster, ou celular. Os atributos topográficos são importantes nos estudos hidrológicos e de solos, e vários deles encontram-se listados e definidos em uma tabela no trabalho de Moore et al. (1993a). Moore et al. (1991) apresentou uma revisão sobre as relações entre atributos topográficos e processos hidrológicos e erosivos da paisagem.

$\mathrm{Na}$ década passada esta abordagem foi utilizada em vários trabalhos, na busca de modelos contínuos de predição das propriedades do solo, partindo-se da premissa de que as condições de atributos-chave dos solos mudem continuamente com as propriedades topográficas (Moore et al., 1993; Odeh et al., 1994; Bruin \& Stein, 1998; Lark, 1999; McKenzie \& Ryan, 1999).

Dentre os vários atributos primários e secundários do relevo, alguns têm se destacado e parecem ser particularmente poderosos e úteis no manejo das culturas e predição espacial de atributos do solo (Skidmore, 1989; Burrough \& MacDonnell, 1998; Lark, 1999):

- Declividade (slope). Medida em graus, é definida pelo plano tangente à superfície, em cada nó do DEM, sendo a taxa máxima de mudança de altitude;

- Exposição solar (aspect). É a direção do compasso desta taxa máxima de mudança de altitude (medido em graus, a partir do norte, no sentido horário). Reflete a irradiância solar e a evapotranspiração em uma localidade específica;

- Curvatura de perfil (profile curvature). Curvaturas são taxas de mudança de declive (medidas em graus por unidade de distância). A curvatura de perfil é 
a taxa de mudança do declive no sentido vertical, a partir de cada nó do DEM. Valores positivos indicam superfície côncava e valores negativos correspondem a superficies locais convexas;

- Curvatura plana (plan curvature, contour curvature). Esta é a curvatura da superfície em cada nó, no plano horizontal. Valores negativos indicam convexidade neste plano e portanto divergência no fluxo de água de superfície;

- Índice de umidade (wetness index). É a medida do potencial de umidade do solo em um dado ponto.

No trabalho de Lark (1999) as formas dominantes de relevo identificadas com o uso da classificação contínua e dos atributos topográficos derivados do DEM foram correlacionadas com as duas principais formações litológicas. As propriedades fĩsicas estudadas (distribuição do tamanho das partículas e conteúdo de água dos solos) mostraram significante relação linear com as classes contínuas derivadas das propriedades topográficas. As propriedades químicas estudadas (conteúdo de matéria orgânica, pH e nutrientes) não mostraram tal relação. O método desenvolvido nesse trabalho foi aplicado em escala de campo (à nível de propriedade) e foi iniciado devido a necessidade de desenvolver-se estratégias de menor custo para mapear a variabilidade do solo nesta escala. A utilidade desta abordagem no manejo ao nível de campo dependerá, segundo o autor: 1) da possibilidade de gerar-se dados de elevação digital à custo razoável; 2) da extensão na qual as variações de atributos chave dos solos, na escala de campo, estejam relacionadas com a topografia.

A disponibilidade de informação topográfica nesta escala provavelmente nao limitará a utilização do método. Sistemas de Posicionamento Global (GPS) podem ser usados para coletar estas informações ao mesmo tempo que os mapas de rendimento são produzidos, quando adotadas práticas da agricultura de precisão. Isto tornará mais fácil a integração do DEM com informações derivadas de regressões com os dados de rendimento. 
Ainda não é claro quais sejam as variáveis do solo mais importantes no manejo na escala de campo, mas é provável que sejam necessárias informações de uma gama de propriedades. Portanto, o uso de DEMs, enquanto potencialmente úteis, não invalidam a utilidade de sensores para medidas intensivas de baixo custo de propriedades químicas do solo (Viscarra Rossel \& McBratney, 1997).

\subsection{Uso da classificação contínua em pedologia.}

Embora limites possam ser reconhecidos e frequentemente usados com bom efeito em estudos de solos e geomorfologia, sendo o solo e o relevo fenômenos contínuos, as divisões são meros artifícios. Segundo Lark (1999) a classificação contínua parece idealmente ajustada para extrair variáveis preditoras a partir de DEMs.

Classificação contínua é um termo usado por McBratney \& Gruijter (1992) para o agrupamento de dados usando a técnica fuzzy k-means. O método de classificação contínua utiliza o conceito de grupos fuzzy (Zadeh, 1965), que são uma forma matemática de lidar com a ambiguidade, a incerteza e a continuidade que caracterizam os fenômenos naturais. Os membros dos grupos fuzzy não compartilham limites exclusivos. É permitido a um indivíduo participação simultânea no universo de classes definidas para o grupo de dados. Portanto, cada indivíduo (seja ele perfil de solo, horizontes, atributos de solos ou do relevo, entre outros) pode ser descrito pelo grau de participação numa série de classes (Odeh et al., 1992).

Ao contrário da classificação tradicional, onde os indivíduos podem ser membros de apenas uma classe, a aplicação da teoria dos grupamentos fuzzy permite aos indivíduos ter participação total, parcial ou nenhuma participação em cada uma das diferentes classes (Slater, 1994). A taxa de participação varia de 0,0 (nenhuma participação na classe) a 1,0 (inteiramente e somente membro de uma classe); o somatório dos valores de participação nas classes de qualquer indivíduo é igual a 1,0 (Irvin et al., 1997). O grau de participação como membro da classe indica o quanto o indivíduo é similar ao centróide de cada classe. Os indivíduos com elevado grau de participação em apenas uma classe são muito similares ao centróide da classe, enquanto 
aqueles que são membros parciais de várias classes se enquadram como intermediários dentro do contínuo (Slater, 1994).

O uso das classes fuzzy é apropriado onde a variação espacial é gradual ao invés de abrupta e tem sido aplicado para descrever fenômenos naturais contínuos na paisagem, tais como atributos de solos (McBratney \& Gruijter, 1992; Odeh et al., 1992; Slater, 1994; Irvin et al., 1997). A base matemática do grupamento fuzzy k-means e os algorítimos computacionais para análise dos dados foram detalhados em várias publicações (Burrough, 1989; McBratney \& Gruijter, 1992; Odeh et al., 1992a).

Este procedimento estabelece um conjunto de $\mathrm{k}$ classes entre $\mathrm{N}$ objetos (por exemplo, localidades de um DEM), onde qualquer objeto i é caracterizado por um vetor, $\mathrm{x}_{\mathrm{i}}$, o qual contém medidas de $v$ variáveis (por exemplo, $v=3$, a saber: declividade, exposição solar e altitude relativa). As classes são grupos de objetos semelhantes entre si, com respeito às variáveis $v$. As classes são contínuas, ou "fuzzy", no sentido que um objeto i não está simplesmente localizado em uma classe, $\mathrm{j}$, e, portanto, fora de todas as outras (como na classifição crisp ou boleana), mas ao contrário tem uma participação finita em cada uma das $k$ classes (Lark, 1999). $\mu_{\mathrm{ij}}$ é o grau de participação do objeto i na classe j, e está sujeito a duas restrições:

$$
\begin{aligned}
& \sum_{\mathrm{j}=1}^{\mathrm{k}} \mu_{\mathrm{ij}}=1, \\
& \mathrm{O} \leq \mu_{\mathrm{ij}} \leq 1,
\end{aligned}
$$

Se $\mu_{\mathrm{ij}}=0$, entao i não se assemelha de nenhuma forma a classe $\mathrm{j}$;

Se $\mu_{\mathrm{ij}}=1$, significa semelhança exclusiva do objeto i na classe $\mathrm{j}$;

Se $0<\mu_{i j}<1$, então $i$ tolera parcial semelhança na classe $\mathrm{j}$, como também em pelo menos uma das outras classes.

A classificação contínua é obtida achando-se valores de participação (membership), $\mu_{\mathrm{ij}}, \mathrm{i}=1, \ldots, \mathrm{N}, \mathrm{j}=1, \ldots, \mathrm{k}$

$$
\sum_{i=1}^{N} \sum_{j=1}^{k} d^{2}{ }_{i, j}\left(\mu_{i j}\right)^{m}
$$


onde m é um "fuzziness expoent" com valor $1<\mathrm{m} \leq 2$; $\mathrm{d}_{\mathrm{ij}}$ é uma norma; uma medida da distância entre o objeto i e o centro da classe j no espaço dimensional $v$ definido pelas variáveis medidas. $\mathrm{O}$ centro da classe $\mathrm{j}$ é um vetor, $\mathrm{c}_{\mathrm{j}}$, dos valores das propriedades $v$ nas quais as classes são definidas e representam o membro típico da classe $\mathrm{j}$ (centróide da classe).

A classificação contínua pode ser obtida usando várias normas. A medida métrica (distance) Euclidean é apropriada se as variáveis $v$ não são correlacionadas dentro das classes (variáveis independentes). A Mahalanobis distance é preferida quando as variáveis mostram correlações que são mais ou menos homogêneas nas classes (dependência entre as variáveis).

$\mathrm{O}$ expoente fuzziness ( $\mathrm{m}$, na equação 3) controla o grau de fuzziness (descontinuidade, incerteza, ambiquidade) da classificação. A escolha do expoente " $m$ " é um pouco subjetiva (Odeh et al., 1992) e a experimentação pode ser desejada para guiar a escolha do parâmetro fuzziness. Onde o expoente é 1, a classificação não produz sobreposição de classes, resultando em classes rígidas. $\mathrm{O}$ aumento dos valores causa mais fuzziness (representando maior continuidade). A maior parte dos estudos de classificação tem usado valores entre 1,1 e 1,5.

A análise fuzzy k-means permite intergrades entre as classes, portanto, os pontos que ficam intermediários entre os centróides das classes têm graus de participação em várias classes. McBratney \& Gruijter (1992) as chamaram de intragrades. No entanto, alguns pontos podem ficar fora do universo descrito pelas classes; estes indivíduos podem ter participação igual nas classes e serem pobremente representados em qualquer classe. Para acomodar estes extragrades McBratney \& Gruijter (1992) definiram uma outra função que permite uma classe de outlier com membros espalhados fora das classes definidas no grupamento dos atributos.

$\mathrm{O}$ uso da classificação contínua ou fuzzy tem sido explorada em levantamentos e classificação de solos (McBratney \& Gruijter, 1992; Burrough et al., 1997; Irvin et al., 1997) e no mapeamento e classificação de indicadores-chave da fertilidade do solo (Dobermann \& Oberthur, 1997; Gruijter et al., 1997; Lagacherie et al., 1997; Freissinet 
et al., 1998; Lark, 1999). Uma revisão sobre várias possibilidades de aplicação na ciência do solo, que podem ser geradas ou adaptadas a partir da lógica e teoria de agrupamentos fuzzy pode ser encontrada no trabalho de McBratney \& Odeh (1997).

\subsection{Geoestatística}

Métodos geoestatísticos, baseados na teoria das variáveis regionalizadas, têm sido aplicados na ciência do solo para auxiliar na compreensão da dependência espacial das propriedades do solo e fornecer um método ótimo de estimativa destas propriedades em localidades não amostradas. A variabilidade espacial pode ser descrita através do semivariograma. Quando evidente, a dependência espacial pode ser modelada e usada num processo conhecido como krigagem, para estimar valores em localidades não amostradas (Jeffrey, 1993). O desenvolvimento detalhado desta teoria pode ser encontrado em Burgess \& Webster (1980), Vieira (1983) e Goovaerts (1997).

O número de pares de dados disponíveis usados para obter-se os semivariogramas não deve ser muito pequeno, para evitar-se mudanças abruptas no semivariograma para pequenas diferenças de distância (Entz \& Chang, 1991). No entanto o custo de amostragem aumenta exponencialmente com a redução da distância do gride. A seleção de um apropriado protocolo de amostragem é dificultado pelo fato da comunidade científica não ter alcançado um consenso quanto a forma de coleta das amostras. Em Entz \& Chang (1991) encontram-se citações de vários trabalhos sobre metodologia de amostragem dentro desta abordagem.

\subsection{Agricultura de Precisão}

Os conceitos básicos do gerenciamento localizado das atividades agrícolas, que constituem a base da Agricultura de Precisão (AP), foram apresentados pela primeira vez em 1929 por Linsley e Bauer (Goering, 1993) quando realizaram os primeiros estudos relacionados com a aplicação localizada de insumos, mais especificamente de calcário. Devido à inexistência de tecnologia adequada, estes conhecimentos foram 
colocados em prática apenas em pequenas áreas e por curto espaço de tempo, uma vez que eram executados manualmente. Com o surgimento de novas tecnologias, capazes de automatizar as tarefas de sensoriamento, aplicação localizada de insumos e medidas pontuais de produtividade, estes conceitos foram retomados dando surgimento à agricultura de precisão.

Adventos tecnológicos tais como sensoriamento remoto, sistema de posicionamento global (GPS) e tratamento em taxas variáveis permitem amostragem georreferenciada e aplicação localizada de insumos. Por outro lado, o uso de sistemas de informação geográfica (GIS) é essencial na operação de bancos de dados e informações que possuem componentes espaciais, funcionando com ferramenta chave na integração e análise dos dados da AP (Usery et al., 1995).

A agricultura de precisão ou gerenciamento localizado da produção agrícola é um conceito que vem evoluindo nas últimas duas décadas e que tem por princípio o manejo localizado das práticas agrícolas à nível de campo, ou seja, em escala em torno de 1:6.000 ou maior. Reconhece o solo como um meio heterogêneo, com propriedades físicas, químicas e biológicas que podem variar espacial e temporalmente dentro do campo, de uma maneira irregular (Trangmar et al., 1986).

$\mathrm{Na}$ atividade agrícola cresce cada vez mais o conflito entre a economia e a ecologia. A utilização de dosagens elevadas de fertilizantes tem causado graves problemas ambientais. Para minimizar tais agressões e aumentar o retorno econômico, Auernhammer et al., (1994) propuseram a realização de balanços entre o fornecimento e a utilização dos fertilizantes pelas culturas, a fim de evitar-se as superdosagens. $\mathrm{O}$ aperfeiçoamento desta técnica pode ser obtido se as reais necessidades de insumos forem medidas e aplicadas de forma localizada.

Uma das principais preocupações em relação à análise da variabilidade dos solos, diz respeito à separação das glebas em zonas de solos relativamente homogêneos, de tamanho e forma apropriados para a aplicação de manejo diferenciado (Holzey, 1993). Preferencialmente, as informações sobre as zonas de manejo devem englobar as principais características que influenciam o crescimento das plantas (Thompson \& Robert, 1995). 
Uma série de fatores devem ser satisfeitos para que haja sucesso na aplicação do manejo localizado. Dentre eles estão incluidos: 1) o sistema adequado de coleta dos dados, 2) a análise e interpretação eficientes da variabilidade espacial dos dados, 3) o conhecimento da resposta do sistema solo-planta às mudanças de manejo e, 4) a evidência de que o manejo espacial das variáveis será mais rentável do que a abordagem tradicional (Moore \& Tyndale-Biscoe, 1999). 


\section{PREDIÇÃO DE ATRIBUTOS DE SOLOS ATRAVÉS DE ANÁLISES TOPOGRÁFICAS EM TOPOSSEQUÊNCIAS DA REGIÃO DOS “CAMPOS GERAIS"/PR}

\subsection{RESUMO}

Uma combinação de ferramentas relativamente recentes foi usada para identificar e caracterizar a variabilidade espacial de atributos do solo com o objetivo de gerar zonas de manejo de fertilizantes. Foram selecionadas quatro topossequências representativas da região dos “Campos Gerais"-PR de acordo com o material de origem dos solos e do tempo de adoção do sistema Plantio Direto (PD) no município de Tibagi $\left(50^{\circ} 20^{\prime} \mathrm{W} ; 24^{\circ} 26^{\prime} \mathrm{S}\right)$. As áreas escolhidas compreendem um campo nativo e três áreas adjacentes cultivadas no sistema PD nos últimos 10 e 20 anos. Os solos foram amostrados em grades de 50,0 $\mathrm{m}$ de espaçamento nas profundidades $0-0,10 ; 0,10-0,20$ $\mathrm{m}$. Os dados utilizados na análise incluíram: altitude, $\mathrm{pH}, \mathrm{MO}, \mathrm{Ca}, \mathrm{Mg}, \mathrm{K}$ trocáveis, $\mathrm{P}$, CTC, densidade do solo, argila, silte, areia e rendimento do trigo. A análise de regressão linear múltipla foi utilizada para explorar as relações entre os atributos topográficos derivados dos modelos de elevação digital e atributos dos solos. Relações significativas foram encontradas entre os atributos topográficos estudados e alguns indicadores chave da fertilidade dos solos, tais como MO, CTC, conteúdo de argila e densidade do solo. A técnica "Fuzzy k-means" foi usada para agrupar valores de atributos de solos e topográficos. Os resultados revelaram a possibilidade de definir zonas de fertilidade dos solos nas topossequências estudadas. 


\subsection{SUMMARY: SOIL ATTRIBUTE PREDICTION USING TERRAIN ANALYSIS IN "CAMPOS GERAIS"/PR OXISOLS}

A combination of relatively recent tools was used to identify processes contributing to soil spatial variability and to create fertilizer management zones. Four representative toposequences of the "Campos Gerais" region were selected according to parent material and no-tillage management period in the Santa Branca farm $\left(50^{\circ} 20^{\prime} \mathrm{W}\right.$; $24^{\circ} 26^{\prime} \mathrm{S}$ ), southern of Brazil. Chosen areas consisted of an undisturbed native field and three adjacent sites cultivated under no-tillage system for the past 10 and 20 years. Surface soil samples of the $0-0,10 ; 0,10-0,20 \mathrm{~m}$ depths were sampled in a 50,0 m grid. Data used in this analysis included: altitude, $\mathrm{pH}, \mathrm{OM}, \mathrm{Ca}, \mathrm{Mg}, \mathrm{P}, \mathrm{K}$ soil tests, soil bulk density, clay, silt and sand contents and wheat yield. Multiple linear regression analysis was performed to explore the relationship between topographic attributes derived from digital elevation model and soil attributes. Significant relationships were found between terrain attributes and some key indicators of soil fertility such as OM, CEC, clay and bulk density. The fuzzy k-means technique was used as a method of grouping selected soil and terrain attributes. The results defined useful clusters of soil potential fertility.

\subsection{INTRODUÇÃO}

Os atributos utilizados no levantamento de solos incluem propriedades relacionadas com a qualidade das terras (Holzhey, 1993) e têm sido largamente utilizados para auxiliar na determinação da aptidão dos solos para uma variedade de usos (Kuilenburg et al., 1982). No entanto, o resultado das análises de solo, ao menos nas camadas superficiais, mostram grande variabilidade dentro das unidades de mapeamento. Nas últimas duas décadas tem crescido o questionamento quanto a adequação destas unidades para fornecer informações para o manejo de práticas agrícolas na escala de campo, levantando-se este novo paradigma na agricultura dos tempos atuais. 
Altas produtividades agrícolas alcançadas atualmente dependem da habilidade de identificar-se os atributos do solo que limitam o crescimento das plantas (Nielsen et al., 1995). Com respeito ao manejo localizado da produção agrícola, a preocupação fundamental em relação a análise da variabilidade dos solos diz respeito à separação das glebas em zonas de solo relativamente homogêneo, de tamanho e forma apropriados para a aplicação de manejo diferenciado (Holzhey, 1993). Alguns dos componentes mais críticos do gerenciamento localizado, também chamado de Agricultura de Precisão (AP) são a escolha da estratégia para gerar o mapa de manejo diferenciado (Thompson \& Robert, 1995) e o custo para obtenção da informação adequada sobre as propriedades dos solos na escala apropriada (McBratney \& Pringle, 1997). Neste sentido, uma linha que vem sendo explorada é o desenvolvimento de métodos de predição das propriedades do solo que façam o melhor uso de informações pré-existentes, particularmente aquelas de baixo custo de obtenção. Uma destas fontes de informação é a topografia (Lark,1999). Particularmente, desde o trabalho de Jenny (1941), é um axioma na ciência do solo que a topografia seja um importante fator no desenvolvimento dos solos.

Irvin et al. (1997) usou atributos topográficos derivados de modelos de elevação digital (DEMs) para identificar quantitativamente os elementos geomórficos da paisagem como alternativa para o delineamento manual destes elementos. Duas técnicas foram comparadas neste estudo: uma classificação não supervisionada (isodata) e uma classificação contínua, ou "fuzzy". Isodata é um método estatístico de agrupamento no qual cada ponto de amostragem é enquadrado em uma classe em particular, enquanto na classificação contínua, ou "fuzzy",cada variável pode ser membro parcial de várias classes.

A classificação contínua é um termo usado por McBratney \& Gruijter (1992) para o agrupamento de dados com o uso da técnica "fuzzy k-means". O método da classificação contínua utiliza os conceitos dos grupamentos "fuzzy" (Zadeh, 1965). Diferentemente da classificação tradicional, onde os indivíduos podem ser membros de apenas uma classe, a aplicação da teoria dos grupamentos "fuzzy" permite aos indivíduos ter participação total, parcial ou nenhuma participação em cada uma das 
diferentes classes (Slater, 1994). A taxa de participação varia de 0,0 (nenhuma participação na classe) e 1,0 (inteiramente e somente membro de uma classe); o somatório dos valores de participação nas classes de qualquer indivíduo é igual a 1,0 (Irvin et al., 1997). O grau de participação como membro da classe indica o quanto o indivíduo é similar ao centróide de cada classe. Os indivíduos com elevado grau de participação em apenas uma classe são muito similares ao centróide da classe, enquanto aqueles que são membros parciais de várias classes se enquadram como intermediários dentro do contínuo (Slater, 1994). O uso das classes "fuzzy"é apropriado onde a variação espacial é gradual ao invés de abrupta e tem sido aplicada para descrever fenômenos naturais contínuos na paisagem, tais como atributos de solos (McBratney \& Gruijter, 1992; Odeh et al., 1992; Slater, 1994; Irvin et al., 1997).

DEM é um caso especial de uma superfície contínua, interpolada, obtida através de dados de altitude, que tem muito uso em GIS. Por outro lado, algorítmos têm sido desenvolvidos para estimar-se atributos topográficos primários e secundários a partir de DEMs (Moore et al., 1993b) usando-se análises espaciais de programas GIS, baseadas em estrutura raster, ou celular. Dikau (1989) demonstrou como a análise digital topográfica pode ser aplicada para quantificar feições do relevo e definir unidades topográficas para mapeamentos geomorfológicos e pedológicos.

Moore et al. (1991) apresentou uma revisão sobre as relações entre atributos topográficos e processos hidrológicos e erosivos na paisagem. Segundo estes autores, estes índices derivados topograficamente parecem ser particularmente poderosos e úteis no manejo das culturas e predição espacial de atributos do solo. Também foram empregados na estratificação de medidas e compartimentação da variabilidade espacial em micro e meso-escala (Hairston \& Grigal, 1991; Odeh et al., 1991).

Atributos topográficos podem ser divididos em primários e secundários (ou compostos). Os atributos primários são calculados diretamente dos dados de elevação e incluem variáveis tais como declividade (slope), exposição solar (aspect), área de captação específica (specific catchment área), comprimento máximo de fluxo (maximum flow path length), curvatura de perfil (profile curvature) e curvatura plana (plan curvature). Todos estes atributos são importantes nos estudos hidrológicos e de 
solos, e encontram-se listados e definidos em uma tabela no trabalho de Moore et al. (1993a) ou em Burrough \& McDonnell (1998). Os atributos secundários envolvem combinações de atributos primários e podem ser derivados por equações que descrevem a física básica destes processos.

Se assumirmos que a variabilidade espacial das propriedades do solo seja função da variabilidade espacial dos fatores formadores do solo e antropogênicos, necessitamos de meios para descrever e explicar a variabilidade espacial destes fatores. No presente estudo, a topografia, o material de origem e o manejo das culturas são os fatores de maior variabilidade, e, supostamente, os fatores primários que estão contribuindo para a variabilidade dos solos.

Este trabalho foi realizado como um passo inicial na identificação dos processos contribuintes na variabilidade espacial de solos com diferenças de material de origem e tempo de adoção do sistema PD, na região dos "Campos Gerais", centro-sul do Paraná. Os objetivos específicos desta pesquisa foram: 1) avaliar as alterações nos atributos do solo com o tempo de cultivo no sistema PD; 2) definir relações estatísticas entre atributos do relevo e atributos dos solos e 3) verificar o potencial do método de classificação contínua ou "fuzzy"como uma ferramenta para gerar zonas de manejo da fertilidade do solo.

\subsection{Material e Métodos}

\subsubsection{Caracterização Geral da Área}

O estudo foi realizado na fazenda Santa Branca $\left(50^{\circ} 23^{\prime} \mathrm{W} ; 24^{\circ} 36^{\prime} \mathrm{S}\right)$ e na fazenda Pousada dos Gaúchos (50 20' W; $24^{\circ} 26^{\prime} \mathrm{S}$ ) localizadas nas proximidades da cidade de Tibagi, no Segundo Planalto do Estado do Paraná (Figura 1).

A topografia das áreas selecionadas para este estudo é constituida por longas vertentes de forma predominantemente convexa, de declive suave $(0-6 \%)$ e altitude variando entre 790 e 910 metros. A vegetação é caracterizada como estepe subtropical de gramíneas baixas, representadas por algumas gramíneas resistentes ao fogo, tais 


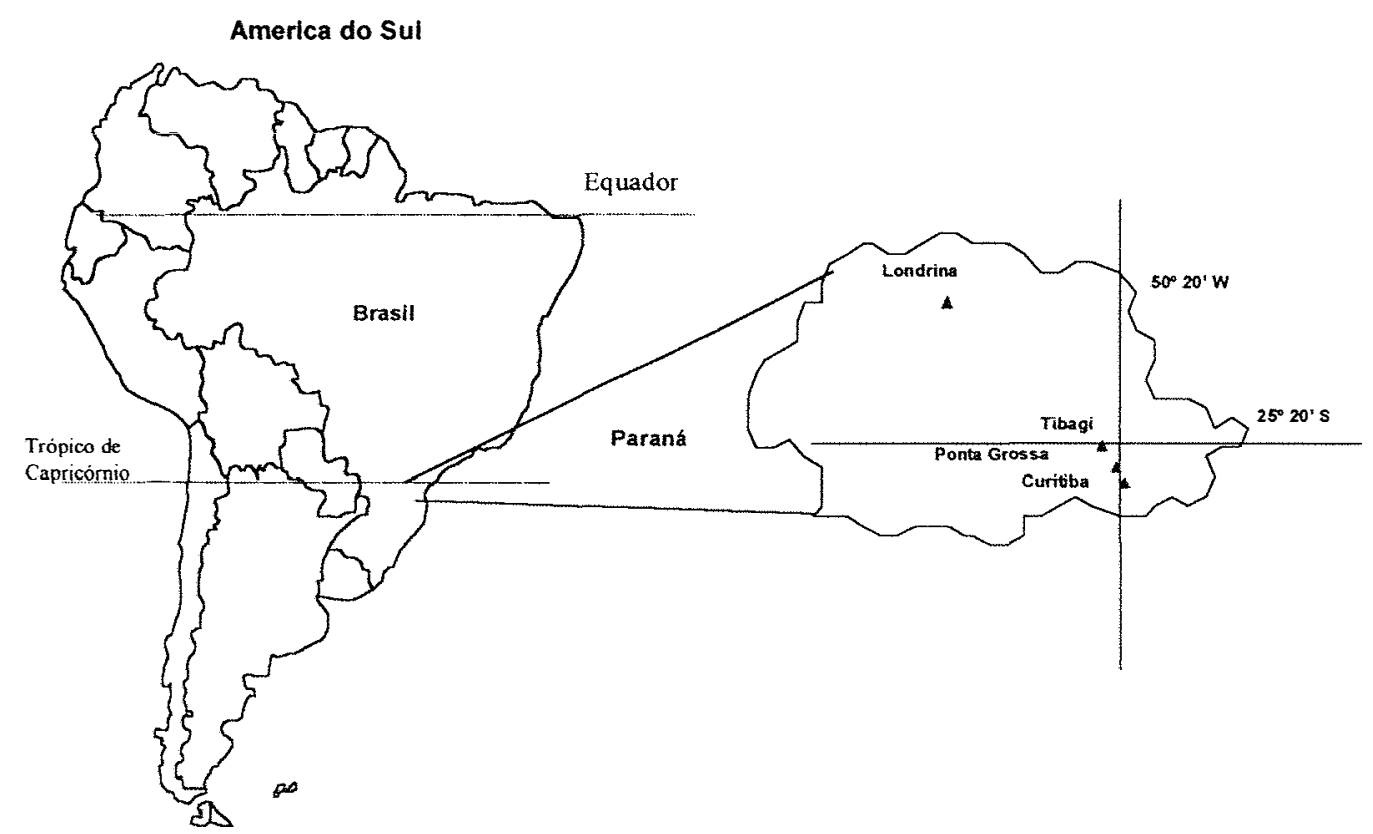

Figura 1. Localização da área de estudo

como: Andropogon sp, Aristida sp, Paspalum sp, Panicum sp., ervas semi-arbustivas e arbustos isolados ou em grupos, entremeadas por florestas de galeria subtropical de Araucária. Segundo Maack, (1981) esta vegetação típica, denominada "Campos Gerais", é provavelmente um relicto do clima árido do Pleistoceno.

O material de origem é constituído por sedimentos clásticos do período devoniano, grupo Paraná, (folhelho da formação Ponta Grossa e arenito da formação Furnas) e material retrabalhado destas duas formações (Trein et al., 1966). O clima da região enquadra-se como subtropical úmido de altitude, tipo $\mathrm{Cfb}$ (classificação de Koeppen), de verões brandos e invernos com geadas frequentes. A precipitação pluviométrica anual é de $1532 \mathrm{~mm}\left(\mathrm{IAPAR}, 1998^{1}\right)$, com boa distribuição durante o ano. A temperatura média mensal é $<22^{\circ} \mathrm{C}$ durante o verão e $<18^{\circ} \mathrm{C}$ durante o inverno (Maack, 1981). Os solos foram classificados como Latossolos Vermelhos (Typic Hapludox), com perfis profundos, muito bem estruturados e drenados, apresentando variações texturais ao longo das vertentes.

\footnotetext{
${ }^{1}$ INSTITUTO AGRONÔMICO DO PARANÁ. Área de Ecofisiologia, Londrina, 1998. Dados climáticos.
} 
Foram selecionadas quatro topossequências de 10 ha $(200 \times 500 \mathrm{~m})$, típicas da região: um campo nativo $(\mathrm{CN})$ e três áreas adjacentes cultivadas em rotação de culturas por 10 (PD10FN, PD10PG) e 20 anos (PD20) no sistema PD. A escolha destas áreas baseou-se no material de origem e textura dos solos, no tipo de vertente e nas práticas culturais. Um resumo das práticas culturais pode ser observado na Tabela 1.

Tabela 1. Rotação de culturas e quantidade de fertilizantes aplicados nas áreas cultivadas a 10 anos (PD10PG e PD10FN) e 20 anos (PD20) no sistema PD

\begin{tabular}{|c|c|c|c|c|c|}
\hline \multirow[t]{2}{*}{ Áreas $^{\dagger}$} & \multirow[t]{2}{*}{ Entradas } & \multirow{2}{*}{$\begin{array}{c}\text { Rotação } \\
\text { de Culturas }\end{array}$} & \multicolumn{3}{|c|}{ Fertilizantes } \\
\hline & & & $\mathrm{N}$ & $\mathrm{P}_{2} \mathrm{O}_{5}$ & $\mathrm{~K}_{2} \mathrm{O}$ \\
\hline & & & & $-\mathrm{Kg} \mathrm{h}$ & 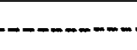 \\
\hline \multirow[t]{2}{*}{ PD10 } & Total & $\mathrm{A} / \mathrm{M} / \mathrm{A} / \mathrm{S} / \mathrm{T} / \mathrm{S}$ & 407 & 685 & 714 \\
\hline & Anual & & 40,7 & 68,5 & 71,4 \\
\hline \multirow[t]{2}{*}{ PD20 } & Total & $\mathrm{A} / \mathrm{M} / \mathrm{A} / \mathrm{S} / \mathrm{T} / \mathrm{S}$ & 643 & 1.472 & 1.361 \\
\hline & Anual & & 32 & 74 & 68 \\
\hline
\end{tabular}

$\uparrow$ Referir-se à Tabela 2 (ou Tabela 15, do Anexo) para descrição das áreas;

$\$ \mathrm{~A}=$ Aveia (Avena sativa) $; \mathrm{M}=$ Milho; $\mathrm{T}=$ Trigo; $\mathrm{S}=$ Soja

O esquema geral da metodologia utilizada está ilustrado na Figura 2. As seções seguintes descrevem os procedimentos específicos usados em cada estágio deste processo.

\subsubsection{Modelo de Elevação Digital (DEM) e Atributos Topográficos}

Os dados de altitude foram medidos com um teodolito em cada ponto das quatro grades de amostragem (Figura 2). As medidas de altitude foram interpoladas usando o interpolador "spline" para criar um DEM de grade regular de 5,0 m, constituido de 4.000 pontos, com o programa Arc View GIS 3.2 - Environmental Systems Research Institute (1999). Este método é apropriado para superficies suaves tais como as vertentes da área de estudo. Em alguns pontos específicos da área, as coordenadas geográficas foram medidas com o uso de GPS. 


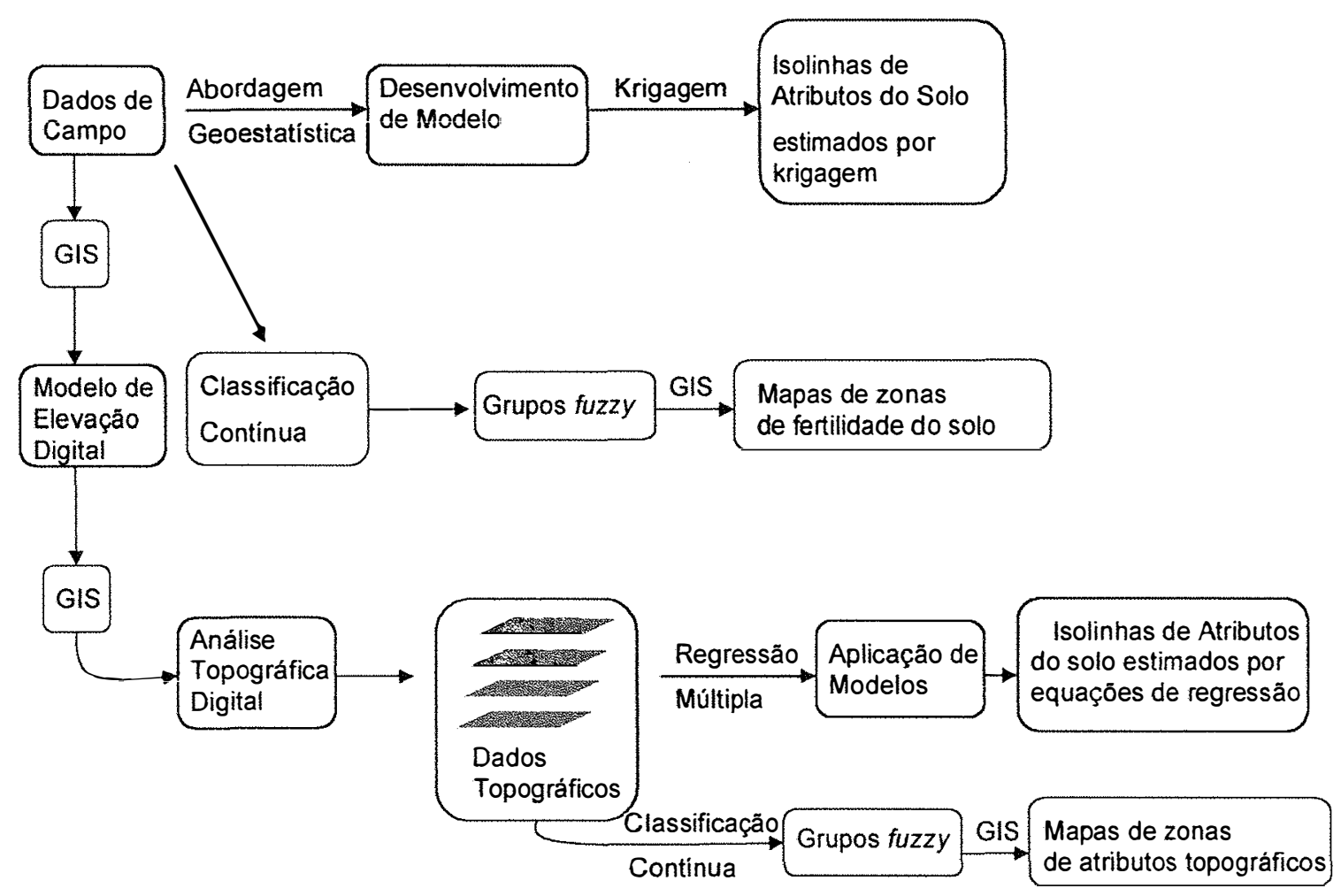

Figura 2 Desenho esquemático da metodologia de modelagem solo-paisagem

Os atributos topográficos foram estimados dos DEMs usando-se análises espaciais do programa Arc View GIS. Uma descrição do método computacional de estimativa de atributos topográficos primários a partir do DEM encontra-se no trabalho de Moore et al. (1993b). Os atributos topográficos primários calculados neste trabalho foram declividade (DECL) e grau de exposição solar (EXP). Também foi calculado um atributo secundário simples que denominamos altitude relativa (AR), obtido pela diferença entre a altitude média e a altitude medida em cada ponto da grade de amostragem.

\subsubsection{Metodologia de amostragem e análise de solo e plantas}

As amostras de solos foram coletadas em cada nó da grade de $50 \times 50 \mathrm{~m}$ $(n=55)$ em maio de 1998, depois da colheita do milho e antes da semeadura do trigo 
(Figura 3). Foram adotadas duas profundidades de amostragem (0-0,10 e 0,10-0,20 m). As amostras foram obtidas cavando-se buracos de dimensão $0,20 \times 0,20 \mathrm{~m}$ e retirandose fatias de 0,020 $\mathrm{m}$ de espessura dos quatro lados, em cada profundidade, para obter-se duas amostras compostas em cada nó da grade. As amostras foram secas ao ar, passadas através de peneiras de 2,0 mm e estocadas para análises subsequentes. Foram coletadas amostras indeformadas nos mesmos lugares e às mesmas profundidades para as medidas de densidade do solo.

Foram abertas três trincheiras de 1,50 $\mathrm{m}$ de profundidade em cada área de estudo para a descrição morfológica (Lemos \& Santos, 1996) e análises físicas, químicas e mineralógicas dos perfis (Figura 3). As posições da vertente foram descritas de acordo com a classificação de Ruhe (1975) (Figura 4).

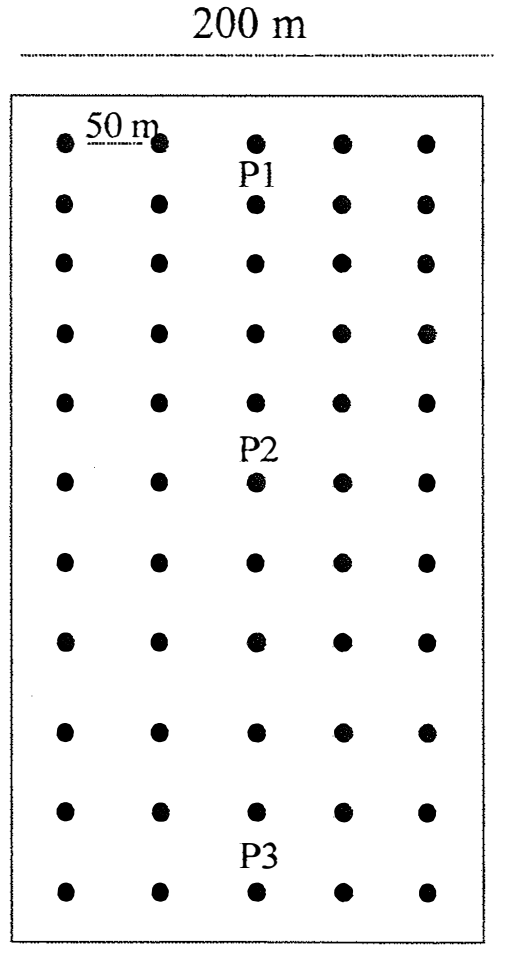

Figura 3 Esquema de amostragem em grade e localização dos perfis de solo (P1, P2, P3).

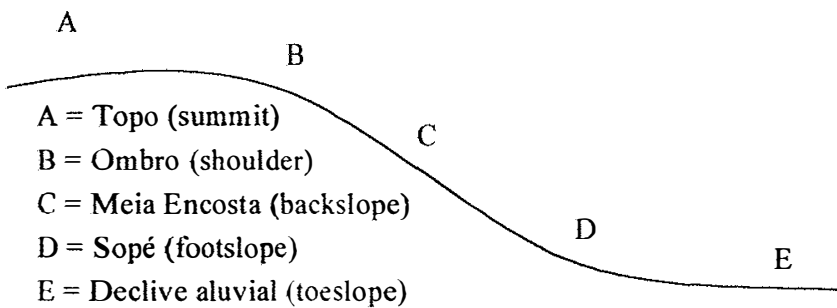

Figura 4 Posições na vertente baseado no esquema de classificação de Ruhe (1975). 
As medidas de rendimento da cultura do trigo foram obtidas através de colheita manual de seis linhas de trigo, numa seção de $4,0 \mathrm{~m}$ de comprimento, sempre imediatamente acima dos pontos de amostragem do solo. Mediu-se a umidade dos grãos de trigo em todos os locais de coleta ajustando-se o peso para $13 \%$ de umidade.

Foram efetuadas análises químicas nas frações de solo $<2 \mathrm{~mm}$. O pH foi medido por potensiometria usando uma solução 1:2 de solo/0,01 $\mathrm{M} \mathrm{CaCl}_{2}$. $\mathrm{Al}, \mathrm{Ca}, \mathrm{Mg}$ e $\mathrm{K}$ trocáveis e $\mathrm{P}$ foram extraídos usando-se resina trocadora de cátions/ânions (Raij et al., 1987). A acidez potencial foi determinada usando-se uma solução tamponada a pH 7,0, de acordo com Raij et al., 1987). O carbono foi determinado por combustão úmida (EMBRAPA, 1997). As frações areia, silte e argila foram separadas, após agitação horizontal de 16 horas, usando-se solução de hexa-metafosfato de sódio como dispersante químico, pelo método do hidrômetro (EMBRAPA, 1997). A densidade global foi determinada pelo método do cilindro volumétrico, descrito por Blake \& Hartge (1986), utilizando-se cilindros com volume interno de cerca de $100 \mathrm{~cm}^{3}$. A difração de Raio-X foi medida por um difratômetro Philips tipo PW3710 BASED com tubo de cobre, de acordo com Jackson (1969).

\subsubsection{Análises Estatísticas e Obtenção de Curvas de Isolinhas de Atributos do Solo}

A afinidade entre os atributos do solo e topográficos foi avaliada através do coeficiente de correlação de Pearson usando-se o programa JMP, versão 3,0 para Windows (Statistical Discovery Software - SAS, 1997). A significância estatística foi analisada para $\mathrm{p}<0,05, \mathrm{p}<0,01$ e $\mathrm{p}<0,001$ e representada por *, ** e $\mathrm{e}^{* * *}$, respectivamente. As isolinhas dos atributos do solo e rendimento do trigo foram estimadas com o uso de abordagem geoestatística descrita por Journel \& Huijbregts (1978), baseada na teoria das variáveis regionalisadas. A krigagem foi usada como método de interpolação e mapas foram produzidos com o programa GS+ for Windows, versão 3.0 (Gamma Design Software, 1999). 


\subsubsection{Relações entre atributos dos solos e topográficos}

A análise de regressão linear múltipla foi utilisada para explorar as relações entre atributos do solo e topográficos usando-se o programa JMP, versão 3,0 para Windows (Statistical Discovery Software - SAS, 1997). As equações de regressão foram usadas no programa Arc View GIS 3.2 - Environmental Systems Research Institute (1999) para estimar-se superfícies de atributos dos solos.

\subsubsection{Classificação contínua ou fuzzy}

A classificação contínua ou "fuzzy" foi usada como método para agrupar-se atributos do solo e topográficos usando-se a técnica "fuzzy k-means". A base matemática desta técnica e os algorítmos computacionais usados para analisar os dados foram detalhados em várias publicações (Burrough, 1989; McBractney \& Gruitjer, 1992; Odeh et al., 1992). O programa Fuzme, Fuzzy k-Means with Extragrades (Australian Center for Precision Agriculture, 1999) foi usado para realizar a classificação contínua. Foi selecionado fuzzy k-means como algorítmo, expoente fuzziness 1,3 e a medida métrica (de distância) Mahalanobis.

\subsection{RESULTADOS E DISCUSSÃO}

Dados selecionados de análises morfológicas, físicas, químicas e mineralógicas dos perfis de solos das quatro topossequências estão apresentados na Tabela 2, como também nas Tabelas 16, 17 e 18 do Anexo. A textura do solo está refletindo as diferenças do material de origem. As áreas de campo nativo e PD10PG, formadas sobre o folhelho Ponta Grossa apresentaram textura muito argilosa. A textura da área PDIOFN, cujo material de origem é o arenito da formação Furnas, apresentou-se predominantemente franco argilo-arenosa, enquanto a área NT20, formada com material retrabalhado destas duas formações, apresentou teor intermediário de argila (argilo-arenosa). 
Tabela 2. Características morfológicas, químicas, físicas e mineralógicas selecionadas dos perfis de solos.

\begin{tabular}{|c|c|c|c|c|c|c|c|}
\hline \multirow[t]{3}{*}{ Propriedades } & \multirow[t]{3}{*}{ Hor $^{\mp}$} & \multicolumn{3}{|c|}{$\mathrm{CN}^{+7}$} & \multicolumn{3}{|c|}{ PD10PG ${ }^{\ddagger}$} \\
\hline & & \multicolumn{6}{|c|}{ Posição na vertente } \\
\hline & & Topo & M.enc. & Sopé & Topo & M.enc. & Sopé \\
\hline \multirow{5}{*}{ Profundidade, $\mathrm{cm}$} & $A P$ & $0-20$ & $0-18$ & $0-20$ & $0-16$ & $0-15$ & $0-17$ \\
\hline & $A B$ & -26 & -27 & -29 & -23 & -24 & -25 \\
\hline & BA & -39 & -36 & -37 & -34 & -35 & -35 \\
\hline & Bw1 & -82 & -85 & -83 & -80 & -78 & -72 \\
\hline & Bw2 & $-150+$ & $-150+$ & $-150+$ & $-150+$ & $-150+$ & $-150+$ \\
\hline \multirow{4}{*}{ Argila, $\mathrm{g} \mathrm{kg}^{-1}$} & Ap & 70 & 71 & 65 & 68 & 68 & 64 \\
\hline & AB & $\begin{array}{l}77 \\
80\end{array}$ & 71 & 68 & 68 & 68 & 66 \\
\hline & $\begin{array}{l}\text { BA } \\
\text { Bw1 }\end{array}$ & $\begin{array}{l}80 \\
82\end{array}$ & $\begin{array}{l}69 \\
78\end{array}$ & 66 & $\begin{array}{l}68 \\
72\end{array}$ & 70 & $\begin{array}{l}70 \\
74\end{array}$ \\
\hline & Bw2 &.$_{-* *}^{* *}$ & - & - & 72 & 74 & 74 \\
\hline \multirow{4}{*}{ Textura } & Ap & M.arg & M.arg & M.arg & M.arg & M.arg & M.arg \\
\hline & $\begin{array}{l}\mathrm{AB} \\
\mathrm{BA}\end{array}$ & $\begin{array}{l}\text { M.arg } \\
\text { M.arg }\end{array}$ & $\begin{array}{l}\text { M.arg } \\
\text { M.arg }\end{array}$ & M.arg & $\begin{array}{l}\text { M.arg } \\
\text { M.arg }\end{array}$ & M.arg & M. arg \\
\hline & $\begin{array}{l}\text { BA } \\
\text { Bw1 }\end{array}$ & $\begin{array}{l}\text { M.arg } \\
\text { M.arg }\end{array}$ & $\begin{array}{l}\text { M.arg } \\
\text { M.arg }\end{array}$ & M.arg & M.arg & $\begin{array}{l}\text { M.arg } \\
\text { M.aro }\end{array}$ & $\begin{array}{l}\text { M.arg } \\
\text { M.ara }\end{array}$ \\
\hline & Bw2 & M.arg & M.arg & $\begin{array}{l}\text { M.arg } \\
\text { M.arg }\end{array}$ & $\begin{array}{l}\text { M.arg } \\
\text { M.arg }\end{array}$ & $\begin{array}{l}\text { M.arg } \\
\text { M.arg }\end{array}$ & $\begin{array}{l}\text { M.arg } \\
\text { M.arg }\end{array}$ \\
\hline \multirow{5}{*}{$\begin{array}{l}\text { Densidade do Solo, } \\
\mathrm{g} \mathrm{cm}^{-3}\end{array}$} & Ap & 1,07 & - & - & 1,12 & 1,16 & 1,01 \\
\hline & $A B$ & 0,91 & - & - & 1,12 & 1,15 & 1,17 \\
\hline & $\mathrm{BA}$ & 0,96 & - & - & 1,13 & 1,20 & 1,23 \\
\hline & Bw1 & 0,87 & - & - & 1,13 & 1,09 & 1,01 \\
\hline & Bw2 & - & - & - & 1,13 & 1,01 & 0,93 \\
\hline \multirow{5}{*}{$\mathrm{pH}\left(0.01 \mathrm{M} \mathrm{CaCl}_{2}\right)$} & $A p$ & 3,9 & 3,7 & 3,6 & 4,8 & 4,9 & 4,6 \\
\hline & $A B$ & 3,7 & 3,6 & 3,5 & 4,2 & 4,4 & 4,0 \\
\hline & $\mathrm{BA}$ & 3,7 & 3,6 & 3,5 & 4,3 & 4,2 & 4,1 \\
\hline & Bw1 & 3,9 & 3,7 & 3,7 & 4,5 & 4,4 & 4,1 \\
\hline & Bw2 & & - & - & 4,7 & 4,6 & 4,4 \\
\hline \multirow{5}{*}{$\begin{array}{l}\text { Al Trocável } \\
\mathrm{mmol}_{\mathrm{c}} \mathrm{dm}^{-3}\end{array}$} & Ap & 14 & 20 & 24 & 0 & 0 & 2 \\
\hline & $A B$ & 16 & 20 & 23 & 5 & 2 & 14 \\
\hline & BA & 13 & 25 & 28 & 6 & 6 & 12 \\
\hline & Bw1 & 10 & 20 & 26 & 3 & 4 & 10 \\
\hline & Bw2 & & - & & 2 & 2 & 3 \\
\hline \multirow{5}{*}{$\begin{array}{l}\text { Matéria Orgânica, } \\
\mathrm{g} \mathrm{dm}^{-3}\end{array}$} & $A p$ & 47 & 45 & 45 & 29 & 31 & 39 \\
\hline & $A B$ & 32 & 47 & 36 & 25 & 31 & 24 \\
\hline & BA & 28 & 37 & 33 & 25 & 24 & 27 \\
\hline & Bw1 & 18 & 23 & 25 & 13 & 20 & 16 \\
\hline & Bw2 & - & - & - & 9 & 11 & 10 \\
\hline \multirow{5}{*}{$\begin{array}{l}\text { P disponível, } \\
\mathrm{mg} \mathrm{dm}^{-3}\end{array}$} & Ap & 6 & 6 & 6 & 8 & 11 & 18 \\
\hline & $A B$ & 3 & 5 & 6 & 4 & 5 & 7 \\
\hline & BA & 3 & 4 & 4 & 2 & 3 & 3 \\
\hline & Bw1 & 2 & 2 & 2 & 2 & 2 & 2 \\
\hline & Bw2 & - & - & - & 1 & 2 & 1 \\
\hline \multirow{5}{*}{$\begin{array}{l}\text { Soma de Bases } \\
\left(\mathrm{Ca}^{++}+\mathrm{Mg}^{+++}+\mathrm{K}^{+}\right) \\
\mathrm{mmol}_{\mathrm{c}} \mathrm{dm}^{-3}\end{array}$} & $A p$ & 21,4 & 24,4 & 19,6 & 75,5 & 82,8 & 76,0 \\
\hline & $A B$ & 4,6 & 19,0 & 14,6 & 26,2 & 38,0 & 20,9 \\
\hline & $\mathrm{BA}$ & 3,3 & 11,5 & 7,8 & 12,4 & 19,2 & 14,5 \\
\hline & Bw1 & 2,6 & 3,1 & 3,2 & 4,3 & 13,4 & 4,6 \\
\hline & Bw2 & & & & 3,2 & 4,2 & 2,2 \\
\hline \multirow{5}{*}{$\mathrm{CTC}, \mathrm{mmol}_{\mathrm{c}} \mathrm{dm}^{-3}$} & $\mathrm{Ap}$ & 187 & 252 & 248 & 140 & 141 & 164 \\
\hline & $A B$ & 171 & 224 & 268 & 106 & 126 & 171 \\
\hline & BA & 138 & 265 & 236 & 100 & 117 & 124 \\
\hline & Bw1 & 101 & 188 & 188 & 56 & 71 & 103 \\
\hline & Bw2 & & & & 45 & 51 & 60 \\
\hline Mineralogia da & Bw1 & Cao, Gb, & Cao, Gb, & Cao, Gb, & Cao, Gb, & Cao, Gb, & Cao, Gb, \\
\hline Fração Argila & & $\begin{array}{l}\text { Hm, Gt, } \\
\text { Vm-Al }\end{array}$ & $\begin{array}{l}H m, G t, \\
V m-A l\end{array}$ & $\begin{array}{l}\mathrm{Hm}, \mathrm{Gt}, \\
\mathrm{Vm}-\mathrm{Al}\end{array}$ & $\begin{array}{l}\mathrm{Hm}, \mathrm{Gt} \\
\mathrm{Vm}-\mathrm{Al}\end{array}$ & $\begin{array}{l}\mathrm{Hm}, \mathrm{Gt} \\
\mathrm{Vm}-\mathrm{Al}\end{array}$ & $\begin{array}{l}\mathrm{Hm}, \mathrm{Gt} \\
\mathrm{Vm}-\mathrm{Al}\end{array}$ \\
\hline
\end{tabular}




\begin{tabular}{|c|c|c|c|c|c|c|c|}
\hline \multirow[t]{3}{*}{ Propriedades } & \multirow[t]{3}{*}{ Hor $^{\mp}$} & \multicolumn{2}{|c|}{ PD20 } & \multicolumn{4}{|c|}{ PD10FN } \\
\hline & & & & Posição n & vertente & & \\
\hline & & Topo & M.enc. ${ }^{*}$ & M.enc. ${ }^{*}$ & Topo & M.enc. ${ }^{*}$ & M.enc. \\
\hline \multirow[t]{5}{*}{ Profundidade, $\mathrm{cm}$} & $A p$ & $0-20$ & $0-16$ & $0-17$ & $0-17$ & $0-19$ & $0-18$ \\
\hline & $A B$ & -29 & -25 & -26 & -30 & -27 & -29 \\
\hline & BA & -43 & -39 & -39 & -47 & -39 & -40 \\
\hline & Bw1 & -80 & -76 & -72 & -83 & -90 & -92 \\
\hline & Bw2 & $-150+$ & $-150+$ & $-150+$ & $-150+$ & $-150+$ & $-150+$ \\
\hline \multirow{5}{*}{ Argila, $\mathrm{g} \mathrm{kg}^{-1}$} & $A p$ & 48 & 38 & 42 & 32 & 24 & 22 \\
\hline & $A B$ & 48 & 38 & 42 & 38 & 28 & 24 \\
\hline & BA & 50 & 42 & 44 & 42 & 30 & 32 \\
\hline & Bw1 & 54 & 46 & 50 & 46 & 34 & 32 \\
\hline & Bw2 & 54 & 46 & 50 & 46 & 38 & 32 \\
\hline \multirow[t]{4}{*}{ Textura } & $A p$ & Arg.Ar & Arg.Ar & Arg.Ar & Fr.Arg.Ar & Fr.Arg.Ar & Fr.Arg.Ar \\
\hline & $A B$ & Arg.Ar & Arg.Ar & Arg.Ar & Arg.Ar & Fr.Arg.Ar & Fr.Arg.Ar \\
\hline & $\begin{array}{l}\text { BA } \\
\text { Bw1 }\end{array}$ & $\begin{array}{l}\text { Arg.Ar } \\
\text { Arg }\end{array}$ & $\begin{array}{l}\text { Arg.Ar } \\
\text { Arg.Ar }\end{array}$ & $\begin{array}{l}\text { Arg.Ar } \\
\text { Arg.Ar }\end{array}$ & $\begin{array}{l}\text { Arg.Ar } \\
\text { Arg.Ar }\end{array}$ & $\begin{array}{l}\text { Fr.Arg.Ar } \\
\text { Fr.Arg.Ar }\end{array}$ & $\begin{array}{l}\text { Fr.Arg.Ar } \\
\text { Fr.Arg.Ar }\end{array}$ \\
\hline & Bw2 & Arg & Arg.Ar & Arg.Ar & Arg.Ar & Arg.Ar & Fr.Arg.Ar \\
\hline \multirow{5}{*}{$\begin{array}{l}\text { Densidade do Solo, } \\
\mathrm{g} \mathrm{cm}^{-3}\end{array}$} & Ap & 1,35 & 1,33 & 1,45 & 1,55 & 1,67 & 1.72 \\
\hline & $A B$ & 1,25 & 1,42 & 1,33 & 1,44 & 1,66 & 1,61 \\
\hline & BA & 1,26 & 1,38 & 1,26 & 1,40 & 1,62 & 1,53 \\
\hline & $B w 1$ & 1,14 & 1,33 & 1,30 & 1,30 & 1,48 & 1,58 \\
\hline & Bw2 & 1,16 & 1,22 & 1,25 & 1,39 & 1,41 & 1,56 \\
\hline \multirow[t]{5}{*}{$\mathrm{pH}\left(0.01 \mathrm{M} \mathrm{CaCl}_{2}\right)$} & $A p$ & 4,8 & 5,3 & 4,6 & 4,8 & 5,5 & 5,3 \\
\hline & $A B$ & 4,2 & 4,1 & 4,1 & 4,6 & 4,8 & 4,2 \\
\hline & $B A$ & 4,2 & 4,2 & 4,2 & 4,0 & 4,2 & 4,1 \\
\hline & Bw1 & 4,5 & 4,2 & 4,2 & 4,4 & 4,4 & 4,2 \\
\hline & Bw2 & 4,6 & 4,5 & 4,4 & 4,3 & 4,8 & 4,2 \\
\hline & $\mathrm{Ap}$ & 2 & 0 & 3 & 0 & 0 & 0 \\
\hline \multirow{4}{*}{$\mathrm{mmol}_{\mathrm{c}} \mathrm{dm}^{-3}$} & $A B$ & 4 & 8 & 7 & 2 & 0 & 3 \\
\hline & BA & 5 & 8 & 8 & 8 & 4 & 8 \\
\hline & Bw1 & 3 & 4 & 4 & 3 & 3 & 4 \\
\hline & Bw2 & 3 & 3 & 3 & 4 & 0 & 4 \\
\hline \multirow{5}{*}{$\begin{array}{l}\text { Matéria Orgânica, } \\
\mathrm{g} \mathrm{dm}^{-3}\end{array}$} & $A p$ & 33 & 35 & 29 & 30 & 24 & 20 \\
\hline & $A B$ & 21 & 19 & 20 & 20 & 15 & 15 \\
\hline & BA & 19 & 18 & 17 & 15 & 9 & 13 \\
\hline & Bw1 & 13 & 14 & 16 & 11 & 9 & 8 \\
\hline & $\mathrm{Bw} 2$ & 12 & 10 & 10 & 11 & 7 & 8 \\
\hline \multirow{5}{*}{$\begin{array}{l}\text { P disponível, } \\
\mathrm{mg} \mathrm{dm}^{-3}\end{array}$} & $A p$ & 51 & 43 & 21 & 21 & 35 & 16 \\
\hline & $A B$ & 3 & 5 & 4 & 5 & 4 & 4 \\
\hline & BA & 2 & 2 & 3 & 2 & 2 & 3 \\
\hline & Bw1 & 1 & 2 & 2 & 2 & 2 & 2 \\
\hline & $\mathrm{Bw} 2$ & 2 & 2 & 2 & 2 & 2 & 2 \\
\hline \multirow{5}{*}{$\begin{array}{l}\text { Soma de Bases } \\
\left(\mathrm{Ca}^{++}+\mathrm{Mg}^{+++}+\mathrm{K}^{+}\right) \text {, } \\
\mathrm{mmol}_{\mathrm{c}} \mathrm{dm}^{-3}\end{array}$} & Ap & 79,7 & 85,6 & 48,3 & 58,3 & 64,5 & 50,4 \\
\hline & $A B$ & 20,0 & 16,9 & 15,5 & 39,2 & 20,1 & 16,4 \\
\hline & BA: & $16 ; 7$ & 11,2 & 9,7 & 8,2 & 7,8 & 8,0 \\
\hline & Bw1 & 11,8 & 9,6 & 9,5 & 6,5 & 6,5 & 4,1 \\
\hline & Bw2 & 4,9 & 6,7 & 2,2 & 2,2 & 5,5 & 2,2 \\
\hline \multirow{5}{*}{ CTC $\left(\mathrm{mmol}_{\mathrm{c}} \mathrm{dm}^{-3}\right)$} & Ap & 138 & 124 & 120 & 100,3 & 89,5 & 78,4 \\
\hline & $A B$ & 108 & 105 & 104 & 97,2 & 58,1 & 74,4 \\
\hline & $\mathrm{BA}$ & 97 & 75 & 82 & 88,2 & 49,8 & 60,0 \\
\hline & Bw1 & 64 & 62 & 74 & 58,5 & 40,5 & 42,2 \\
\hline & Bw2 & 52 & 45 & 44 & 44,2 & 33,5 & 44,2 \\
\hline Mineralogia da & Bw1 & Cao, Gb, & Cao, Gb, & $\mathrm{Cao}, \mathrm{Gb}$ & $\mathrm{Cao}, \mathrm{Gb}$ & Cao, Gb, & Cao, Gb, \\
\hline Fração Argila & & $\begin{array}{r}\mathrm{Hm}, \mathrm{Gt}, \\
\mathrm{Vm}-\mathrm{Al}\end{array}$ & $\begin{array}{l}\mathrm{Hm}, \mathrm{Gt} \\
\mathrm{Vm}-\mathrm{Al}\end{array}$ & $\begin{array}{l}\mathrm{Hm}, \mathrm{Gt}, \\
\mathrm{Vm}-\mathrm{Al}\end{array}$ & $\begin{array}{l}\mathrm{Hm}, \mathrm{Gt} \\
\mathrm{Vm}-\mathrm{Al}\end{array}$ & $\begin{array}{r}\mathrm{Hm}, \mathrm{Gt}, \\
\mathrm{Vm}-\mathrm{Al}\end{array}$ & $\begin{array}{r}\mathrm{Hm}, \mathrm{Gt}, \\
\mathrm{Vm}-\mathrm{Al}\end{array}$ \\
\hline
\end{tabular}

${ }^{\mp}$ Horizontes, ${ }^{\text {ff }}$ Campo Nativo (estepe subtropical), ${ }^{\mp}$ Plantio Direto (10 anos) - Material de Origem: folhelho da formação Ponta Grossa, ${ }^{\ddagger \ddagger}$ Plantio Direto (20 anos) - Material de Origem: material retrabalhado das formações Ponta Grossa e Furnas, ${ }^{\ddagger \ddagger}$ Plantio Direto (10 anos) Material de Origem: arenito da formação Furnas, Cao (Caolinita), Gb (Gibbisita), Vm-Al (Vermiculita aluminizada), Hm (Hematita), Gt (Goetita), M.arg. (muito argilosa) Arg (argila), Arg.Ar (argilo-arenosa), Fr.Arg.Ar (franco argilo-arenosa), ${ }^{*}$ meia encosta, ${ }^{* *}$ dados não coletados. 
Os solos das quatro áreas de estudo foram classificados como LATOSSOLOS VERMELHOS Distróficos típicos A moderado (Typic Hapludox). Apresentaram algumas distinções ao $5^{\circ}$ nível categórico (nível de família) de acordo com o Sistema Brasileiro de Classificação de Solos (EMBRAPA, 1999). Sendo assim, a textura variou de média (PD20 e PD10FN) a muito argilosa (CN e PD10PG), o percentual de bases no complexo sortivo dos solos cultivados em PD enquadrou-os como hipodistróficos e a elevada saturação por alumínio dos solos do campo nativo classificou -os como álicos. A despeito das diferenças no material de origem, a mineralogia da fração argila apresentou-se qualitivamente bastante similar (Tabela 2) tendo em vista a avançada maturidade dos solos. Quantitativamente ocorreram algumas diferenças (EMBRAPA, 1999) distinguindo-os como: cauliníticos no $\mathrm{CN}$, caulinítico-oxídicos na área PD10PG e predominantemente gibbisiticos-oxídicos nas áreas PD10FN e PD20 (Tabela 17, do Anexo). Os valores da densidade do solo variaram de acordo com a textura e o conteúdo de matéria orgânica. As análises químicas dos solos da área de campo nativo evidenciaram os baixos valores de $\mathrm{pH}, \mathrm{P}$ e bases trocáveis dos solos da região dos “Campos Gerais" (Tabela 2).

Foram exploradas neste estudo somente as relações entre os atributos dos solos e topográficos medidos na camada de $0-0,10 \mathrm{~m}$. A similaridade do relevo nas quatro áreas pode ser observada nas representações tridimensionais topográficas (DEMs) (Figura 5) obtidas através da interpolação dos dados de altitude em uma grade regular de 5,0 metros. Usando-se as análises topográficas descritas anteriormente foram calculados os valores para altitude relativa (AR), declividade (DECL) e grau de exposição solar (EXP) que podem ser visualizados na Figura 6. AR foi o atributo topográfico melhor correlacionado com os atributos do solo (Tabelas 3a e 3b). Os valores de AR positivos estão localizados acima da altitude média e os negativos abaixo desta altitude, onde os valores de AR são nulos. Os coeficientes de correlação de Pearson entre $\mathrm{AR}$ e $\mathrm{MO}$ foram menores no campo nativo $\left(\mathrm{r}=0,30^{*}\right)$ do que nas áreas cultivadas em PD $\left(r=0,37^{* *}, r=0,60^{* * *}, r=0,66^{* * *}\right.$, para PD10PG, PD10FN e PD20 respectivamente), evidenciando a tendência de concentração de $\mathrm{MO}$ nas posições mais 
(a)

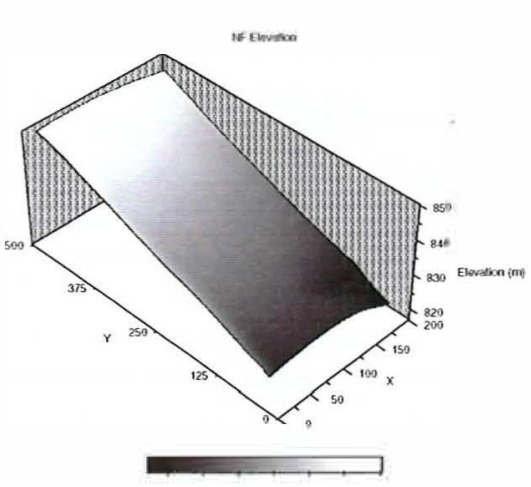

(c)

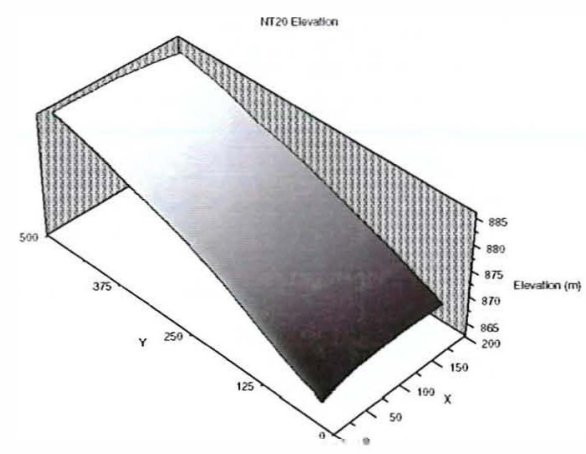

860 (b)

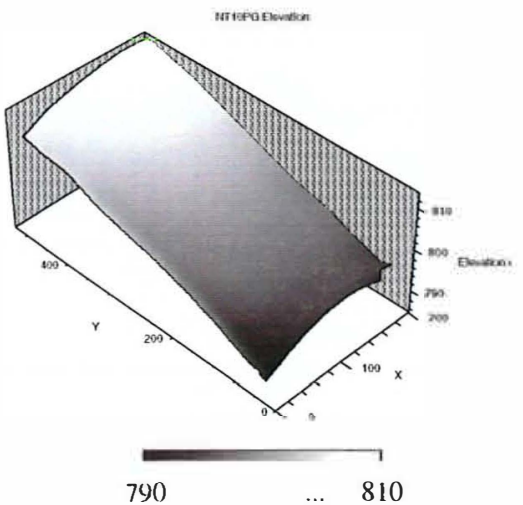

(d)

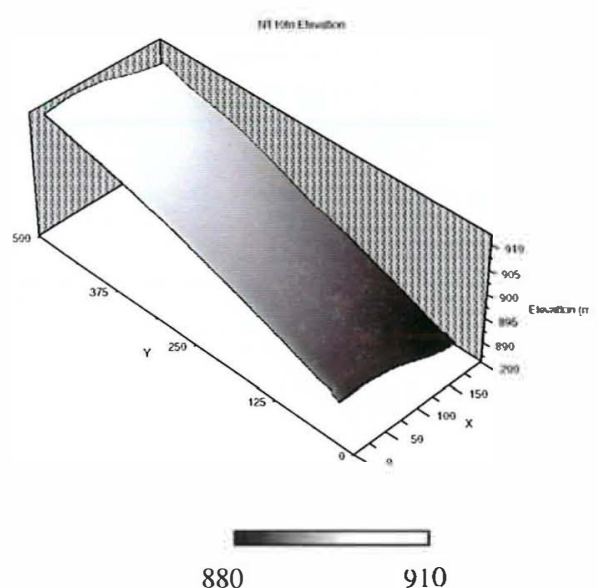

Figura 5. Modelo de Elevação Digital (DEM) das quatro áreas de estudo: a) $\mathrm{CN}$; b) PD10PG; c) PD20; d) PD10FN. As escalas referem-se às altitudes em metros. Referir-se à Tabela 2 para descrição das áreas. 


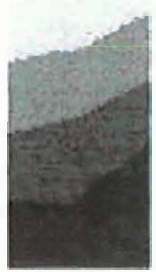

(1)

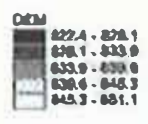

(a) NF

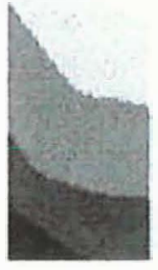

(b) NT10PG
(5)

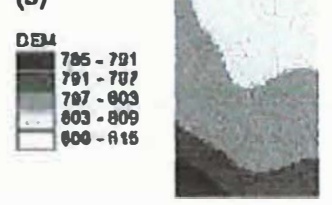

(9)

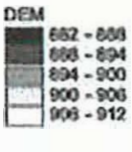

(c) NT 10FN
(2)

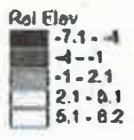

(6)

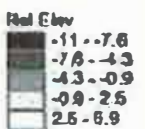

20.25
$26-6.9$

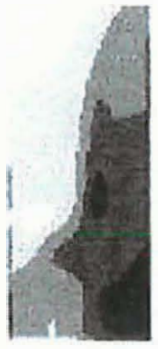

(7)
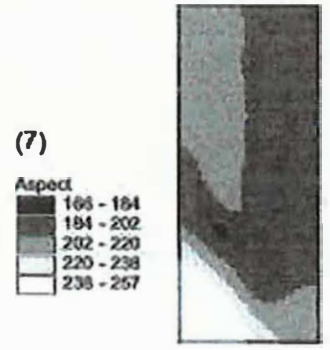

(8)

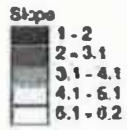

(12)

(11)
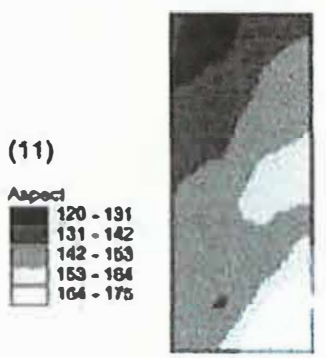

8000
07.127
1.77
27.27
27.47
47.67

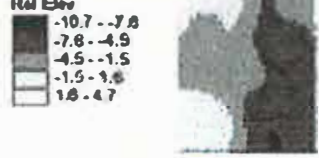

(14)
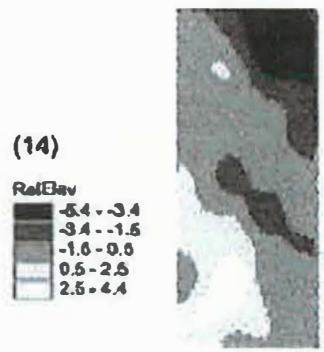

(15)

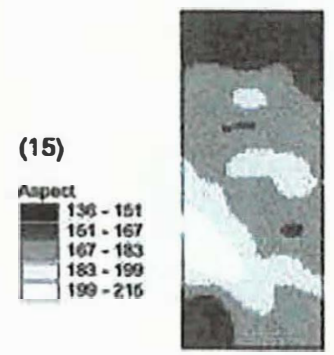

(16)

Skppo
$0.9-12$
12.1 .9
12.2 .0
2.6 .33
3

2.5 .8 .4

(त) NTM

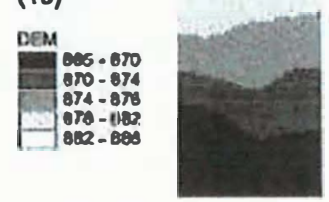

Figura 6. Modelo de Elevação Digital (DEM) e atributos topográficos derivados dos DEMs das quatro áreas de estudo. (RelElev $=$ altitude relativa, Aspect $=$ exposição solar, Slope = declividade; (a) campo nativo, (b) PD10PG, (c)PD10FN, (d) PD20). Referir-se à Tabela 2 para descrição das áreas. 


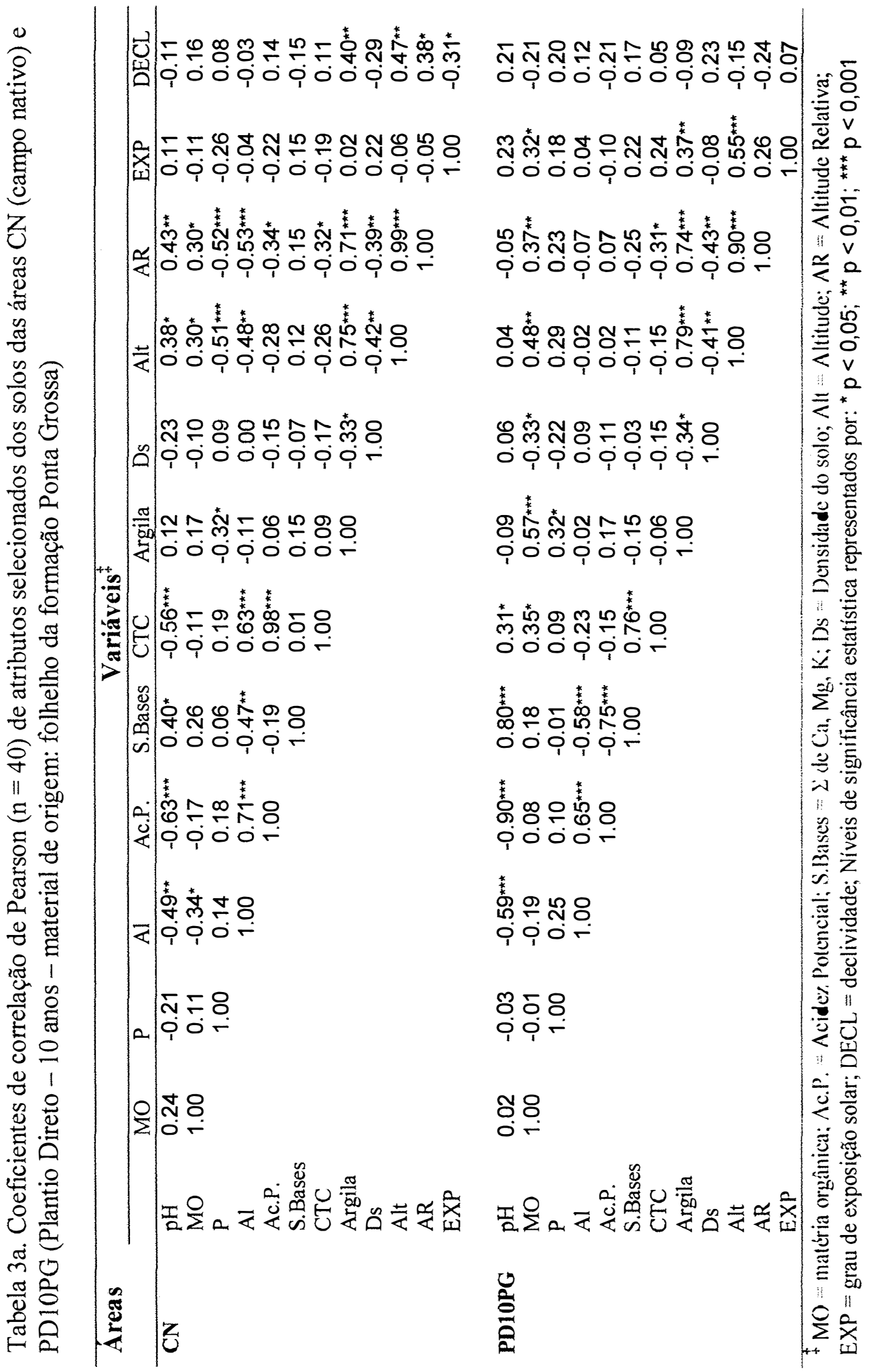




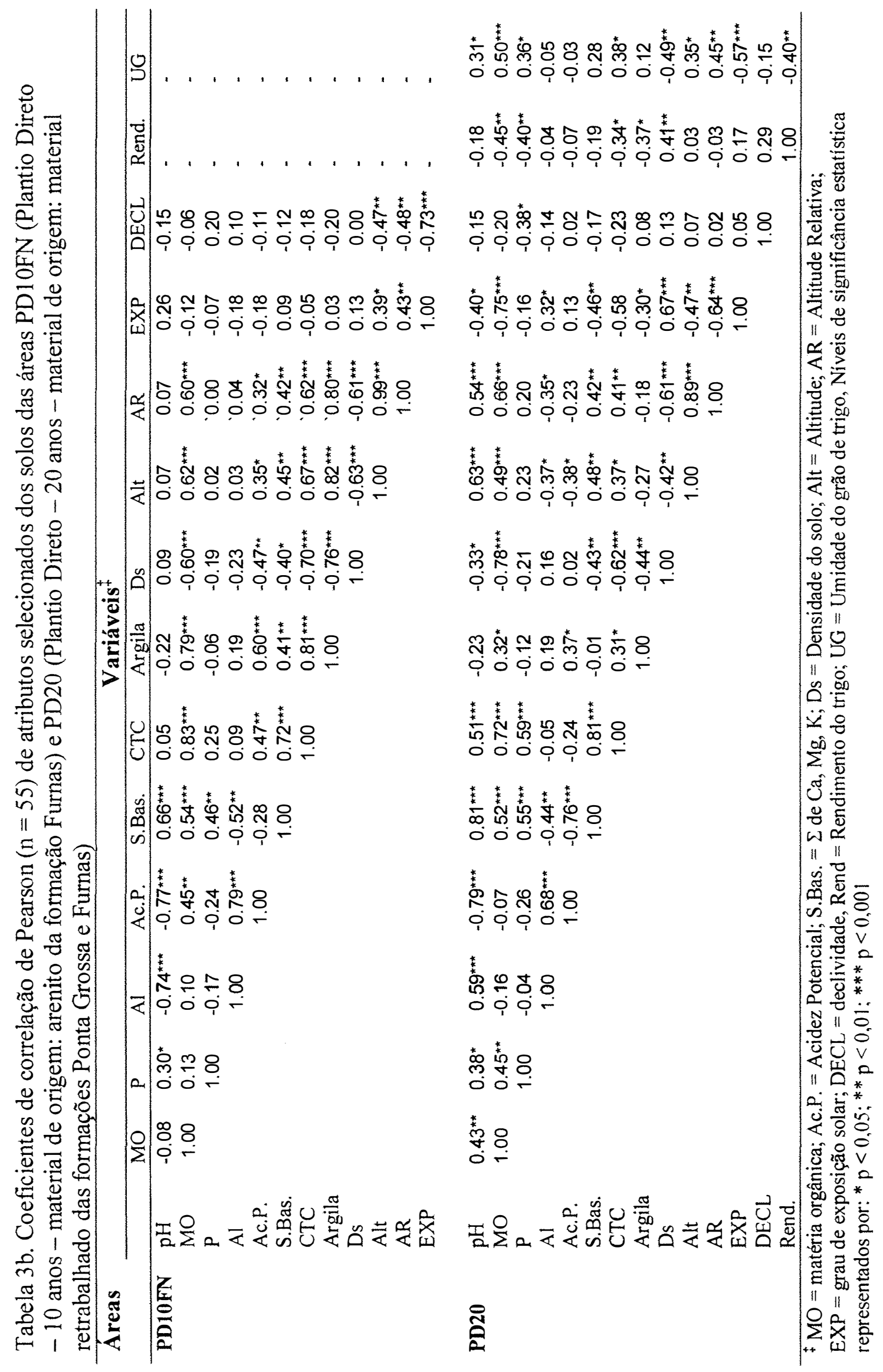


elevadas das vertentes dos solos cultivados no sistema PD. Esta tendência está melhor caracterizada nas áreas PD20 e PD10FN, ou seja, nos solos de textura argilo-arenosa e franco argilo-arenosa, respectivamente e podem ser visualizadas nas Figuras 20 a 27 do Anexo. Consequentemente a densidade do solo nestas áreas apresentou coeficiente de correlação negativa com $\mathrm{AR}\left(\mathrm{r}=-0,60^{* * *}\right.$, em ambas áreas). Foi também encontrada correlação positiva entre AR e CTC $\left(\mathrm{r}=0,41^{* *}, \mathrm{r}=0,62^{* * *}\right.$, nas áreas PD20 e PD10FN respectivamente) e soma de bases $(r=0,42 * *$, em ambas áreas acima citadas) (Tabelas $3 a$ e $3 b)$.

O coeficiente de correlação de Pearson entre acidez potencial e CTC no CN apresentou correlação positiva e altamente significativa $\left(\mathrm{r}=0,98^{* * *}\right)$, o mesmo não ocorrendo nos demais tratamentos $\left(\mathrm{r}=-0,15^{\mathrm{ns}} ; 0,47^{* *} ;-0,24^{\text {ns }}\right)$ nas áreas PD10PG, PD10FN e PD20 respectivamente (Tabelas 3a e 3b). Esta é uma indicação de que com a conversão do $\mathrm{CN}$ em áreas de cultivo no sistema $\mathrm{PD}$ por longo período, haja uma

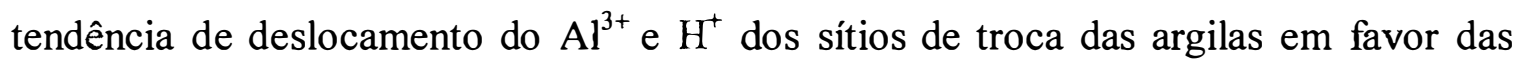
bases trocáveis, resultando no aumento do $\mathrm{pH}$ (Tabela 2). Além disso, nas áreas cultivadas em PD, a MO está positivamente correlacionada com a CTC $\left(r=0,35^{*}\right.$; $0,72 * * *$ e $0,82 * * *$, para NT10PG, NT20 e NT10FN respectivamente) (Tabelas $3 \mathrm{a}$ e 3 b), portanto aumentando os coeficientes de correlação proporcionalmente a diminuição no teor de argila dos solos (Tabela 2). Estes resultados ressaltam a importância da manutenção da $\mathrm{MO}$ no aumento da CTC, e, provavelmente, na carga negativa líquida dos solos, como discutido nos trabalhos de Uehara \& Keng (1975) e Uehara (1995). A manutenção dos resíduos culturais na superficie dos solos sob sistema PD pode aumentar a reciclagem e decomposição gradual dos resíduos culturais, resultando em um aumento no carbono orgânico do solo e liberação de bases trocáveis. Por outro lado, a posição de topo, especificamente nesta paisagem, está relacionada com reduzido escorrimento superficial, colaborando para a manutenção de fertilizantes, calcário e resíduos culturais. Sanchez (1976) e Uehara (1995) consideraram o aumento da carga negativa líquida e CTC como a melhor prática de manejo em solos de carga variável. Por outro lado, Raij (1969) e Silva et al. (1994) observaram em Latossolos do Estado de São Paulo e região do Cerrado que a matéria orgânica do solo contribuiu em 74 \% e 
$75 \%$ respectivamente, na capacidade de troca de cátions total dos solos, caracterizando a elevada importância da MO nos solos de carga variável.

Os coeficientes lineares e angulares dos atributos topográficos e os coeficientes de determinação $\left(\mathrm{R}^{2}\right)$ das relações descrevendo a distribuição da $\mathrm{MO}$, argila, $\mathrm{pH}, \mathrm{P}$, CTC, densidade do solo (Ds), umidade do grão de trigo por ocasião da colheita (UG) e rendimento do trigo encontram-se na Tabela 4. As equações de regressão múltipla responderam por 0,29 a $0,53 \%, 0,20$ a $0,54 \%, 0,52$ a $0,73 \%$ e 0,32 a $0,65 \%$ da variabilidade dos atributos dos solos medidos nas áreas CN, PD10PG, PD10FN, PD20 respectivamente (Tabela 4). Portanto, o melhor modelo de predição de atributos do solo obtido com o uso destas equações foi encontrado para a área PD10FN, ou seja, para os solos de textura franco argilo-arenosa formados a partir do arenito da formação Fumas. Os atributos melhor estimados foram MO, conteúdo de argila, densidade do solo e CTC (Tabela 4). Em um estudo similar, as equações encontradas por Moore et al. (1993b) em uma área de 5,4 ha no Estado de Colorado/USA, responderam por 41 a $64 \%$ da variabilidade do conteúdo da $\mathrm{MO}$, do $\mathrm{pH}$, da espessura do horizonte $\mathrm{A}$, do $\mathrm{P}$, e dos teores de areia e silte. Neste caso, a declividade e o índice de umidade foram os atributos topográficos melhor correlacionados com os atributos do solo.

As áreas estudadas cobrem uma porção da paisagem relativamente pequena e têm limitada variação dos atributos topográficos. $\mathrm{Na}$ aplicação desta metodologia em áreas de paisagem mais heterogênea, outros atributos topográficos, tais como curvatura plana e de perfil, área de captação de água e índice de umidade podem ser importantes (Burrough \& MacDonnell, 1998; Moore et al., 1993b).

As equações de regressão foram usadas para estimar a distribuição espacial dos atributos do solo. Nas Figuras 7, 8, 9, 10a e 10b pode-se comparar os mapas de isolinhas de selecionados atributos do solo estimados por krigagem com os mapas obtidos com o uso das equações de regressão linear múltipla nas áreas CN, PD10PG, PD10FN e PD20 respectivamente.

$\mathrm{O}$ rendimento do trigo foi medido somente na área $\mathrm{PD} 20$ e não apresentou correlação significativa com os atributos topográficos e grande parte dos atributos do solo estudados. Os atributos melhor correlacionados com o rendimento foram: 


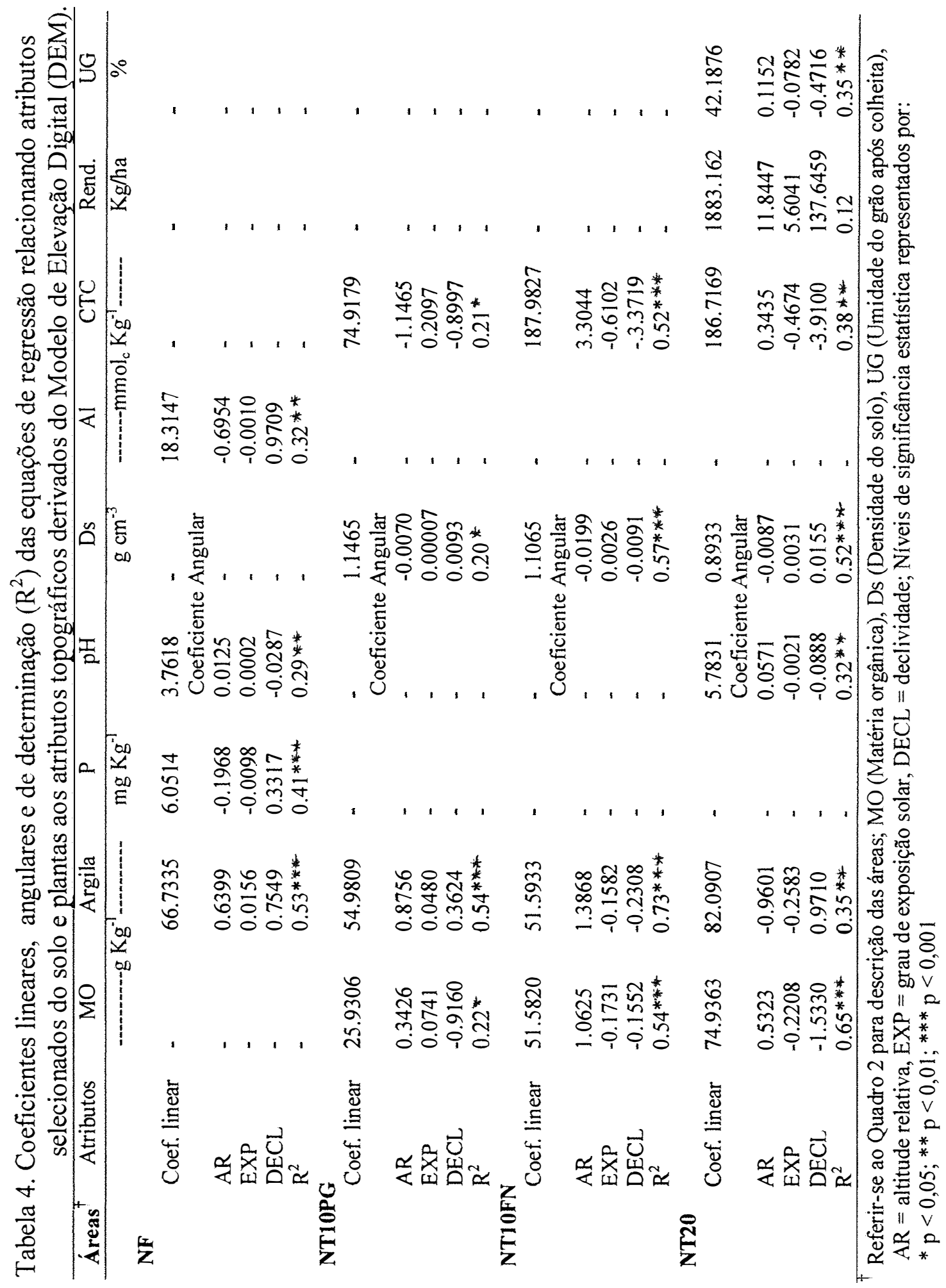



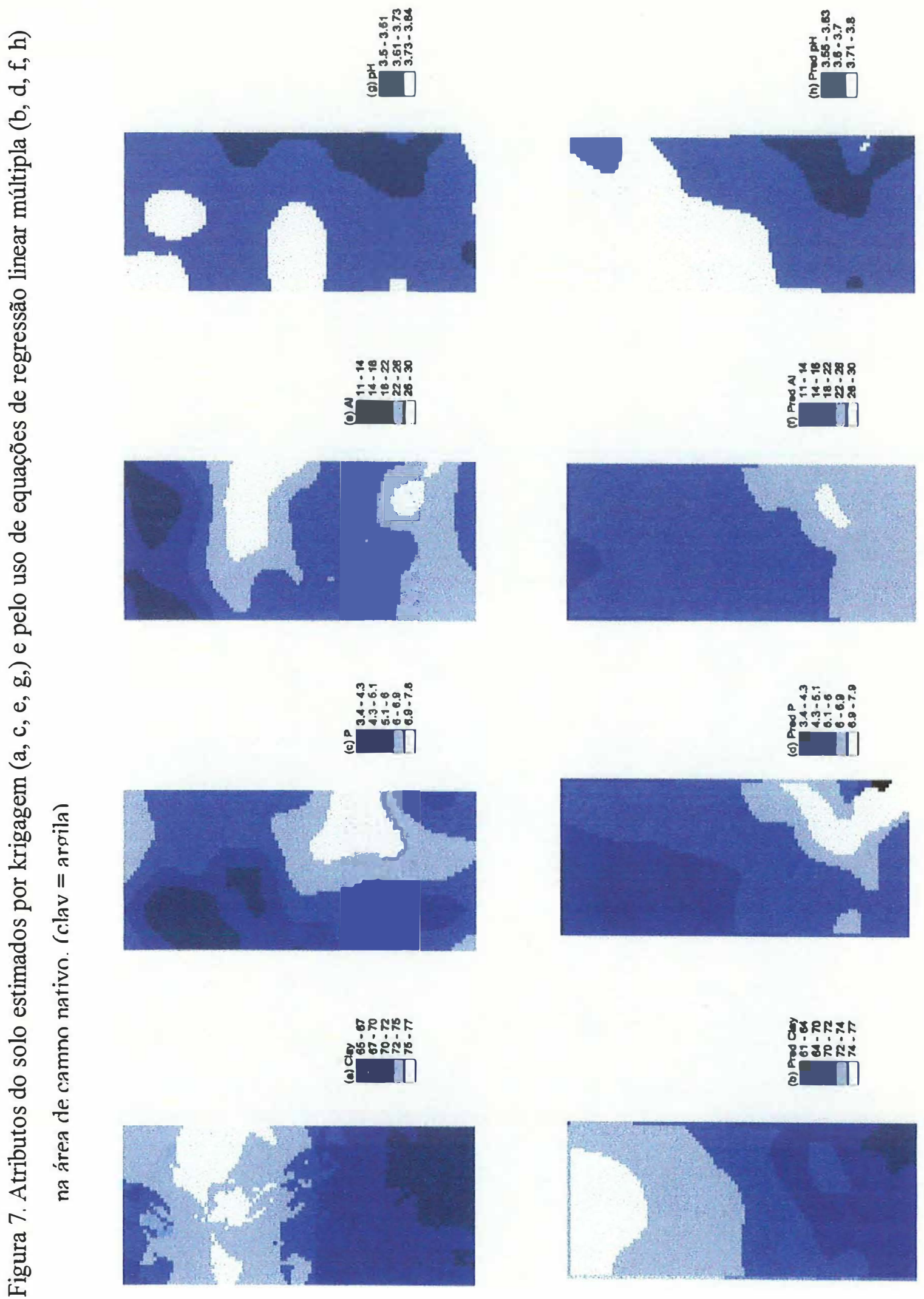

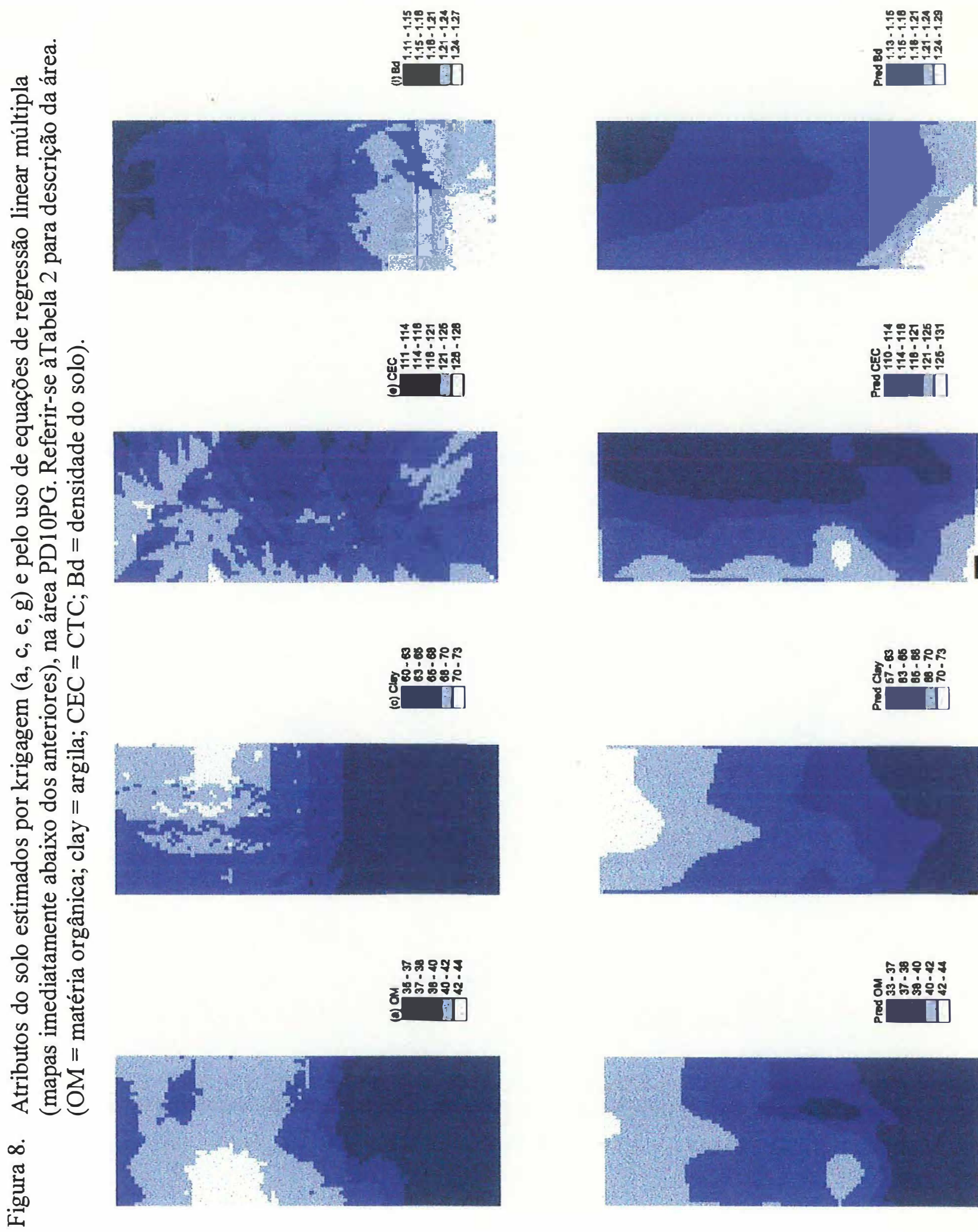

구우저ㄷㅝㅠ-

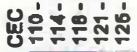
[1]

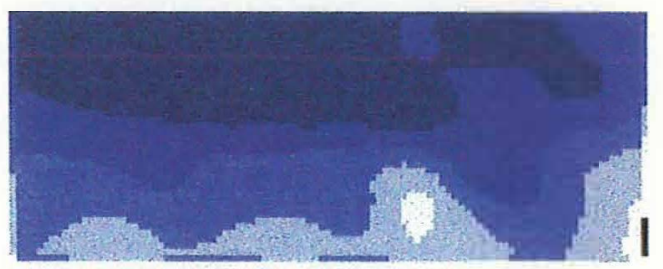

88 8웅 ชิำ (1)

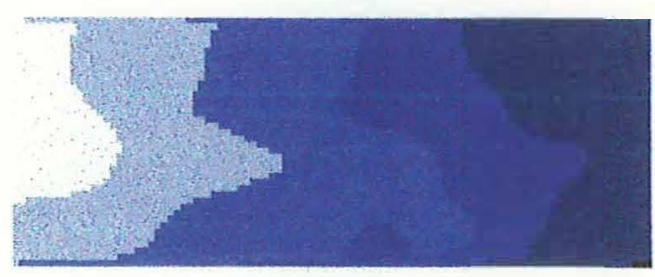

서요욱구

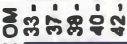
ह

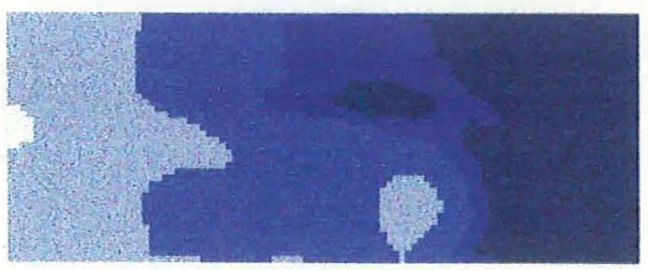




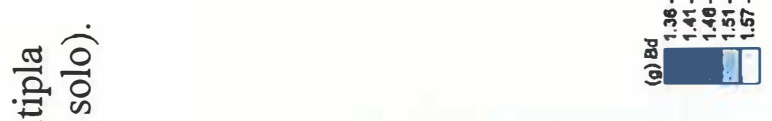

₹

薄

๓ํำ

D1

ह

콕 웅

능

త

엉

is I

के II

可

ஹ。

จ
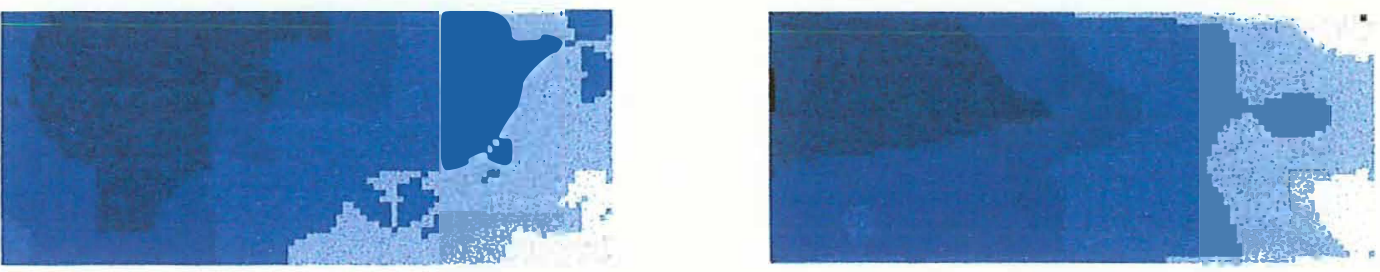

20 11

岢项

ชิ ชే

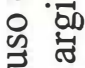

에 11

离

का ชే

क.

० 0

త్రీ శర

द्व:

品

ฮี

'క్ $\|$ 엉

¿잉에

n

冚告

.

की

유 원

ㅇำ ส

음

ข 도

분

है

a

직

可

ำ

쑹ํํำ
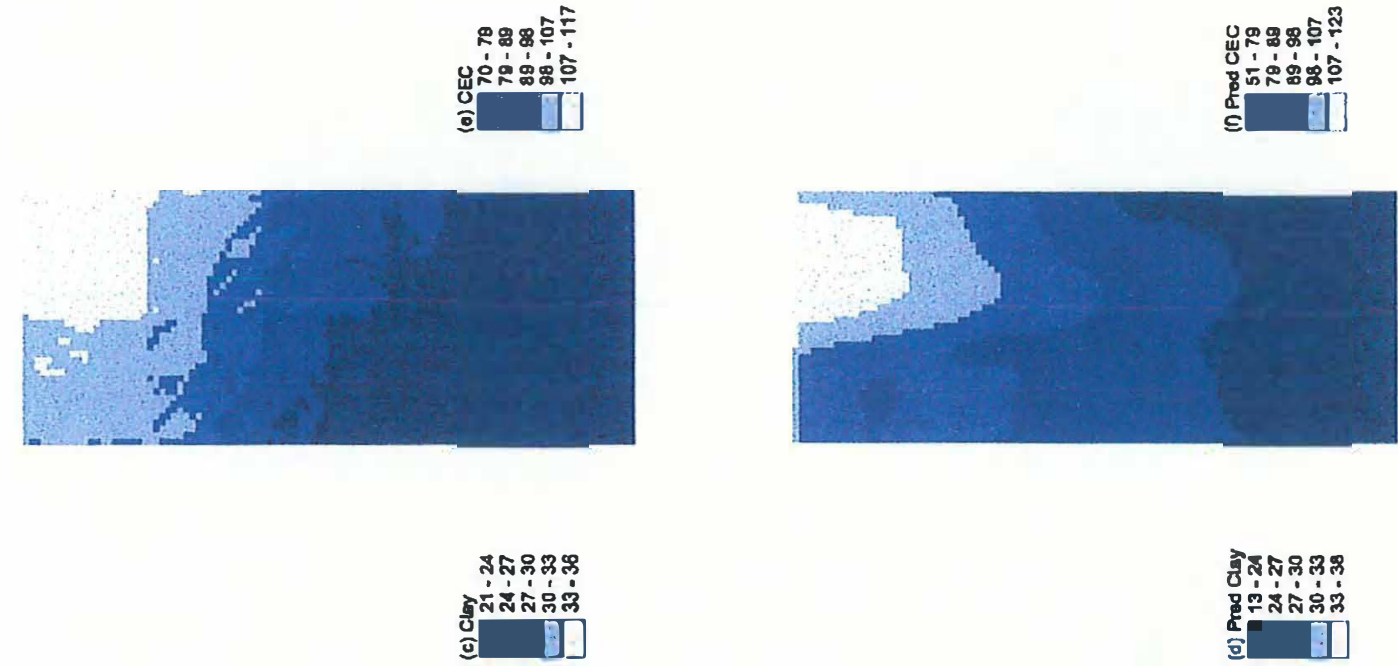

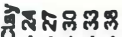

บ도슬

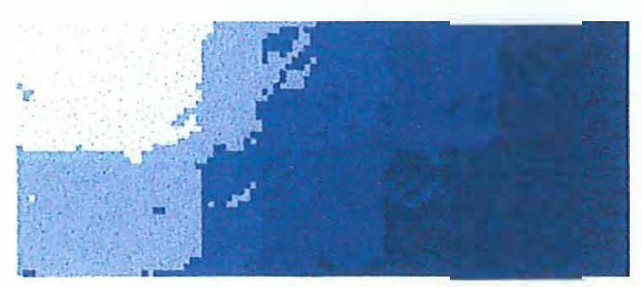

可 D

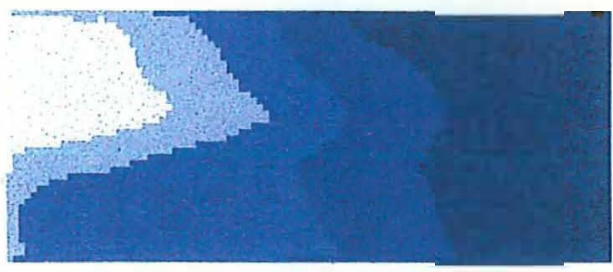

ำ 저유

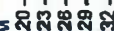

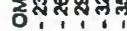

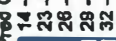
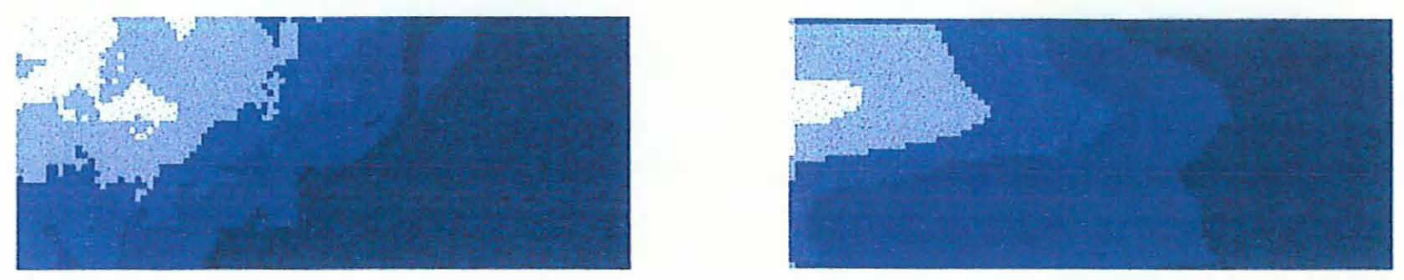


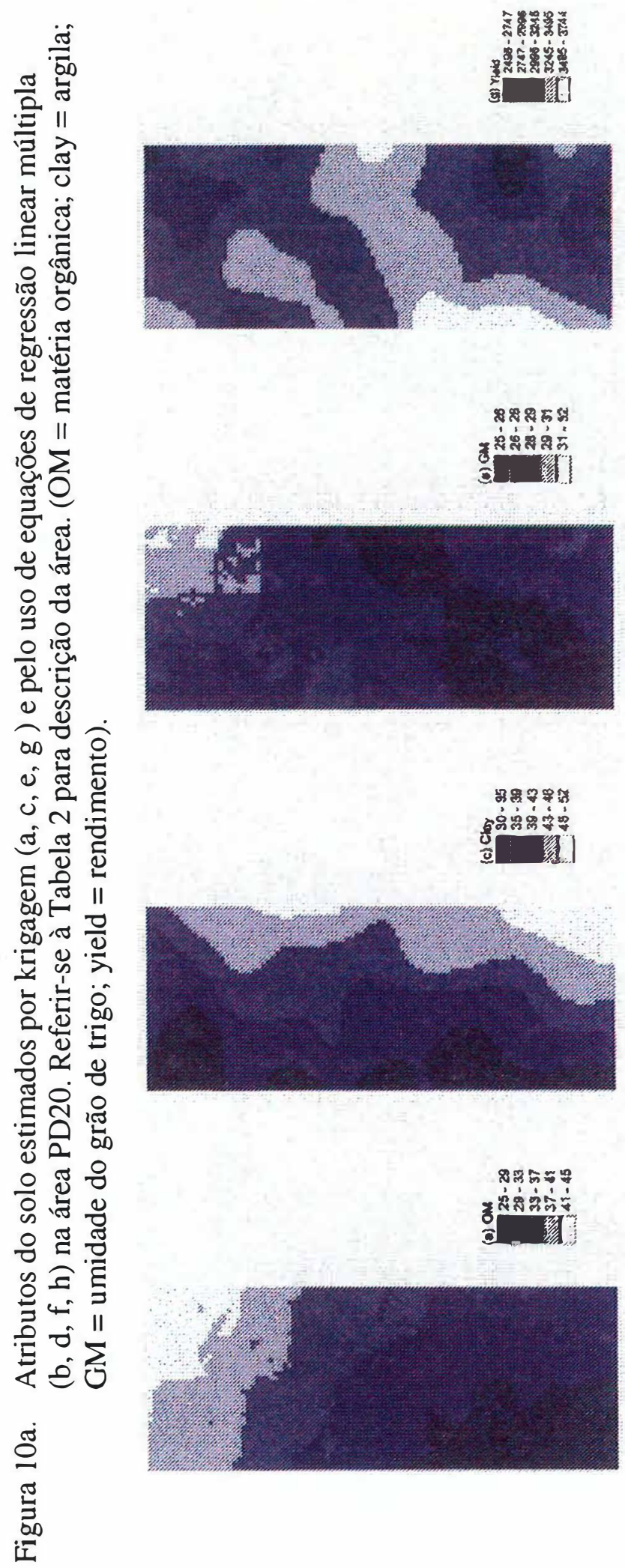

䇣等等琴

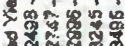

,

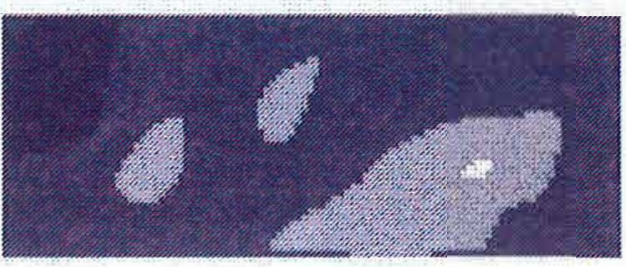

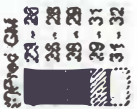

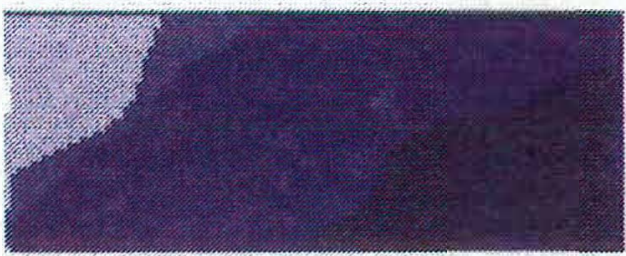

ริำ

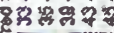

है

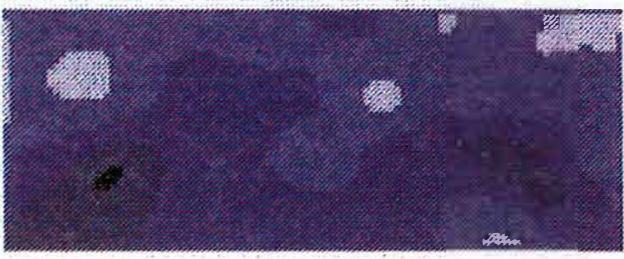

중중

的要它-

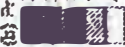

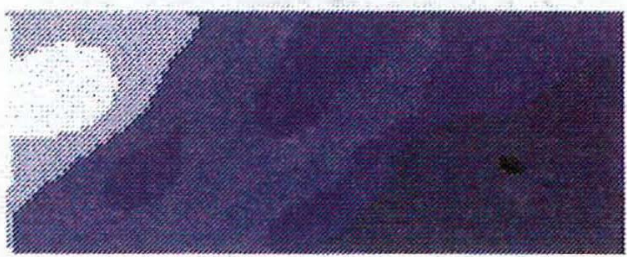



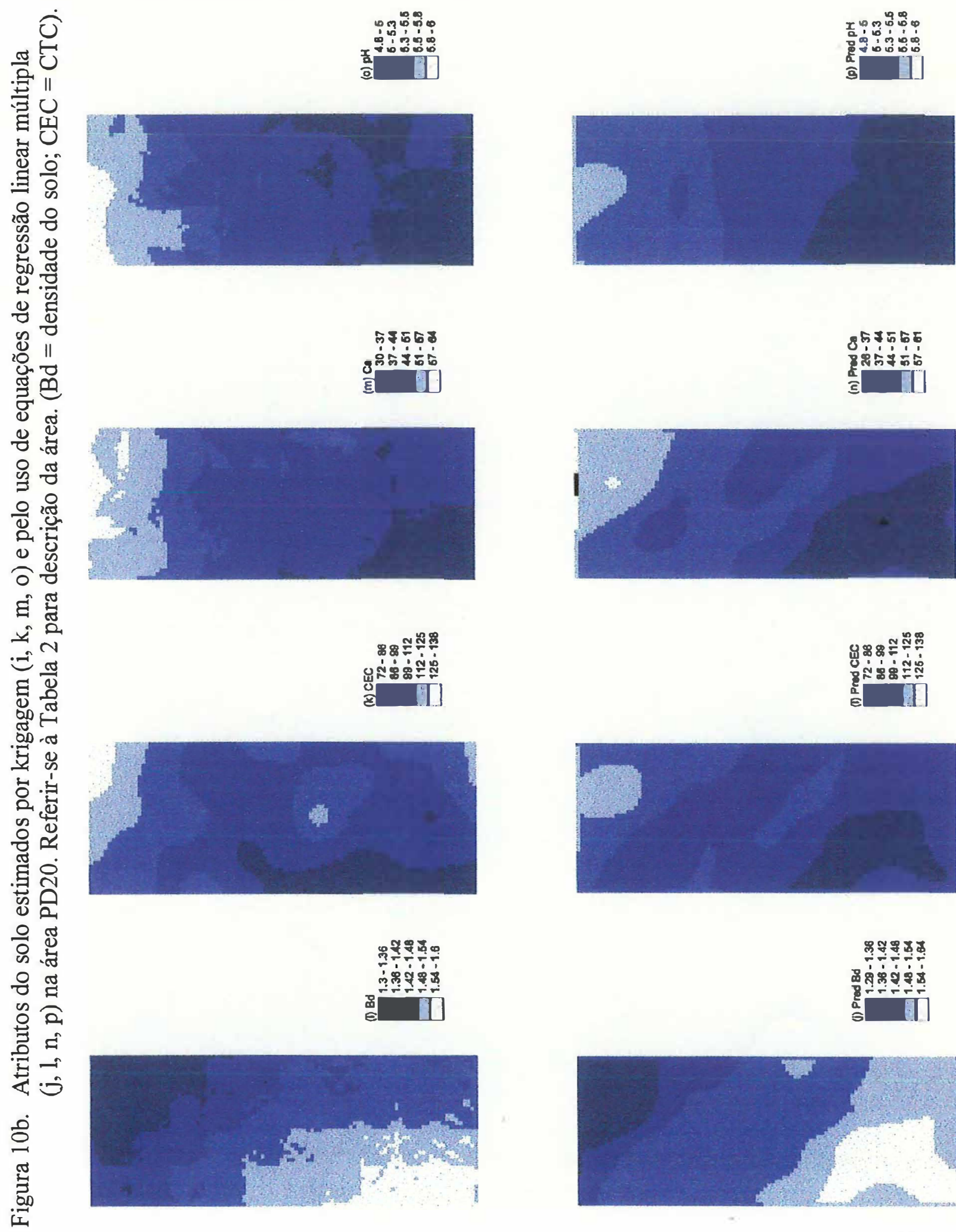

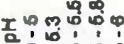

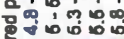

递

?

10

8है 556

的舟

్ㅣ

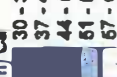
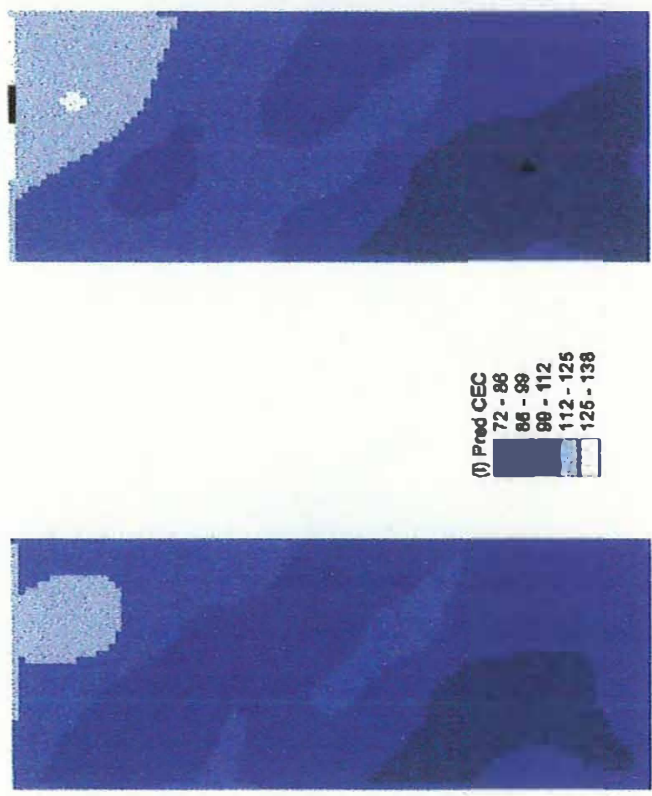

ㅇำำำ

品安 ต่

8다다

น

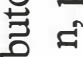

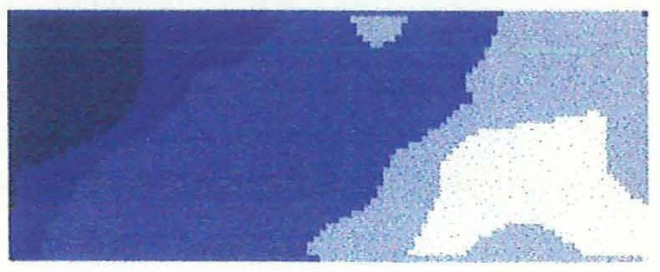


MO $\left(\mathrm{r}=-0,45^{* *}\right), \mathrm{P}\left(\mathrm{r}=-0,40^{* *}\right), \mathrm{CTC}\left(\mathrm{r}=-0,34^{*}\right)$, argila $\left(\mathrm{r}=-0,37^{*}\right)$, UG $(\mathrm{r}=-$ $\left.0,40^{* *}\right)$ e Ds $\left(\mathrm{r}=0,41^{* *}\right)$. Estes resultados foram contrários a nossa expectativa e podem ter sido influenciados pela distribuição das chuvas em 1998 (Figura 11). Pode-se observar que as chuvas neste ano, no período que antecedeu a colheita, foram $122 \%$ superiores a média dos anos anteriores. Historicamente, nesta região, chuvas desta natureza têm afetado a produtividade do trigo. O impacto da precipitação elevada durante o desenvolvimento e colheita do rigo pode ter escondido, ou mesmo invertido, os efeitos de atributos dos solos.

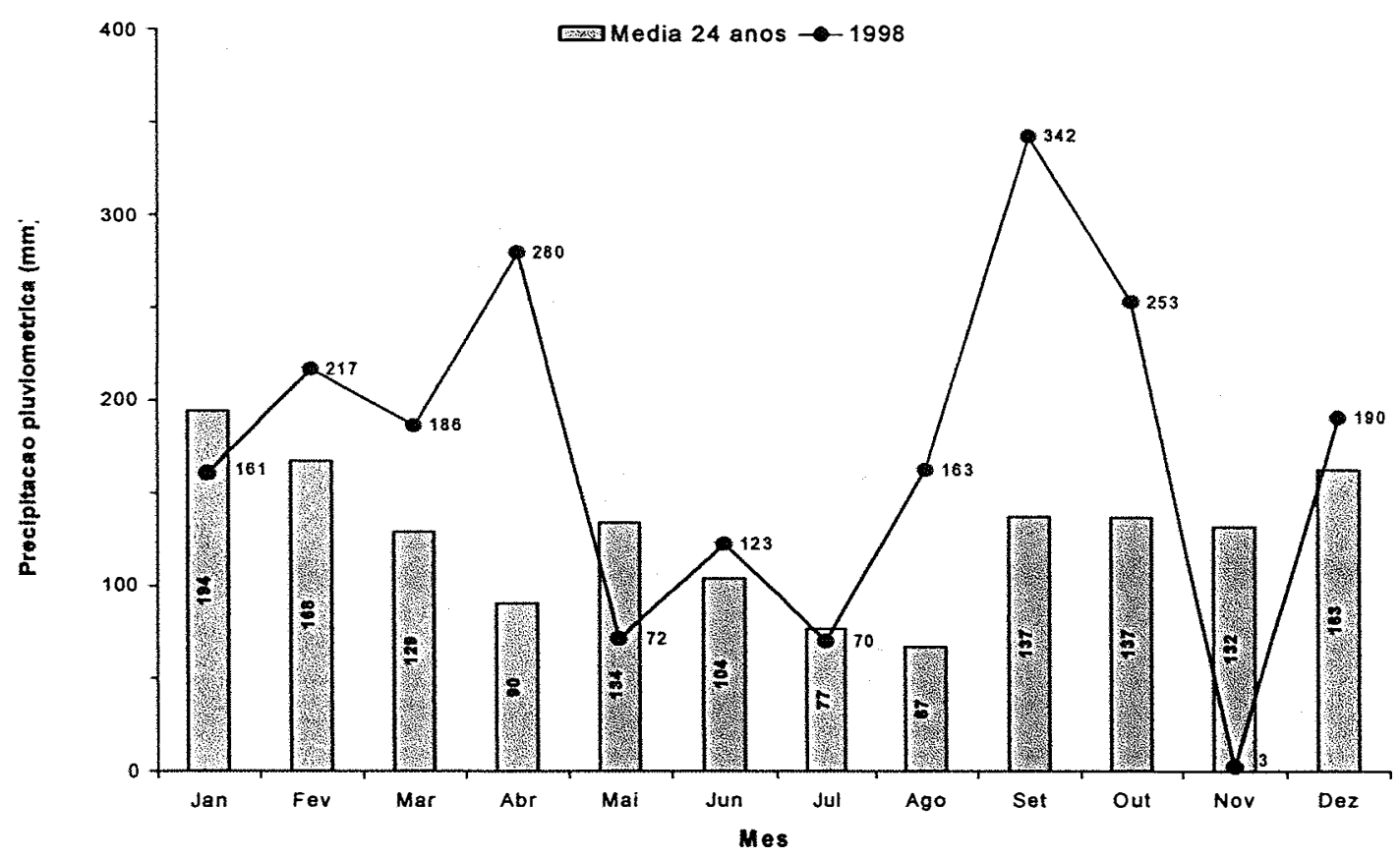

Figura 11. Distribuição da procipitação pluviométrica anual: as barras representam a média dos últimos 24 anos e a linha representa o ano de 1998. Fonte: Fundação ABC $\left(1998^{2}\right)$.

A abordagem da classificação contínua (técnica fuzzy $k$-means) foi usada tentativamente na identificação e mapeamento de áreas com propabilidade de apresentarem limitações similares e respostas semelhantes à aplicação de fertilizantes. Foi escolhida uma classificação simples, de somente três classes, para explorar a estratégia de definição de zonas de manejo de fertilizantes e corretivos. Somente os resultados obtidos na área PD10FN foram apresentados neste trabalho.

\footnotetext{
${ }^{2}$ FUNDAÇÃO ABC. Castro, 1998. Dados climáticos.
} 
Foi considerado o mapeamento de duas qualidades da fertilidade do solo: (1) fertilidade do solo potencial, agrupando-se os valores de MO, conteúdo de argila e CTC nas duas profundidades estudadas. Estes atributos do solo foram escolhidos por serem indicadores chave da fertilidade do solo, principalmente em solos de carga variável, como também por sofrerem alterações mais lentas ao longo do tempo; (2) disponibilidade de nutrientes, expressa pelo teor de $\mathrm{Ca}, \mathrm{Mg}, \mathrm{P}$ e $\mathrm{K}$.

Os grupamentos identificados agrupando-se os valores de MO, argila e CTC caracterizaram zonas com diferente potencial de manejo da fertilidade do solo (Figura 12 - 1a, 1b, 1c). Estes resultados revelaram dependência espacial dos atributos dos solos nas áreas cultivadas. Os centroídes das classes (Tabela 5) mostram que a classe "a" está agrupando as áreas de menores valores dos atributos citados, a classe "c" compreende os indivíduos com valores mais elevados destes atributos e a classe " $b$ " concentra o conjunto de indivíduos de valores intermédiarios. Os centróides das classes representam os valores dos atributos dos indivíduos que são inteiramente representados pela classe, ou seja, que apresentam grau de participação 1,0 na escala de 0,0 a 1,0 . O grau de similaridade dos indivíduos ao centróide das classes está representado na escala das Figuras 12 e 13. Portanto, quanto mais se aproximar da cor branca a representação do indivíduo nestas figuras, melhor representado o mesmo estará pelos valores dos centróides da classe (ver explicação mais detalhada na revisão, ítem 2.6, p.15).

A classificação obtida para os atributos topográficos também dividiu a área em zonas distintas (Figura 12 -2a, 2b, 2c e Tabela 5). Acrescentando-se os valores de argila aos dos atributos topográficos a distribuição espacial dos grupos de solos gerados foi similar à obtida no grupamento dos indicadores chave citados acima (Figura 12-3a, $3 \mathrm{~b}, 3 \mathrm{c}$ e Tabela 5). Isto significa que obtendo-se os valores do DEM e agrupando-os aos dados de conteúdo de argila de áreas similares desta região seja possível identificar-se e mapear-se, em primeira instância, zonas de manejo de fertilizantes com razoável acurácia e menor custo, empregando-se o conjunto de técnicas citadas neste trabalho.

Por outro lado, as zonas geradas com os valores de $\mathrm{Ca}$ e $\mathrm{Mg}$ (Figura. 13 - 1a, 1b, 1c e Tabela 5) e P e K (Figura 13 - 2a, 2b, 2c e Tabela 5) também mostraram 

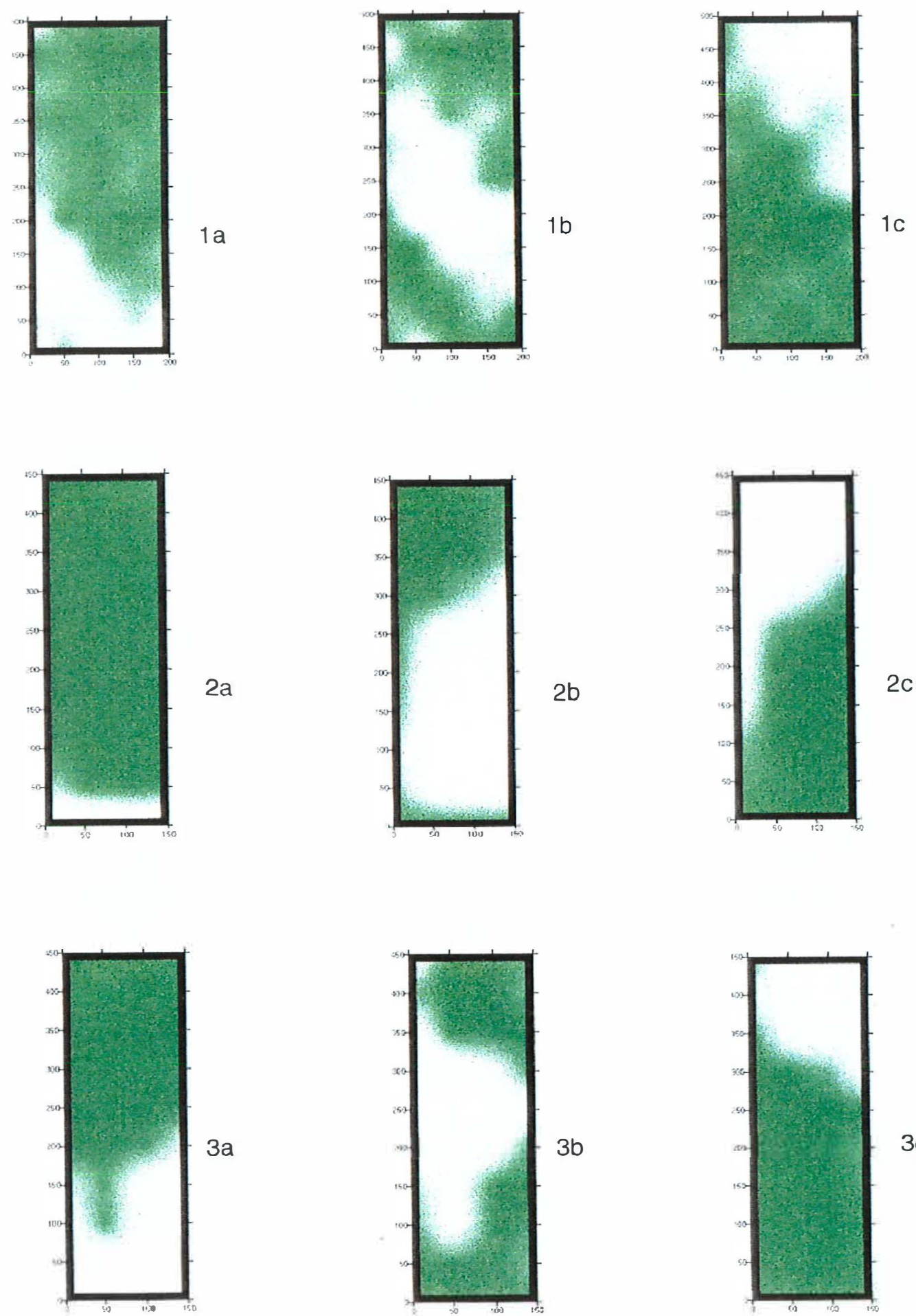

2c

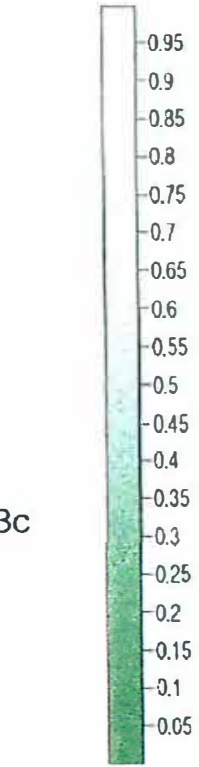

Figura 12. Zonas geradas com os valores de MO, CTC e argila nas profundidades de 0-0,10 e 0,10-0,20 m ( $\mathrm{a}, 1 \mathrm{~b}, 1 \mathrm{c})$, com os valores dos atributos topográficos $(2 \mathrm{a}, 2 \mathrm{~b}, 2 \mathrm{c})$ e com os valores dos atributos topográficos + conteúdo de argila (3a, 3b, 3c) na área PDI0FN. Os valores da legenda especificam a taxa de participação dos indivíduos em cada classe. 

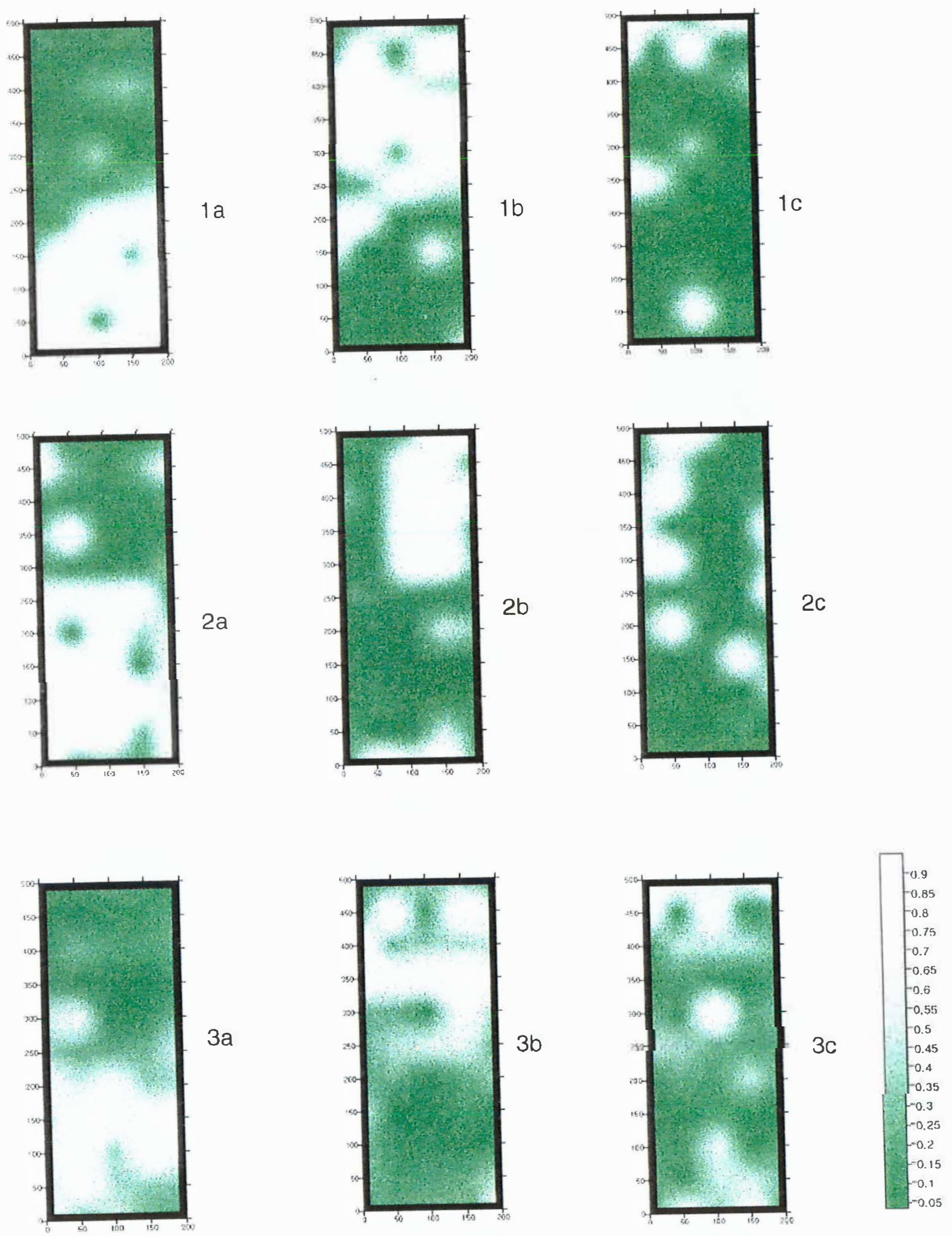

Figura 13. Zonas geradas com os valores de $\mathrm{Ca}$ e $\mathrm{Mg}$ ( $1 \mathrm{a}, \mathrm{lb}$ e $1 \mathrm{c}$ ), de $\mathrm{P}$ e $\mathrm{K}$ ( $2 \mathrm{a}, 2 \mathrm{~b}$ e 2c) e de $\mathrm{Ca}, \mathrm{Mg}, \mathrm{P}, \mathrm{K}$ (3a, 3b e 3c) nas profundidades de 0-0,10; 0,10-0,20 m na área PD10FN. Os valores da legenda especificam a taxa de participação dos indivíduos em cada classe. 
Quadro 5 - Centróides das classes obtidas agrupando-se atributos de solos e topográficos da área PD10FN.

\begin{tabular}{|c|c|c|c|c|c|c|c|c|c|}
\hline \multirow{2}{*}{$\begin{array}{c}\begin{array}{c}\text { Grupos de } \\
\text { Atributos }\end{array} \\
\mathrm{MO}+\mathrm{CEC}\end{array}$} & \multirow{2}{*}{ lasse } & \multicolumn{8}{|c|}{ Atributos / Centróides } \\
\hline & & $\mathrm{MO}^{+}$ & $\operatorname{CTC}^{\dagger}$ & Arg. ${ }^{\top}$ & $\mathrm{MO}^{\mathrm{ff}}$ & $\mathrm{CTC}^{\mathrm{ff}}$ & Arg. ${ }^{7 \mp}$ & & \\
\hline \multirow[t]{3}{*}{+ Argila } & a & 21.8 & 76.4 & 23.6 & 16.1 & 65.0 & 26.3 & - & - \\
\hline & b & 24.4 & 83.4 & 27.2 & 18.9 & 70.2 & 26.3 & - & - \\
\hline & c & 30.9 & 105.7 & 33.1 & 22.0 & 83.8 & 33.6 & - & - \\
\hline Atributos & & $\mathrm{AR}$ & EXP & DECL & & & & & \\
\hline \multirow[t]{3}{*}{ do relevo } & $\mathrm{a}$ & -5.7 & 143.6 & 2.4 & - & - & - & - & - \\
\hline & $\mathrm{b}$ & -1.7 & 147.1 & 3.6 & - & - & - & - & - \\
\hline & $\mathrm{c}$ & 2.7 & 159.9 & 2.1 & - & - & - & - & - \\
\hline Atributos & & AR & EXP & DECL & Argila & & & & \\
\hline do relevo & a & -3.9 & 146.9 & 3.1 & 22.8 & - & - & - & - \\
\hline \multirow{2}{*}{+ argila } & b & 0.9 & 157.2 & 2.7 & 25.0 & - & - & - & - \\
\hline & $\mathrm{c}$ & 3.0 & 152.2 & 2.5 & 33.5 & - & - & - & - \\
\hline \multirow[t]{4}{*}{$\mathrm{Ca}, \mathrm{Mg}$} & & $\mathrm{Ca}^{+}$ & $\mathrm{Mg}^{\dagger}$ & $\mathrm{Ca}^{\dagger+}$ & $\mathrm{Mg}^{\dagger \dagger}$ & & & & \\
\hline & a & 27.7 & 11.7 & 17.1 & 7.6 & - & - & - & - \\
\hline & b & 35.8 & 14.0 & 12.3 & 8.1 & - & - & - & - \\
\hline & $\mathrm{c}$ & 40.8 & 19.2 & 19.2 & 13.1 & - & - & - & - \\
\hline \multirow[t]{4}{*}{$\mathrm{P}, \mathrm{K}$} & & $\mathrm{P}^{+}$ & $\mathrm{K}^{\dagger}$ & $\mathrm{P}^{+\dagger}$ & $\mathrm{K}^{+\dagger}$ & & & & \\
\hline & $\mathrm{a}$ & 18.4 & 2.5 & 6.0 & 2.0 & - & - & - & - \\
\hline & b & 19.5 & 3.9 & 8.0 & 3.1 & - & - & - & - \\
\hline & $\mathrm{c}$ & 25.9 & 4.8 & 6.4 & 2.1 & - & - & - & - \\
\hline $\mathrm{Ca}, \mathrm{Mg}$, & & $\mathrm{Ca}^{\dagger}$ & $\mathrm{Mg}^{\dagger}$ & $\mathrm{P}^{\dagger}$ & $\mathrm{K}^{\dagger}$ & $\mathrm{Ca}^{\dagger \dagger}$ & $\mathrm{Mg}^{+\dagger}$ & $\mathrm{P}^{+\dagger}$ & $\mathrm{K}^{\dagger^{\dagger}}$ \\
\hline \multirow[t]{3}{*}{$\mathrm{P}, \mathrm{k}$} & $\mathrm{a}$ & 29.4 & 12.3 & 21.7 & 3.1 & 13.3 & 6.6 & 6.3 & 2.1 \\
\hline & $\mathrm{b}$ & 36.4 & 14.5 & 18.3 & 3.6 & 14.1 & 9.0 & 6.5 & 2.4 \\
\hline & c & 36.4 & 16.1 & 21.4 & 3.7 & 20.1 & 11.8 & 7.6 & 2.6 \\
\hline
\end{tabular}
(considerando a altitude média como referência); EXP = grau de exposição solar (medido em graus, a partir do norte, no sentido horário); DECL = declividade (\%)

coerência espacial e similar distribuição no espaço. Esta tendência permanece ao agrupar-se os quatro atributos citados (Figura 13 - 3a, 3b, 3c e Tabela 5). Estes resultados fortalecem a validade da hipótese do uso dos mencionados atributos indicadores de fertilidade dos solos na obtenção de zonas de manejo de fertilizantes em topossequências similares na região dos Campos Gerais.

As abordagens citadas neste trabalho são promissoras em áreas onde os levantamentos de solo estão disponíveis em escala pequena (tais como levantamentos exploratórios e de reconhecimento), racionalizando a sub-divisão das glebas em áreas 
de controle mais homogêneas. Estas técnicas podem ser também úteis para guiar a amostragem de solos na divisão de glebas em escala mais fina visando o gerenciamento localizado de fertilizantes.

\subsection{CONCLUSÕES}

1 - O material de origem e o relevo são responsáveis por importantes diferenças nas características dos solos da região dos "Campos Gerais" e portanto estão controlando o comportamento de propriedades importantes no manejo das culturas.

2 - O cultivo de solos no sistema PD por longo período reduziu a acidez potencial, aumentando o $\mathrm{pH}$ dos solos. Adicionalmente observou-se aumento na $\mathrm{MO}$, CTC e saturação por bases, principalmente nos solos localizados nas posições mais elevadas das vertentes e formados a partir do arenito da formação Furnas e material retrabalhado das formações Furnas e Ponta Grossa.

3 - O uso de equações de regressão linear múltipla, obtidas a partir de atributos topográficos derivados do DEM e atributos dos solos mostrou-se uma ferramenta promissora na predição de alguns atributos-chave da fertilidade dos solos da região dos "Campos Gerais", tais como: argila, matéria orgânica, CTC e densidade do solo.

4 - A variabilidade espacial de atributos do solo observada nestas áreas é uma indicação da possibilidade de benefício com a aplicação localizada de fertilizantes.

5 - A técnica fuzzy $k$-means mostrou-se uma ferramenta útil na geração de zonas de manejo de fertilizantes em solos da região dos Campos Gerais. 


\section{VARIABILIDADE DA FERTILIDADE DO SOLO EM TOPOSSEQUENCIAS DA REGIÃO DOS “CAMPOS GERAIS"-PR: AVALIANDO O POTENCIAL PARA O GERENCIAMENTO LOCALIZADO DE FERTILIZANTES}

\subsection{RESUMO}

A Agricultura de Precisão (AP) envolve o gerenciamento localizado de solos e culturas de acordo com as condições específicas da área. Este estudo foi realizado como um passo inicial na avaliação da variabilidade da $\mathrm{MO}, \mathrm{pH}, \mathrm{K}, \mathrm{Ca}, \mathrm{Mg}$ e rendimento do trigo em três topossequências da região dos "Campos Gerais"- PR, e para avaliar o potencial para AP. As áreas foram selecionadas de acordo com o material de origem e tempo de adoção do sistema plantio direto (PD). A fertilidade do solo foi altamente variável e muito estratificada nas três áreas de estudo. Os teores de $\mathrm{MO}, \mathrm{Ca}$ e $\mathrm{Mg}$ trocáveis aumentaram de acordo com o teor de argila dos solos. O rendimento do trigo apresentou variações, porém, neste ano agrícola, houve baixa correlação desta variável com a fertilidade do solo. A técnica fuzzy k-means de agrupamento de variáveis comprovou sua utilidade na criação de zonas de manejo dos fertilizantes e indicou dependência espacial na demanda de $\mathrm{P}$ e $\mathrm{K}$. Os atributos dos solos mostraram diferenças na dependência espacial. Modelos geoestatísticos anisotrópicos lineares foram definidos para a maioria das variáveis estudadas. MO foi a variável que apresentou maior dependência espacial. A recomendação de fertilizantes seria similar na aplicação uniforme e no gerenciamento localizado, mas a distribuição de fertilizantes nas áreas seria espacialmente diferente, o que representaria aumento potencial no rendimento do trigo. 


\subsection{SUMMARY: NUTRIENT VARIABILITY IN LONG-TERM NO-TILLAGE OXISOLS OF SOUTHERN BRAZIL: ASSESSING POTENTIAL FOR SITE-SPECIFIC MANAGEMENT}

Site-specific management (SSM) involves the variable management of soils, crops, and pests according to localized conditions within a field. This study was performed as an initial step to assess the variability of $\mathrm{OM}, \mathrm{pH}, \mathrm{P}, \mathrm{K}, \mathrm{Ca}, \mathrm{Mg}$ and wheat yield in three typical Oxisols toposequences of the "Campos Gerais" region, of southern Brazil, and to evaluate the potential for site-specific fertilizer management. The toposequences were selected according to parent material and no-tillage adoption time. Soil fertility was highly variable and very stratified for three studied sites. The values of $\mathrm{OM}$ content and exchangeable $\mathrm{Ca}$ and $\mathrm{Mg}$ increased according to the clay content of the sites. Wheat yield was highly variable but there was little correlation of wheat yield with soil fertility. The fuzzy k-means clustering technique has proven to be useful to create distinctive zones of $\mathrm{P}$ and $\mathrm{K}$ fertilizer management. The soil properties displayed differences in spatial dependence. Linear anisotropoc geostatistical models were defined for most of the soil variables measured for all sites. Fertilizer recommendation was similar for uniform versus SSM, but the distribution of fertilizer within the field would be spatially different.

\subsection{INTRODUÇÃO}

A agricultura de precisão (AP) envolve o gerenciamento localizado de solos, culturas, pragas e doenças. Uma série de fatores devem ser satisfeitos para que aja sucesso na aplicação do manejo localizado. Dentre eles estão incluidos o sistema adequado de coleta dos dados, a análise e interpretação eficientes da variabilidade espacial dos dados, o conhecimento da resposta do sistema solo-planta às mudanças de 
manejo e evidência de que o manejo espacialmente variável será mais rentável do que as abordagens tradicionais (Moore \& Tyndale-Biscoe, 1999).

Devido à natureza espacialmente contínua da paisagem, dos processos de formação do solo e do zoneamento climático é razoável que medidas de solos tomadas em proximidade umas das outras estejam correlacionadas. Também é razoavel que variações espaciais e temporais em um ou mais atributos ecológicos estejam relacionadas com variações de outros parâmetros ou propriedades intrínsecas da paisagem (Nielsen \& Alemi, 1989).

Como as propriedades e os nutrientes dos solos variam através da paisagem, aplicações uniformes de fertilizantes podem resultar em áreas super ou sub-adubadas. A erosão superficial, ou a lixiviação de áreas super fertilizadas podem contaminar o manancial aquífero, enquanto o rendimento das culturas pode diminuir em áreas subfertilizadas (Cahn et al., 1994). Portanto, os modelos espaciais e temporais das propriedades dos solos e atributos indicativos da qualidade do solo devem ser conhecidos para minimizar impactos ambientais e aumentar a rentabilidade. Além disso, para integrar e regionalizar informações de pontos especificos para largas escalas, é essencial o conhecimento da natureza destes modelos (Wendroth et al., 1997).

Tanto a estatística clássica quanto a estatística espacial são úteis no estudo das relações entre variáveis, embora as premissas e os enfoques básicos possam diferir. Enquanto a abordagem clássica enfatiza relações entre variáveis independentemente da distribuição espacial, os métodos da estatística espacial enfatizam correlações e distribuições espaciais das variáveis (Mallarino et al., 1999).

Os métodos geoestatísticos comprovaram sua utilidade para detectar, modelar e estimar os modelos espaciais de diversos tipos de dados, tais como atributos de solos e rendimento de culturas. A geoestatística inclui variografia e krigagem. A variografia é utilizada para caracterizar e modelar a variância espacial dos dados através de semivariogramas. Neste processo, a similaridade entre amostras é determinada em função da distância entre as mesmas. Quando evidente, a dependência espacial pode ser modelada e usada num processo conhecido como krigagem, para estimar-se valores em 
localidades não amostradas (Jeffrey, 1993). O desenvolvimento detalhado desta teoria pode ser encontrado em Burgess \& Webster (1980), Vieira (1983) e Goovaerts (1997).

Um dos desafios da AP é determinar quais os principais fatores responsáveis pela variação no rendimento das culturas. De acordo com Mulla \& Schepers (1997), dentre os fatores mais importantes estão incluídos: infestação de pragas e doenças, matéria orgânica, conteúdo de água disponível, drenagem do solo, disponibilidade de nutrientes, textura do solo e $\mathrm{pH}$.

O clima interage de maneira complexa com a topografia afetando o rendimento das culturas. Propriedades fisicas dos solos, tais como conteúdo de argila e areia (Ovalles \& Collins, 1986; Sá, 1995) e teor de matéria orgânica (Miller et al., 1998; Bhatti et al., 1991) foram altamente correlacionados com a posição na vertente. A interdependência entre o rendimento das culturas e propriedades dos solos tem sido mostrada por vários autores (Ciha, 1984; Mulla et al., 1992; Pierce, 1995). Ciha (1984) demonstrou que o rendimento do trigo estava principalmente relacionado com a posição da vertente. Esta relação podia ser notada especialmente nos anos secos, parecendo ser dependente da profundidade da camada superficial. O estudo de Timlin et al. (1998) sugere que a topografia e fatores relacionados, tais como profundidade e drenagem do solo, tenham tido um grande efeito no rendimento do milho. $\mathrm{O}$ rendimento de grãos tem sido mais fortemente relacionado com propriedades do solo relacionadas com a capacidade de retenção de água (Stone et al., 1985; Hanna et al., 1982; Pierce et al., 1995; Cora, 1997). De acordo com Moore \& Tyndale-Biscoe (1999) o rendimento é uma variável difícil de ser traduzida em estratégias de manejo, pelo fato de integrar muitas variáveis que afetam o desenvolvimento das culturas e por apresentar diferentes tendências de ano para ano.

A variabilidade do solo pode ocorrer naturalmente, como resultado da complexidade geológica e processos pedogenéticos, ou por processos antropogênicos. A introdução do sistema plantio direto (PD) no Brasil, no início da década de 1970 proporcionou uma técnica para o controle da erosão (Ramos, 1976; Wunche \& Denardin, 1978; Mondardo, 1978; Derpsch et al., 1986; Blevins et al., 1997) e aumento da matéria orgânica do solo (Sidiras \& Pavan,1985; Thomas,1990; Sá, 1997; Kinsela, 
1997). Atualmente, 32 \% da área cultivada com grãos no Brasil (cerca de 13,5 milhões de ha) são manejadas no sistema $\mathrm{PD}$, das quais 70,5 \% estão localizadas na região sul do país (FEBRAPDP, 2000). Por outro lado, os solos formados sobre os folhelhos da formação Ponta Grossa e os arenitos da Formação Fumas no ecossistema dos "Campos Gerais"- PR assumem significativa importância pelo seu potencial na produção intensiva de grãos.

Este trabalho foi realizado como uma primeira etapa na avaliação da variabilidade da $\mathrm{MO}, \mathrm{pH}, \mathrm{P}, \mathrm{K}, \mathrm{Ca}, \mathrm{Mg}$ e rendimento do trigo e para verificar o potencial para o manejo localizado de fertilizantes em solos da região dos "Campos Gerais"- PR.

\subsection{MATERIAL E MÉTODOS}

O estudo foi realizado na fazenda Santa Branca $\left(50^{\circ} 23^{\prime} \mathrm{W} ; 24^{\circ} 36^{\prime} \mathrm{S}\right)$ próximo da cidade de Tibagi, localizada na região centro-sul do Estado do Paraná (Figura 1, capítulo 3, p.26).

A topografia das áreas selecionadas para este estudo é constituida por longas vertentes de forma predominantemente convexa, de declive suave $(0-6 \%)$ e altitude variando entre 790 e 910 metros. A vegetação natural, denominada"Campos Gerais", constitui-se de estepe subtropical de gramíneas baixas (Maack, 1981). O clima da região enquadra-se como subtropical úmido de altitude, tipo Cfb (classificação de Koeppen), com precipitação pluviométrica média de $1532 \mathrm{~mm}$ bem distribuídas durante o ano (Maack, 1981). A litologia da área estudada é constituida essencialmente por sedimentos clásticos do período devoniano, grupo Paraná, denominados formação Furnas e Ponta Grossa (Trein et al., 1966).

Foram selecionadas três topossequências com área de 10 ha $(200 \times 500 \mathrm{~m})$, representativas da região: duas áreas cultivadas em rotação de culturas por 10 anos (PD10FN , PD10PG) e uma por 20 anos (PD20) no sistema PD. A escolha destas áreas baseou-se no material de origem e textura dos solos, no tipo de vertente e nas práticas 
culturais. Um resumo das práticas culturais pode ser observado na Tabela 1 (capítulo 3, p. 27).

As amostras foram obtidas nos nós de grades de $50 \times 50 \mathrm{~m}(\mathrm{~N}=55)$ em Maio/1988, após a colheita do milho e antes da semeadura do trigo (Figura 3, capítulo 3, p. 29). Utilizou-se teodolito e fita métrica para melhor definição da grade e o georreferenciamento dos pontos limítrofes das áreas foi obtido através do Sistema de Posicionamento Global (GPS). As medidas de altitude em cada ponto da grade foram obtidas com uso de teodolito.

As amostras de solo foram coletadas em duas profundidades (0-0,10 e $0,10-0,20$ $\mathrm{m}$ ) em buracos de dimensão $0,20 \times 0,20 \mathrm{~m}$, retirando-se fatias de $0,020 \mathrm{~m}$ de espessura dos quatro lados, para cada profundidade, obtendo-se duas amostras compostas em cada nó. As amostras foram secas ao ar, passadas através de peneiras de 2,0 mm e estocadas para as análises subsequentes. Foram coletadas amostras indeformadas nos mesmos lugares e às mesmas profundidades para as medidas de densidade global.

Foram abertas três trincheiras de 1,50 $\mathrm{m}$ de profundidade em cada área de estudo para a descrição morfológica (Lemos \& Santos, 1996) e análises físicas, químicas e mineralógicas dos perfis (Figura 3, capítulo 3, p. 29).

As medidas de rendimento da cultura do trigo foram obtidas através de colheita manual de seis linhas de trigo, numa seção de 4,0 m de comprimento, sempre imediatamente acima dos pontos de amostragem do solo. Mediu-se a umidade dos grãos de trigo em todos os locais de coleta ajustando-se o peso para $13 \%$ de umidade.

Foram efetuadas análises químicas nas frações de solo $<2 \mathrm{~mm}$. O pH foi medido por potensiometria usando uma solução 1:2 de solo/0,01 $\mathrm{M} \mathrm{CaCl}_{2}$. $\mathrm{Al}, \mathrm{Ca}, \mathrm{Mg}$ e $\mathrm{K}$ trocáveis e $\mathrm{P}$ foram extraídos usando-se resina trocadora de cátions/ânions (Raij et al., 1987). A acidez potencial foi determinada usando-se uma solução tamponada a pH 7,0, de acordo com Raij et al., 1987). O carbono foi determinado por combustão úmida (EMBRAPA, 1997). As frações areia, silte e argila foram separadas, após agitação horizontal de 16 horas, usando-se solução de hexa-metafosfato de sódio como dispersante químico, pelo método do hidrômetro (EMBRAPA, 1997). A densidade global foi determinada pelo método do cilindro volumétrico, descrito por Blake \& Hartge 
(1986), utilizando-se cilindros com volume interno de cerca de $100 \mathrm{~cm}^{3}$. A difração de Raio-X foi medida por um difratômetro Philips tipo PW3710 BASED com tubo de cobre, de acordo com Jackson (1969).

A recomendação de fertilizantes foi calculada para cada ponto da grade (gerenciamento localizado) e pela média (adubação uniforme, ou convencional) de acordo com a recomendação do IAC (Raij et al., 1996) para atingir rendimentos superiores a 3,0 ton/ha. O potencial de resposta do rendimento do trigo foi estimado através da curva de resposta de fertilizantes (Comissão de Fertilidade do Solo, RS/SC, 1995).

A afinidade entre os atributos do solo e o rendimento do trigo foi avaliada através do coeficiente de correlação de Pearson com o programa JMP, versão 3,0 para Windows (Statistical Discovery Software - SAS, 1997). A significância estatística foi analisada para $\mathrm{p}<0,05, \mathrm{p}<0,01$ e $\mathrm{p}<0,001$ e representada por $*{ }^{* *}$ e ${ }^{* * *}$, respectivamente. O programa GS+ for Windows, versão 3.0 (Gamma Design software, 1999) foi usado para realizar as análises geoestatísticas. Cada parâmetro foi submetido a análise de semivariância para cada um dos cinco modelos isotrópicos e anisotrópicos: linear, linear/sill, esférico, exponencial e gausiano, de acordo com a teoria das variáveis regionalizadas descrita por Journel \& Huijbregts (1978) e Goovaerts (1997).

O programa "Fuzme, Fuzzy k-Means with Extragrades" (Australian Centre for Precision Agriculture, 1999) foi usado tentativamente como ferramenta para gerar zonas de recomendação de fertilizantes usando a técnica "fuzzy k-means". A base matemática do agrupamento fuzzy k-means e os algorítmos computacionais para a análise dos dados foram detalhados por Burrough (1989), McBratney \& Gruijter (1992), e Odeh et al. (1992). O algorítmo fuzzy k-means e a medida métrica de distância Mahalanobis foram usados para gerar três classes de solos de acordo com a demanda de fertilizantes. Porém neste caso, o parâmetro de controle do programa (expoente fuzziness) foi ajustado para produzir classes mais rígidas preferencialmente às classes "fuzzy" ou contínuas (expoente Fuzzy $=1.1$ ). A maior parte dos estudos de classificação de solos tem usado valores de expoente fuzziness entre 1,1 e 1,5. Onde o expoente é 1 , a classificação não produz sobreposição de classes, resultando em classes rígidas. $\mathrm{O}$ aumento dos valores 
causa mais fuzziness (representando maior continuidade) (ver maior detalhamento desta técnica no capítulo 2 , ítem 2.6, p.15). Os mapas com o delineamento das zonas de demanda de fertilizantes $\mathrm{P}$ e $\mathrm{K}$ foram criados com o programa Surfer 7.0 (Golden Software, Inc., 1999) usando vizinhos naturais ("natural neighbor") como método de interpolação.

\subsection{RESULTADOS E DISCUSSÃO}

\subsubsection{Perfis de solos}

Dados selecionados de análises morfológicas, físicas, químicas e mineralógicas dos perfis de solos das quatro topossequências estão apresentados na Tabela 2 (capítulo 3, p. 32 e 33, como também nas Figuras 16, 17 e 18, do Anexo). A textura do solo está refletindo as diferenças do material de origem. As áreas de campo nativo e PD10PG, formadas sobre o folhelho Ponta Grossa apresentaram textura muito argilosa. A textura da área PD10FN, cujo material de origem é o arenito da formação Furnas, apresentou-se predominantemente franco argilo-arenosa, enquanto a área PD20, formada com material retrabalhado destas duas formações, apresentou teor intermediário de argila (argiloarenosa).

Os solos das quatro áreas de estudo foram classificados como LATOSSOLOS VERMELHOS Distróficos típicos A moderado (Typic Hapludox). Apresentaram algumas distinções ao $5^{0}$ nível categórico (nível de família) de acordo com o Sistema Brasileiro de Classificação de Solos (EMBRAPA, 1999). Sendo assim, a textura variou de média (PD20 e PD10FN) a muito argilosa (PD10PG). A despeito das diferenças no material de origem, a mineralogia da fração argila apresentou-se qualitivamente bastante similar tendo em vista a avançada maturidade dos solos (Tabela 2, capítulo 3, p. 32 e 33). Quantitativamente ocorreram algumas diferenças distinguindo-os como: predominantemente caulinítico-oxídicos na área PD10PG e gibbisiticos-oxídicos nas áreas PD10FN e PD20 (EMBRAPA, 1999) (ver Tabela 17, do Anexo). Os valores da densidade do solo variaram de acordo com a textura e o conteúdo de matéria orgânica. 


\subsubsection{Estatística clássica}

A fertilidade do solo foi altamente variável espacialmente e muito estratificada nas três áreas amostradas (Tabela 6). Por outro lado, o efeito do espaçamento da grade de amostragem (50 ou $100 \mathrm{~m}$ ) na média dos atributos estudados foi insignificante (Tabela 7).

A média dos valores de $\mathrm{pH}$ nas três áreas variou entre 5,0 - 5,2 (0-0,10 m de profundidade) e 4,5 - 4,6 (0,10 - 0,20 $\mathrm{m}$ de profundidade) portanto enquadrados na classe média e baixa respectivamente de acordo com a classificaçao proposta por Raij et al. (1996) (Tabela 6). Por outro lado, a variação pontual do pH variou em 1,3 (PD10PG e PD10FN) e 2.1 (PD20) unidades nas duas profundidades estudadas, alcançando as classes alta e muito alta na camada de $0-0,10 \mathrm{~m}$. A maior variação ocorreu na área PD20.

Os valores de fósforo $(\mathrm{P})$ variaram da classe muito baixa à média $(\mathrm{PD} 10 \mathrm{PG})$ e baixa à alta (PD10FN e PD20) na camada de $0-0,10 \mathrm{~m}$ e de muito-baixa a média na camada de 0,10-0,20 m. As maiores variações ocorreram na área PD20 e PD10FN onde o P disponível variou num fator de 5 e 6,5 respectivamente. Embora tenha sido aplicada a mesma quantidade de fertilizante nas três áreas, o aumento do nível de $\mathrm{P}$ foi menor na área PD10PG provavelmente devido ao mais elevado teor de argila e, conseqüentemente, à maior contribuição dos óxido-hidróxidos de $\mathrm{Fe}$ e $\mathrm{Al}$ na adsorção de P. Por outro lado, o nível da matéria orgânica nesta área está alto nas duas profundidades e, em média, mais elevado em relação às demais áreas, demonstrando a habilidade dos componentes da fração argila deste solo na formação de complexos estáveis com a matéria orgânica. Entretanto, a maior variabilidade de MO foi observada na área PD20. O limite superior dos valores de MO foram coincidentes nestas duas áreas a despeito do maior teor de argila na área PD10PG. Esta é uma indicação de que o maior tempo de cultivo sob o sistema plantio direto na área PD20 possa estar contribuindo para a concentração da MO em localidades específicas da área. 
Tabela 6. Sumário estatístico de atributos do solo nas três áreas amostradas no sistema de grade $(N=55)$ na fazenda Santa Branca/PR.

\begin{tabular}{|c|c|c|c|c|c|}
\hline Atributos & Prof. $(m)^{\frac{1}{7}}$ & Parâmetro & & Área $^{\mp t}$ & \\
\hline \multirow{7}{*}{$\mathrm{pH}$} & \multirow{4}{*}{$0-0.10$} & & PD10PG & PD20 & PD10FN \\
\hline & & Média & 5.1 & 5.2 & 5.0 \\
\hline & & Desv. Padrão & 0.3 & 0.4 & 0.3 \\
\hline & & Amplitude & $4.6-5.9$ & $4.4-6.5$ & $4.4-5.6$ \\
\hline & \multirow[t]{3}{*}{$0.10-0.20$} & Média & 4.6 & 4.5 & 4.5 \\
\hline & & Desv. Padrão & 0.3 & 0.3 & 0.4 \\
\hline & & Amplitude & $4.2-5.4$ & $4.1-6.0$ & $4.0-5.3$ \\
\hline \multirow{6}{*}{$\begin{array}{l}\mathrm{MO} \\
\left(\mathrm{g} \mathrm{dm}^{-3}\right)\end{array}$} & \multirow[t]{3}{*}{$0-0.10$} & Média & 39 & 34 & 25 \\
\hline & & Desv. Padrão & 5 & 6 & 5 \\
\hline & & Amplitude & $31-49$ & $21-49$ & $18-37$ \\
\hline & \multirow[t]{3}{*}{$0.10-0.20$} & Média & 30 & 22 & 19 \\
\hline & & Desv. Padrão & 4 & 3 & 3 \\
\hline & & Amplitude & $19-39$ & $15-29$ & $13-27$ \\
\hline \multirow[t]{6}{*}{$\mathrm{P}\left(\mathrm{mg} \mathrm{dm} \mathrm{m}^{-3}\right)$} & \multirow[t]{3}{*}{$0-0.10$} & Média & 10 & 23 & 21 \\
\hline & & Desv. Padrão & 5 & 9 & 8 \\
\hline & & Amplitude & $4-27$ & $8-40$ & $7-46$ \\
\hline & \multirow[t]{3}{*}{$0.10-0.20$} & Média & 5 & 5 & 7 \\
\hline & & Desv. Padrão & 2 & 3 & 2 \\
\hline & & Amplitude & $2-9$ & $2-19$ & $4-14$ \\
\hline \multirow{6}{*}{$\begin{array}{l}\text { K trocável } \\
\left(\mathrm{mmol}_{\mathrm{c}} \mathrm{dm}^{-3}\right)\end{array}$} & \multirow[t]{3}{*}{$0-0.10$} & Média & 3.8 & 3.2 & 3.5 \\
\hline & & Desv. Padrão & 1.4 & 0.8 & 1.3 \\
\hline & & Amplitude & $1.2-7.7$ & $1.3-5.2$ & $1.4-6.7$ \\
\hline & \multirow[t]{3}{*}{$0.10-0.20$} & Média & 2.3 & 2.5 & 2.3 \\
\hline & & Desv. Padrão & 1.2 & 0.9 & 0.6 \\
\hline & & Amplitude & $0.9-8.8$ & $1.2-5.4$ & $1.0-3.7$ \\
\hline \multirow{6}{*}{$\begin{array}{l}\text { Ca trocável } \\
\left(\mathrm{mmol}_{\mathrm{c}} \mathrm{dm}^{-3}\right)\end{array}$} & \multirow[t]{3}{*}{$0-0.10$} & Média & 52 & 44 & 34 \\
\hline & & Desv. Padrão & 11 & 13 & 10 \\
\hline & & Amplitude & $30-85$ & $21-82$ & $17-61$ \\
\hline & \multirow[t]{3}{*}{$0.10-0.20$} & Média & 29 & 19 & 15 \\
\hline & & Desv. Padrão & 11 & 9 & 8 \\
\hline & & Amplitude & $12-58$ & $7-59$ & $5-45$ \\
\hline \multirow{6}{*}{$\begin{array}{l}\text { Mg trocável } \\
\left(\mathrm{mmol}_{\mathrm{c}} \mathrm{dm}^{-3}\right)\end{array}$} & \multirow[t]{3}{*}{$0-0.10$} & Média & 24 & 17 & 14 \\
\hline & & Desv. Padrão & 7 & 8 & 5 \\
\hline & & Amplitude & $12-51$ & $7-41$ & $7-31$ \\
\hline & \multirow[t]{3}{*}{$0.10-0.20$} & Média & 21 & 9 & 9 \\
\hline & & Desv. Padrão & 10 & 5 & 4 \\
\hline & & Amplitude & $7-48$ & $2-38$ & $2-22$ \\
\hline
\end{tabular}

\footnotetext{
₹ Profundidade de amostragem; ${ }^{\mathrm{*}} \mathrm{PD} 10 \mathrm{PG}=$ Plantio Direto $(10$ anos $)-$ Material de Origem: folhelho da formação Ponta Grossa, PD20 = Plantio Direto (20 anos) - Material de Origem: material retrabalhado das formações Ponta Grossa e Furnas, PD10FN = Plantio Direto (10 anos) - Material de Origem: arenito da formação Furnas

${ }^{\ddagger \ddagger}$ Refere-se aos valores mínimos e máximos dos atributos
} 
Tabela 7. Efeito do espaçamento de amostragem na média de atributos do solo nas três áreas do estudo.

\begin{tabular}{|c|c|c|c|c|c|c|}
\hline Areas & \multicolumn{2}{|c|}{ PD10PG } & \multicolumn{2}{|c|}{ PD10FN } & \multicolumn{2}{|c|}{ PD20 } \\
\hline Espaçamento (m) & 50 & 100 & 50 & 100 & 50 & 100 \\
\hline Atributos & & & & & & \\
\hline $\mathrm{pH}$ & 5.2 & 5.2 & 5.0 & 4.9 & 5.3 & 5.3 \\
\hline $\mathrm{MO}$ & 39 & 40 & 25 & 26 & 34 & 34 \\
\hline$P$ & 11 & 10 & 21 & 20 & 23 & 22 \\
\hline K & 3.8 & 4.1 & 3.5 & 3.3 & 3.2 & 3.3 \\
\hline $\mathrm{Ca}$ & 52 & 53 & 34 & 31 & 44 & 46 \\
\hline $\mathrm{Mg}$ & 24 & 25 & 14 & 13 & 17 & 18 \\
\hline
\end{tabular}

A média dos valores de potássio $(\mathrm{K})$ atingiu o nível médio $(0,10-0,20 \mathrm{~m})$ e alto $(0-0,10 \mathrm{~m})$ mas os valores variaram da classe baixa à muito alta. Os teores de cálcio (Ca) e magnésio $(\mathrm{Mg})$ estão aumentando de acordo com o teor de argila e MO nas três áreas. A média dos valores de Ca enquadrou-se na classe média $(0-0,10 \mathrm{~m})$ e baixa $(0,10-0,20 \mathrm{~m})$ enquanto a média dos valores de $\mathrm{Mg}$ foi baixa em ambas profundidades. Porém, os valores de $\mathrm{Ca}$ variaram da classe baixa à média na área PD10FN e da classe baixa a alta nas demais áreas enquanto o $\mathrm{Mg}$ variou da classe baixa à média na camada de $0-0,10 \mathrm{~m}$ (Tabela 6).

Em geral, a maior variabilidade espacial foi observada na área PD20, indicando que o maior tempo sob o sistema PD possa estar contribuindo para o aumento da variabilidade espacial nas áreas de estudo. A maior variabilidade no conteúdo de MO nesta área e a tendência de concentração de $\mathrm{MO}$ em pontos específicos do terreno pode estar controlando a variabilidade espacial de outros atributos. Pierce et al. (1995), estudando a variabilidade espacial de nutrientes em solos do estado de Michigan/USA, também encontraram grande estratificação e variabilidade em áreas cultivadas no sistema PD.

As correlações entre atributos do solo foram mais elevadas quando analisadas em cada transeção ao longo da vertente $(\mathrm{N}=11)$ (Figura 3, capítulo 3, p. 29) do que na grade como um todo $(\mathrm{N}=55$ ) (Tabela 8 ). Esta observação indica que tendências de variabilidade de atributos relativamente nítidas ao longo das topossequências possam estar sendo atenuadas pela variabilidade espacial dentro da área como um todo. 
Tabela 8. Coeficiente de correlação de Pearson de atributos selecionados em todos os pontos da grade de amostragem $(\mathrm{N}=55)$ e em cada um dos 5 transceptos ao longo das vertentes $(\mathrm{N}=11)$ nas três áreas estudadas.

\begin{tabular}{|c|c|c|c|c|c|c|c|}
\hline \multirow{2}{*}{$\begin{array}{l}\text { Atributos } \\
\text { correlacionados }\rfloor\end{array}$} & \multirow{3}{*}{$\begin{array}{l}\text { Áreast† } \\
\text { PD10PG }\end{array}$} & \multirow{2}{*}{$\begin{array}{l}\text { Toda a } \\
\text { grade } \pm\end{array}$} & \multicolumn{5}{|c|}{ Transeçõesł‡ } \\
\hline & & & 1 & 2 & 3 & 4 & 5 \\
\hline & & & & & & & \\
\hline MO x S. Bases* & & 0.29 & 0.34 & .*** & 0.36 & - & 0.32 \\
\hline MO x Argila & & 0.45 & 0.68 & 0.71 & 0.41 & 0.68 & - \\
\hline $\mathrm{MO} \times \mathrm{P}$ & & - & - & 0.28 & - & 0.51 & 0.80 \\
\hline CTC x S. Bases & & 0.85 & 0.92 & 0.94 & 0.72 & 0.62 & 0.71 \\
\hline CTC x MO & & 0.47 & 0.34 & - & 0.54 & 0.75 & 0.70 \\
\hline CTC $\times$ Argila & & - & - & - & - & 0.36 & 0.44 \\
\hline Alt** x CTC & & - & 0.38 & - & - & - & 0.63 \\
\hline Alt x Argila & & 0.77 & 0.83 & 0.80 & 0.83 & 0.80 & 0.69 \\
\hline Alt $\times$ S. Bases & & - & 0.36 & -0.30 & - & -0.40 & 0.48 \\
\hline Alt $\times \mathrm{pH}$ & & - & - & - & 0.27 & -0.40 & 0.40 \\
\hline \multirow[t]{2}{*}{ Alt $\times \mathrm{P}$} & & 0.34 & - & 0.32 & 0.25 & 0.68 & 0.64 \\
\hline & PD20 & & & & & & \\
\hline MO x S. Bases & & 0.63 & 0.81 & 0.75 & 0.54 & 0.58 & 0.61 \\
\hline MO x Argila & & 0.28 & 0.46 & - & - & - & - \\
\hline $\mathrm{MO} \times \mathrm{P}$ & & 0.44 & 0.83 & 0.31 & - & 0.72 & 0.71 \\
\hline CTC x S. Bases & & 0.86 & 0.95 & 0.76 & 0.95 & 0.89 & 0.91 \\
\hline CTC x MO & & 0.77 & 0.87 & 0.83 & 0.53 & 0.72 & 0.65 \\
\hline CTC $\times$ Argila & & 0.27 & - & - & - & - & - \\
\hline Alt $\times$ CTC & & 0.42 & 0.86 & 0.58 & 0.44 & 0.30 & 0.29 \\
\hline Alt x Argila & & -0.29 & 0.50 & - & - & -0.77 & -0.47 \\
\hline Alt $\times$ S. Bases & & 0.52 & 0.84 & 0.50 & 0.56 & 0.46 & 0.38 \\
\hline Alt $\times \mathrm{pH}$ & & 0.67 & 0.84 & 0.73 & 0.78 & 0.55 & 0.50 \\
\hline \multirow[t]{2}{*}{ Alt $\times \mathrm{P}$} & & 0.32 & 0.79 & - & - & - & 0.54 \\
\hline & PD10FN & & & & & & \\
\hline MO x S. Bases & & 0.61 & 0.74 & 0.76 & 0.49 & 0.63 & 0.63 \\
\hline MO x Argila & & 0.79 & 0.55 & 0.80 & 0.94 & 0.75 & 0.70 \\
\hline $\mathrm{MO} \times \mathrm{P}$ & & - & 0.55 & - & 0.42 & - & - \\
\hline CTC $x$ S. Bases & & 0.73 & 0.85 & 0.89 & 0.89 & 0.87 & 0.73 \\
\hline CTC x MO & & 0.84 & & & & & \\
\hline CTC $x$ Argila & & 0.72 & 0.70 & 0.93 & 0.93 & 0.68 & 0.72 \\
\hline Alt x CTC & & 0.66 & 0.67 & 0.79 & 0.83 & 0.82 & 0.86 \\
\hline Alt $x$ Argila & & 0.70 & 0.88 & 0.88 & 0.93 & 0.94 & 0.90 \\
\hline Alt $\times \mathrm{S}$. Bases & & 0.42 & 0.45 & 0.70 & 0.35 & 0.57 & 0.57 \\
\hline Alt $\times \mathrm{pH}$ & & - & - & - & $=$ & - & - \\
\hline Alt $\times \mathrm{P}$ & & - & - & - & 0.32 & -0.36 & - \\
\hline
\end{tabular}




\subsubsection{Recomendação de fertilizantes}

As recomendações de fertilizantes foram calculadas de acordo com Raij et al. (1996). Na Tabela 9 pode-se comparar a quantidade de fertilizante recomendada na aplicação baseada na média (aplicação uniforme ou convencional), no gerenciamento localizado (aplicação de acordo com a demanda em cada ponto da grade) e por zonas de manejo de fertilizantes, geradas com a utilização da técnica fuzzy k-means. Os valores de $\mathrm{P}$ e $\mathrm{K}$ recomendados de acordo com o gerenciamento localizado foram agrupados usando o programa"Fuzme"para gerar zonas de recomendação de fertilizantes (P e K), que podem ser visualizadas no mapa produzido pelo programa "Surfer" (Figura 14). Pode-se observar que nestes dois últimos casos não houve alteração na quantidade de fertilizantes recomendada (Tabela 9).

A Tabela 10, que apresenta os valores dos centróides das três classes, mostra a combinação das recomendações de $\mathrm{P}$ e $\mathrm{K}$ para cada área. Os centróides das classes representam a demanda de fertilizantes $\mathrm{P}$ e $\mathrm{K}$ na classe considerada. Assim, por exemplo, na zona representada pela classe "a", a demanda de fertilizantes seria de 60 $\mathrm{Kg} \mathrm{ha}^{-1}$ de $\mathrm{P}_{2} \mathrm{O}_{5}$ e $10 \mathrm{Kg} \mathrm{ha}^{-1}$ de $\mathrm{K}_{2} \mathrm{O}$. Na classificação contínua, os centróides das classes representam os indivíduos que são inteiramente representados pela classe, ou seja, que apresentam grau de participação 1,0 na escala de 0,0 a 1,0 (ver escala apresentada na Figura 14). Portanto, o grau de similaridade dos indivíduos ao centróide das classes está representado nesta escala. Quanto mais se aproximar da cor branca a representação do indivíduo, melhor representado o mesmo estará pelos valores dos centróides da classe.

As zonas de manejo de fertilizantes estão indicando dependência espacial na demanda de $\mathrm{P}$ e $\mathrm{K}$ nas três áreas de estudo (Figura 14). Os centróides das classes (Tabela 10) mostram que a classe "a" está agrupando áreas de menor demanda de P e K. Principalmente nas áreas PD10PG e PD10FN, parece estar havendo uma tendência de concentração de fertilizantes nas posições superiores da vertente (topo, ombro e meia encosta superior) (Figura 14, Tabela 10) (ver também Figuras 22 a 27 do Anexo). 
Tabela 9. Comparação da recomendação de fertilizantes (P e K) na aplicação uniforme (pela média, ou convencional) e no gerenciamento localizado.

\section{Recomendação de Fertilizantes}

\begin{tabular}{|c|c|c|c|c|c|}
\hline \multirow[b]{2}{*}{ Área† } & \multirow[b]{2}{*}{ Fertilizante } & \multirow[b]{2}{*}{ Profundidade } & Uniforme & \multicolumn{2}{|c|}{ Gerenciamento localizado } \\
\hline & & & & $\begin{array}{l}\text { Ponto a } \\
\text { ponto }\end{array}$ & $\begin{array}{c}\text { Zonas de } \\
\text { fertilidade }\end{array}$ \\
\hline & & $\mathrm{m}$ & - & $-\ldots-$ Kg ha & - \\
\hline \multirow[t]{6}{*}{ PD10PG } & $\mathrm{P}_{2} \mathrm{O}_{5}$ & $0-0.10$ & 60 & 65 & 67 \\
\hline & & $0.10-0.20$ & 90 & 87 & 87 \\
\hline & & $0-0.20$ & 75 & 76 & 77 \\
\hline & $\mathrm{K}_{2} \mathrm{O}$ & $0-0.10$ & 10 & 14 & 12 \\
\hline & & $0.10-0.20$ & 20 & 23 & 24 \\
\hline & & $0-0.20$ & 15 & 19 & 18 \\
\hline \multirow[t]{6}{*}{ PD20 } & $\mathrm{P}_{2} \mathrm{O}_{5}$ & $0-0.10$ & 40 & 45 & 45 \\
\hline & & $0.10-0.20$ & 90 & 84 & 85 \\
\hline & & $0-0.20$ & 65 & 65 & 65 \\
\hline & $\mathrm{K}_{2} \mathrm{O}$ & $0-0.10$ & 10 & 15 & 13 \\
\hline & & $0.10-0.20$ & 20 & 20 & 21 \\
\hline & & $0-0.20$ & 15 & 17 & 17 \\
\hline \multirow[t]{6}{*}{ PDIOFN } & $\mathrm{P}_{2} \mathrm{O}_{5}$ & $0-0.10$ & 40 & 44 & 44 \\
\hline & & $0.10-0.20$ & 60 & 77 & 76 \\
\hline & & $0-0.20$ & 50 & 60 & 60 \\
\hline & $\mathrm{K}_{2} \mathrm{O}$ & $0-10$ & 10 & 14 & 13 \\
\hline & & $10-20$ & 20 & 20 & 22 \\
\hline & & $0-20$ & 15 & 17 & 17 \\
\hline
\end{tabular}

$\dagger$ Referir-se a Tabela 6 (p.62) ou Tabela 15 do Anexo para descrição das áreas.

Tabela 10 -Centróides das três classes dos grupamentos gerados pelo programa "Fuzme" a partir da recomendação de fertilizantes no gerenciamento localizado.

\section{Classes Centróides}

$\begin{array}{llll}\text { Áreas }^{\ddagger} & \text { PD10PG } & \text { PD20 } & \text { PD10FN }\end{array}$

$\begin{array}{llllllll}\text { Fertilizantes } & \text { P } & \text { K } & P & \text { K } & P & \text { K }\end{array}$

\begin{tabular}{ccccccc} 
a & 60 & 10 & 40 & 10 & 40 & 10 \\
b & 60 & 20 & 40 & 20 & 40 & 20 \\
c & 90 & 10 & 60 & 10 & 60 & 10 \\
\hline
\end{tabular}

₹ Referir-se a Tabela 6 (p.62) (ou Tabela 15 do Anexo) para a descrição das áreas. 

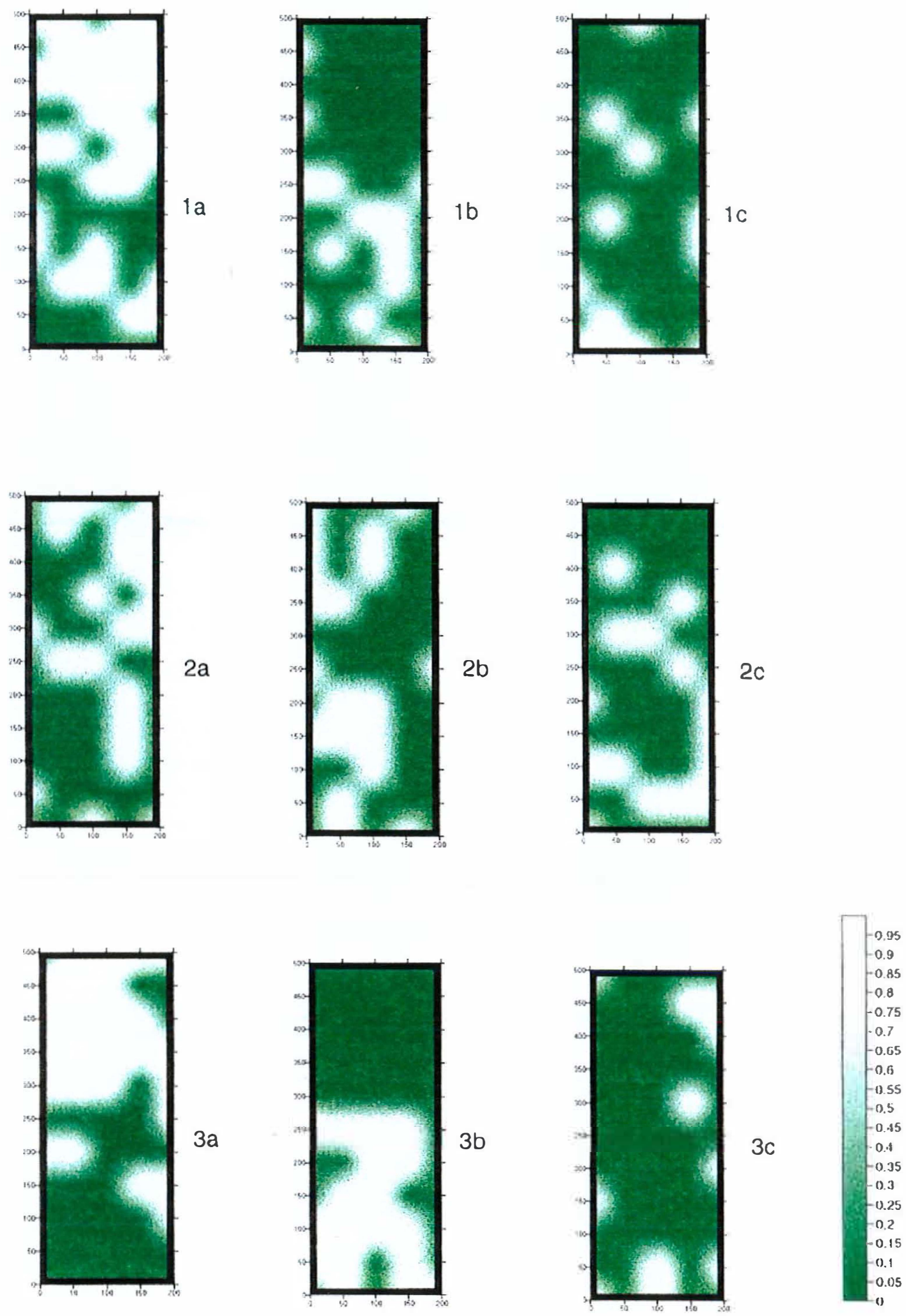

Figura 14. . Zonas geradas com a recomendação dos fertilizantes P e K para as áreas PD10PG $(1 \mathrm{a}, 1 \mathrm{~b}, 1 \mathrm{c}), \mathrm{NT} 20(2 \mathrm{a}, 2 \mathrm{~b}, 2 \mathrm{c})$ e NT10FN (3a, 3b, 3c). Os valores da legenda especificam a taxa de participação dos indivíduos em cada classe. 
A recomendação de fertilizantes para a camada de $0,10-0,20 \mathrm{~m}$ foi maior do que para a camada de $0-0,10 \mathrm{~m}$ devido a estratificação de P e K no sistema PD (Tabela 9). A recomendação de $\mathrm{P}$ e K por hectare (ha), baseada na média das recomendações para as duas camadas, foi similar quando calculada (1) na aplicação uniforme, (2) no gerenciamento localizado. Por outro lado, no sistema PD, estudos suportam a recomendação de fertilizantes baseada na camada de $0-0,10$ m (Sá, 1999). Neste caso, o uso de fertilizantes por ha seria ligeiramente maior no gerenciamento localizado, porém a distribuição espacial dos fertilizantes dentro da área seria diferente (Figura $14 \mathrm{e}$ Tabela 9).

Tendo em vista a camada superficial de $0-0,10 \mathrm{~m}$, somente poucas áreas seriam super-adubadas usando aplicação uniforme (Tabela 11). Por outro lado, a quantidade de áreas sub-adubadas alcançaria maiores proporções: $24 \%$ na área PD10PG $(\mathrm{P}$ e K); 27 e $34, \%$ na área PD20 (P e K respectivamente) e 20 e 32,7 \% na área PD10FN (P e K respectivamente).

Tabela 11. Estimativa de áreas super e sub-adubadas comparando-se as aplicações de fertilizantes $\mathrm{P}$ e $\mathrm{K}$ pelo método convencional (cálculo baseado na média) com o gerenciamento localizado.

\begin{tabular}{|c|c|c|c|c|}
\hline Áreał & Fertilizante & $\begin{array}{l}\text { Profundidade } \\
\mathrm{m}\end{array}$ & $\begin{array}{l}\text { Áreas super } \\
\text { adubadas }\end{array}$ & $\begin{array}{l}\text { Areas sub- } \\
\text { adubadas }\end{array}$ \\
\hline \multirow[t]{5}{*}{ PD10PG } & \multirow{3}{*}{$\mathrm{P}_{2} \mathrm{O}_{5}$} & & & \\
\hline & & $0-0.10$ & 9 & 24 \\
\hline & & $0.10-0.20$ & & \\
\hline & \multirow{2}{*}{$\mathrm{K}_{2} \mathrm{O}$} & $0-0.10$ & 0 & 24 \\
\hline & & $0.10-0.20$ & 18 & 25 \\
\hline \multirow[t]{4}{*}{ PD20 } & \multirow[t]{2}{*}{$\mathrm{P}_{2} \mathrm{O}_{5}$} & $0-0.10$ & 0 & 27 \\
\hline & & $0.10-0.20$ & 18 & 0 \\
\hline & \multirow[t]{2}{*}{$\mathrm{K}_{2} \mathrm{O}$} & $0-0.10$ & 0 & 34 \\
\hline & & $0.10-0.20$ & 22 & 11 \\
\hline \multirow[t]{4}{*}{ PDI0FN } & \multirow[t]{2}{*}{$\mathrm{P}_{2} \mathrm{O}_{5}$} & $0-0.10$ & 2 & 20 \\
\hline & & $0.10-0.20$ & 0 & 56 \\
\hline & \multirow[t]{2}{*}{$\mathrm{K}_{2} \mathrm{O}$} & $0-0.10$ & 0 & 32 \\
\hline & & $0.10-0.20$ & 18 & 9 \\
\hline
\end{tabular}

† Referir-se à Tabela 6 (p. 62) ou Tabela 15 do Anexo para descrição das áreas. 
Considerando-se a camada de 0,10 - 0,20 m, uma maior porcentagem da área seria super-adubada usando-se a aplicação uniforme (Tabela 11), causando prejuízo ao meio ambiente (Sheppers, 2000).

A avaliação da aplicação do gerenciamento localizado de fertilizantes pode ser feita levando-se em conta (1) o aumento potencial do rendimento de culturas associado à aplicação localizada de fertilizantes em relação à aplicação uniforme, (2) a quantidade de fertilizante super-aplicado. O cálculo do aumento potencial de rendimento assume que áreas com valores de $\mathrm{P}$ e $\mathrm{K}$ inferiores à média aumentariam o rendimento em proporção à curva de resposta de fertilizantes (Pierce et al., 1995).

Estes cálculos foram feitos para a camada de $0-0,10 \mathrm{~m}$ da área PD20. De acordo com a curva de resposta de fertilizantes (Comissão de Fertilidade do Solo, $\mathrm{RS} / \mathrm{SC}$, 1995), as áreas sub-adubadas com $\mathrm{P}$ e $\mathrm{K}$ representam um decréscimo potencial de $425 \mathrm{Kg} \mathrm{ha}^{-1}$ e $160 \mathrm{Kg} \mathrm{ha}^{-1}$ de grãos de trigo, respectivamente. Seguindo este raciocínio, enquanto a aplicação de fertilizantes no gerenciamento localizado resultaria em aumento insignificante de custo, o decréscimo potencial de rendimento da cultura de trigo poderia resultar em perda considerável de rentabilidade. Neste caso, a quantidade de adubo aplicado seria praticamente o mesmo porém com diferente distribuição espacial (Figura 14).

\subsubsection{Rendimento do trigo}

$\mathrm{O}$ rendimento do trigo foi medido somente na área PD20 e não apresentou correlação significativa com os atributos topográficos e grande parte dos atributos do solo estudados (Tabela 12). Os atributos melhor correlacionados com o rendimento foram: $\mathrm{MO}\left(\mathrm{r}=-0,45^{* *}\right), \mathrm{P}\left(\mathrm{r}=-0,40^{* *}\right), \mathrm{CTC}\left(\mathrm{r}=-0,34^{*}\right)$, argila $\left(\mathrm{r}=-0,37^{*}\right)$, Umidade do grão (UG) $\left(r=-0,40^{* *}\right)$ e Densidade do solo (Ds) $\left(r=0,41^{* *}\right)$. Estes resultados foram contrários a nossa expectativa e podem ter sido influenciados pela distribuição das chuvas em 1998 (Figura 11, capítulo 3, p. 47). Pode-se observar que as chuvas neste ano, no período que antecedeu a colheita, foram $122 \%$ superiores a média dos anos anteriores. Historicamente, nesta região, chuvas desta natureza têm afetado a 
produtividade do trigo. O impacto da precipitação elevada durante o desenvolvimento e colheita do trigo pode ter escondido, ou mesmo invertido, os efeitos de atributos dos solos. Neste ano agrícola, as propriedades do solo relacionadas com a capacidade de retenção de água foram mais relevantes do que a maioria dos nutrientes analisados para explicar as variações no rendimento do trigo (Tabela 12).

Tabela 12. Coeficientes de correlação dePearson (r) entre rendimento do trigo e atributos do solo na área PD20.

\begin{tabular}{ll}
\hline Atributos & Coef. de correlação (r) \\
\hline pH & $-0.18^{\text {ns }}$ \\
MO & $-0.45^{* *}$ \\
CTC & $-0.34^{*}$ \\
P & $-0.40^{* *}$ \\
K & $-0.07^{\text {ns }}$ \\
Ca & $-0.21^{\text {ns }}$ \\
Mg & $-0.18^{\text {ns }}$ \\
Argila & $-0.37^{*}$ \\
Densidade do solo & $0,41^{* *}$ \\
Umidade do grão de trigo & $-0.48^{* *}$ \\
\hline Níveis de significância estatística representados por: ns = não significativo, ${ }^{*} p<0,05 ;$ \\
${ }^{* *} p<0,01 ;{ }^{* * *} p<0,001$
\end{tabular}

\subsubsection{Geoestatística}

O teste Shapiro-Wilk (ou a estatística W) de normalidade foi realizado para cada conjunto de dados antes da determinação do semivariograma. Uma transformação logarítmica foi imposta para as variáveis que não apresentaram distribuição normal, o que é um requerimento para o desenvolvimento do semivariograma (Cambardella \& Karlen, 1999).

A análise de semivariância revelou diferenças na dependência espacial das propriedades do solo e rendimento do trigo (Tabela 13 e 14; Figuras 15, 16 e 17) que podem ser visualisadas nas Figuras 18 e 19 (como também nas Figuras 20 a 27 do Anexo) através das isolinhas de atributos interpolados por krigagem obtidas com o uso do programa GS+ (Gamma Design software, 1999). 
Tabela 13. Parâmetros dos semivariogramas da análise geoestatística da fertilidade do solo nas três áreas de estudo.

\begin{tabular}{|c|c|c|c|c|c|c|c|}
\hline Atributos & $\begin{array}{l}\text { Prof. } \\
\text { (m) }\end{array}$ & Modelot & $\begin{array}{l}\text { Efeito } \\
\text { Pepita }\end{array}$ & Patamar & $\begin{array}{l}\text { Alcance } \\
\text { (m) }\end{array}$ & $\mathrm{C} /(\mathrm{Co}+\mathrm{C})+\dagger$ & $\mathrm{R}^{2}+T^{2}$ \\
\hline \multicolumn{8}{|l|}{ PD10PG } \\
\hline $\mathrm{pH}$ & & $\mathrm{L}$ & 0.065 & 0.297 & 4092 & 0.78 & 0.41 \\
\hline $\mathrm{MO}^{*}$ & & $E$ & 0.009 & 0.033 & 1526 & 0.72 & 0.60 \\
\hline P* & & L & 0.184 & 0.606 & 1195 & 0.70 & 0.35 \\
\hline K & & E & 1.22 & 4.29 & 1964 & 0.71 & 0.64 \\
\hline $\mathrm{Ca}$ & & L & 86 & 265 & 912 & 0.68 & 0.45 \\
\hline \multirow[t]{2}{*}{$\mathrm{Mg}^{*}$} & & $\mathrm{~L}$ & 0.047 & 0.162 & 839 & 0.71 & 0.40 \\
\hline & $0.10-0.20$ & $\mathrm{~L}$ & 0.063 & 0.161 & 1090 & 0.61 & 0.54 \\
\hline $\mathrm{MO}^{*}$ & & $\mathrm{~L}$ & 0.012 & 0.064 & 1011 & 0.81 & 0.45 \\
\hline $\mathrm{P}^{*}$ & & $\mathrm{~L}$ & 0.050 & 0.345 & 727 & 0.85 & 0.51 \\
\hline $\mathrm{K}$ & & $\mathrm{S}$ & 1.101 & 3.600 & 2377 & 0.69 & 0.24 \\
\hline $\mathrm{Ca}$ & & L & 109 & 278 & 1303 & 0.60 & 0.38 \\
\hline $\mathrm{Mg}^{*}$ & & $\mathrm{~L}$ & 0.189 & 0.471 & 1342 & 0.60 & 0.27 \\
\hline \multicolumn{8}{|l|}{ PD20 } \\
\hline $\mathrm{pH}$ & & L & 0.047 & 0.429 & 543 & 0.89 & 0.59 \\
\hline MO & & $\mathrm{L}$ & 0.100 & 182 & 848 & 0.99 & 0.95 \\
\hline P* & & $\mathrm{S}$ & 0.136 & 0.421 & 1723 & 0.67 & 0.39 \\
\hline K & & $E$ & 0.233 & 1.403 & 1109 & 0.83 & 0.42 \\
\hline $\mathrm{Ca}$ & & $E$ & 79.4 & 376 & 1499 & 0.79 & 0.55 \\
\hline \multirow[t]{2}{*}{$M g^{*}$} & & $\mathrm{~L}$ & 0.115 & 0.496 & 1056 & 0.77 & 0.50 \\
\hline & $0.10-0.20$ & L & 0.062 & 0.165 & 1159 & 0.62 & 0.65 \\
\hline MO & & E & 0.010 & 24.6 & 658 & 1.0 & 0.89 \\
\hline P* & & L & 0.233 & 0.547 & 5091 & 0.57 & 0.18 \\
\hline K & & $E$ & 0.66 & 1.98 & 3747 & 0.66 & 0.43 \\
\hline $\mathrm{Ca}$ & & S & 51.4 & 180.3 & 1643 & 0.71 & 0.53 \\
\hline $\mathrm{Mg}^{*}$ & & L & 0.23 & 0.601 & 3853 & 0.62 & 0.14 \\
\hline \multicolumn{8}{|l|}{ PD10FN +} \\
\hline & $0-0.10$ & & & & & & \\
\hline $\mathrm{pH}$ & & L & 0.085 & 0.199 & 78080 & 0.57 & 0.11 \\
\hline $\mathrm{MO}^{*}$ & & L & 0.002 & 0.121 & 678 & 0.98 & 0.82 \\
\hline P* & & L & 0.082 & 0.357 & 825 & 0.77 & 0.40 \\
\hline $\mathrm{K}^{*}$ & & $\mathrm{~L}$ & 0.054 & 0.321 & 606 & 0.83 & 0.84 \\
\hline $\mathrm{Ca}$ & & $\mathrm{L}$ & 57.9 & 285.7 & 815 & 0.80 & 0.73 \\
\hline \multirow[t]{2}{*}{$\mathrm{Mg}^{*}$} & & $\mathrm{~L}$ & 0.089 & 0.365 & 1237 & 0.75 & 0.60 \\
\hline & $0.10-0.20$ & & & & & & \\
\hline $\begin{array}{l}\mathrm{pH} \\
\text { MO* }\end{array}$ & & $\begin{array}{l}L \\
L\end{array}$ & $\begin{array}{l}0.125 \\
0.0001\end{array}$ & $\begin{array}{l}0.377 \\
0.0992\end{array}$ & $\begin{array}{l}7480 \\
602\end{array}$ & $\begin{array}{l}0.67 \\
0.99\end{array}$ & 0.12 \\
\hline $\mathrm{P}^{*}$ & & $\mathrm{~L}$ & $\begin{array}{l}0.0001 \\
0.089\end{array}$ & $\begin{array}{l}0.0992 \\
0.210\end{array}$ & 1936 & 0.58 & 0.20 \\
\hline $\mathrm{K}^{*}$ & & E & 0.066 & 0.297 & 7056 & 0.79 & 0.44 \\
\hline $\mathrm{Ca}$ & & L & 62 & 199 & 1950 & 0.69 & 0.41 \\
\hline $\mathrm{Mg}^{*}$ & & E & 0.173 & 0.608 & 1668 & 0.71 & 0.51 \\
\hline
\end{tabular}

$\uparrow$ Modelos: $\mathrm{L}=$ Linear, $\mathrm{S}=$ Esférico, $\mathrm{E}=$ Exponencial;*Transformação logarítmica;

$¥$ Referir-se à Tabela 6 para descrição das áreas (p.62); †† Proporção de estrutura espacial;

††† Coeficiente de Regressão - fornece uma indicação do quanto o modelo se ajusta aos dados do semivariograma 


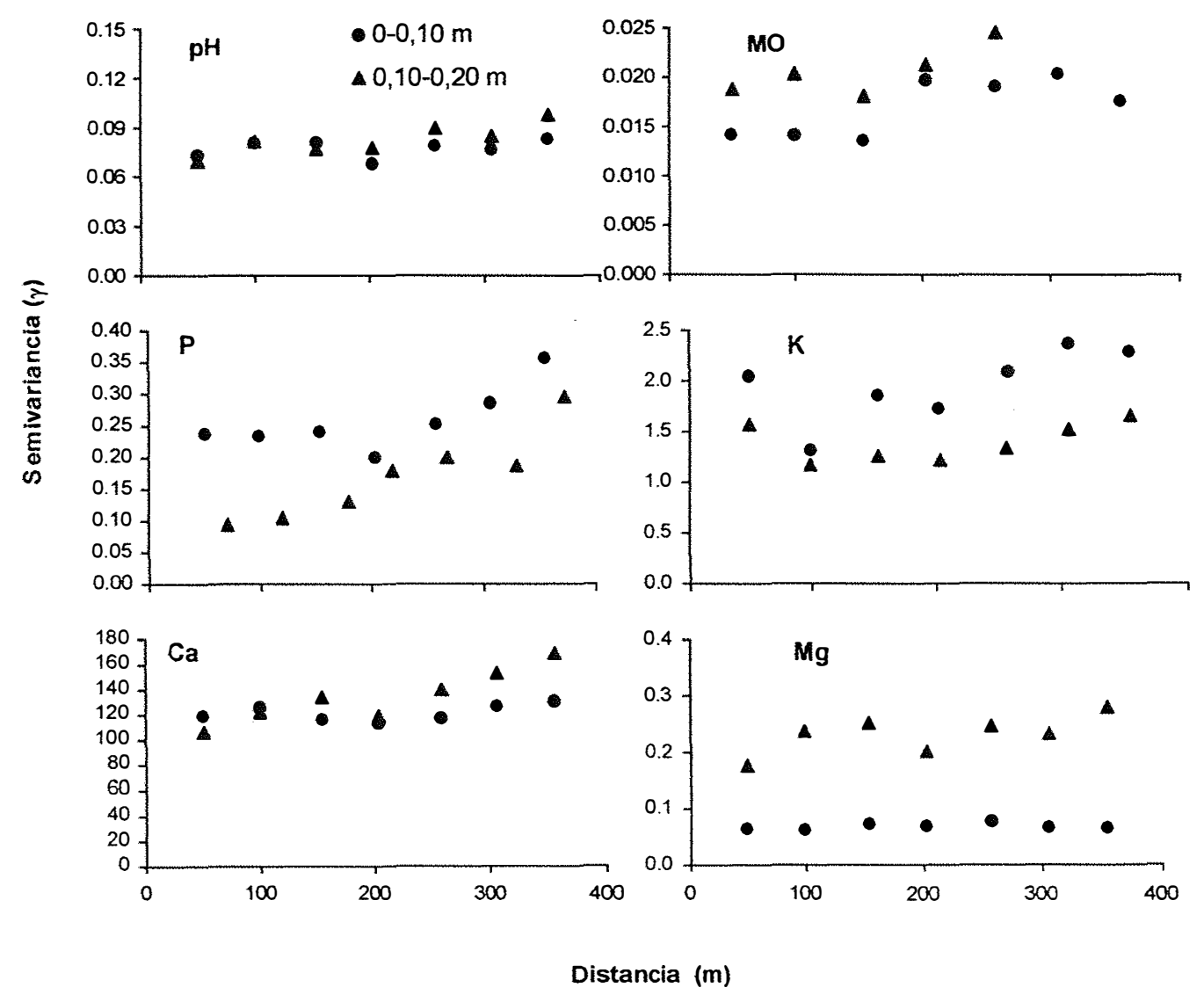

Figura 15. Semivariogramas de atributos do solo nas profundidades de $0-0,10$ e $0,10-0,20 \mathrm{~m}$ na área PD10PG. 

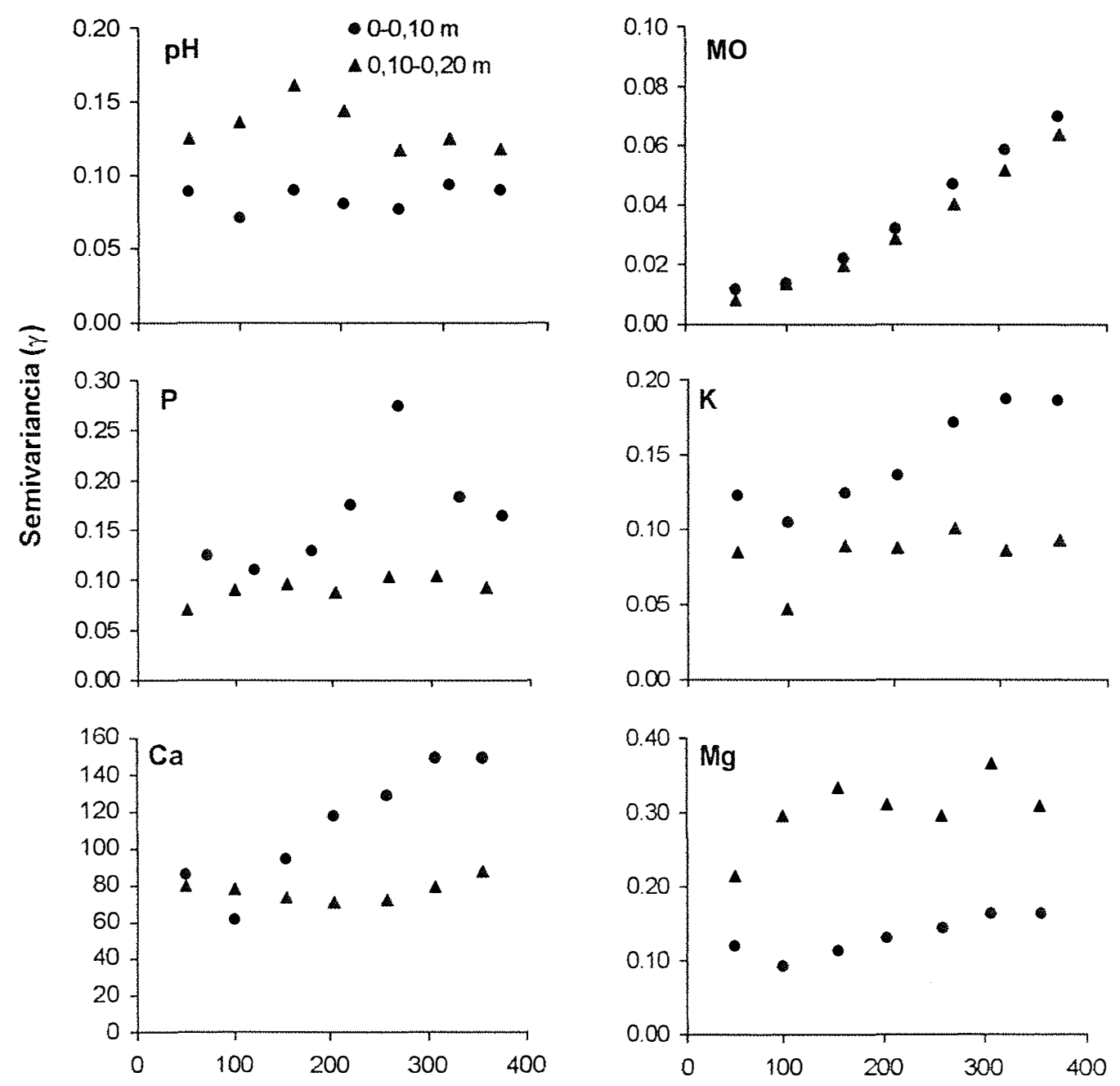

\section{Distancia (m)}

Figure 16. Semivariogramas de atributos do solo nas profundidades de $0-0,10$ e $0,10-0,20 \mathrm{~m}$ na área PD10FN. 

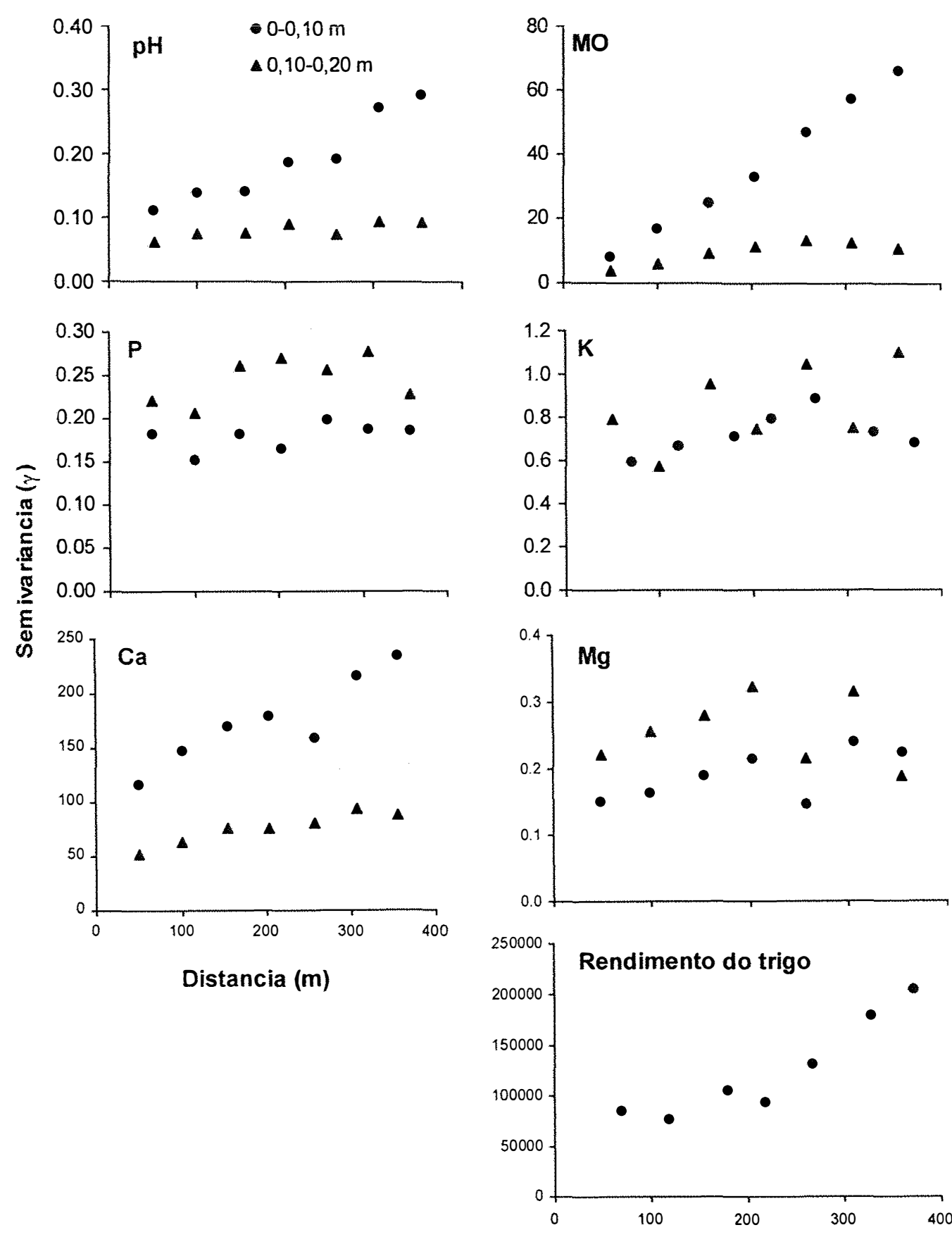

Distancia (m)

Figure 17. Semivariogramas de atributos do solo nas profundidades de $0-0,10$ e $0,10-0,20 \mathrm{~m}$ na área PD20. 
$\mathrm{pH}$

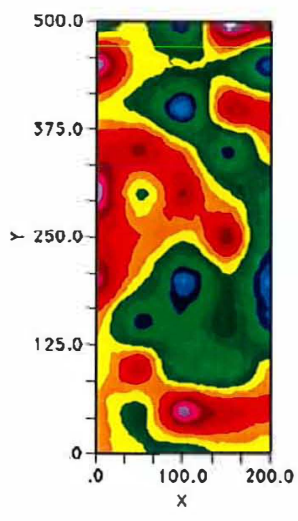

$P$

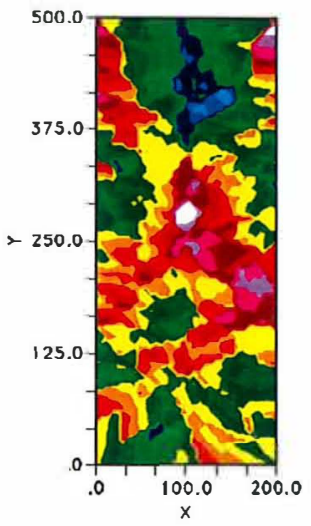

CTC

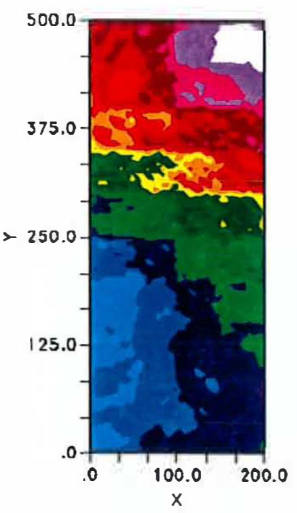

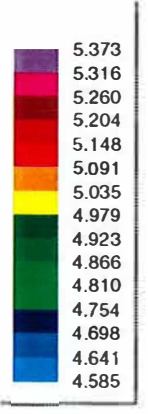
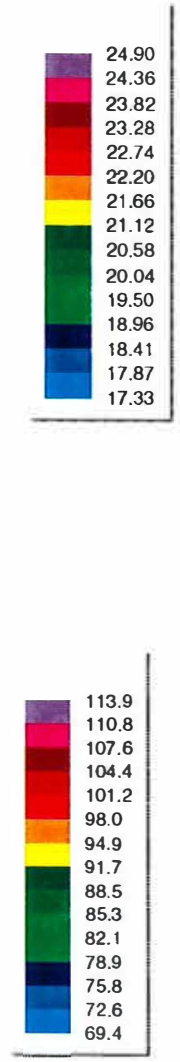

MO
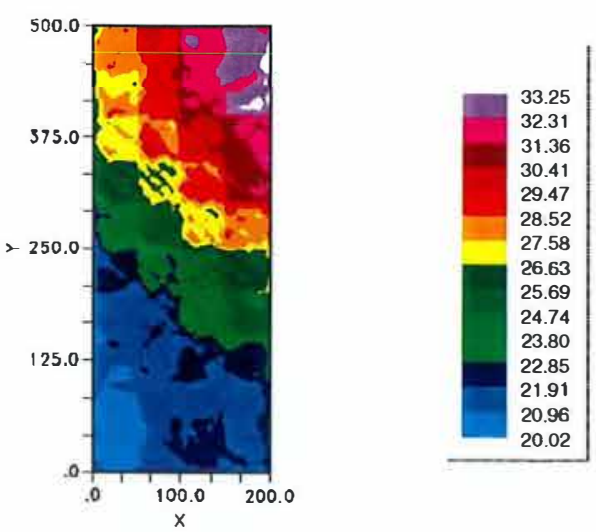

SB
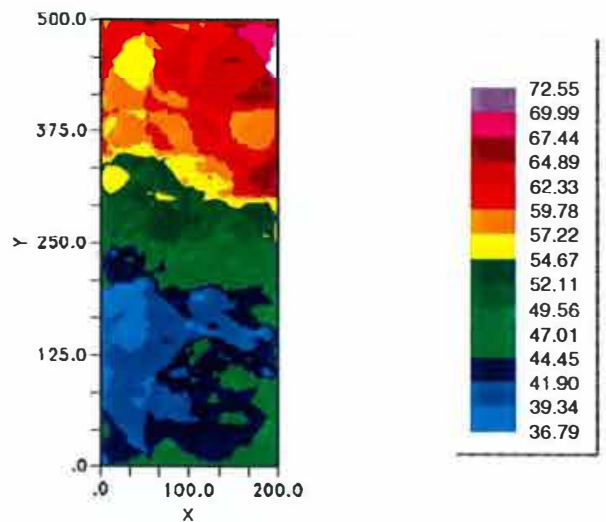

Argila

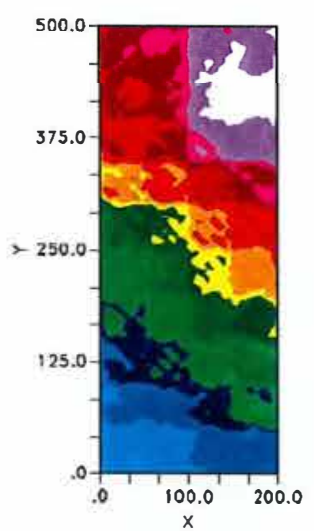

Figura 18. Mapas de isolinhas de atributos do solo estimados por krigagem da area PDI0FN, na profundidade de $0-0,10 \mathrm{~m}$.

( $\mathrm{SB}=$ soma de bases trocáveis). 

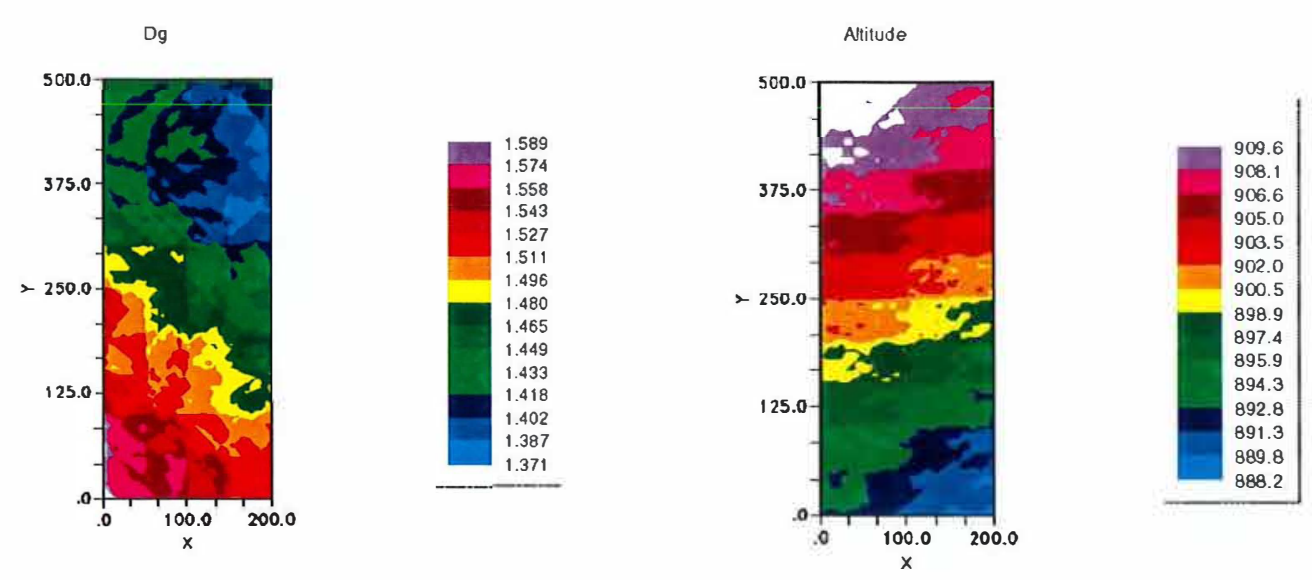

Figura 19. Mapas de isolinhas dos dados de altitude e densidade do solo (camada de 0-0,10 m) estimados por krigagem da área PDIOFN.

Tabela 14. Sumário estatístico e parâmetros de semivariogramas da análise geoestatística do rendimento do trigo e umidade do grão do trigo por ocasião da colheita na área PD20.

\begin{tabular}{|c|c|c|}
\hline Parâmetros & $\begin{array}{l}\text { Rendimento do Trigo } \\
\left(\mathrm{Kg} \mathrm{ha}^{-1}\right)\end{array}$ & $\begin{array}{l}\text { Umidade do grão } \\
\left(\mathrm{g} \mathrm{Kg}^{-1}\right)\end{array}$ \\
\hline Média & 3154 & 27.6 \\
\hline Desv. Padrão & 3402 & 2.9 \\
\hline Mínimo & 2310 & 21.0 \\
\hline Máximo & 3824 & 40.0 \\
\hline Efeito pepita & 50800 & 1.93 \\
\hline Patamar & 259831 & 26.3 \\
\hline Modelo & $\mathrm{L}$ & $\mathrm{L}$ \\
\hline $\mathrm{R}^{2}$ & 0.47 & 0.71 \\
\hline $\mathrm{C} / \mathrm{Co}+\mathrm{C}$ & 0.80 & 0.92 \\
\hline
\end{tabular}

Modelos anisotrópicos lineares foram definidos para a maior parte das variáveis de solos medidas nas três áreas de estudo. Modelos anisotrópicos exponenciais e esféricos definiram as demais variáveis. No modelo esférico a semivariância aumenta 
com a distância entre as amostras até um nível constante (patamar) à uma determinada distância (alcance), onde pares de pontos não estão mais auto-correlacionados. O modelo exponencial é similar ao modelo esférico pelo fato de aproximar-se do patamar gradualmente, mas difere deste modelo na taxa pela qual o patamar é alcançado e pelo fato de que o modelo e o patamar nunca realmente convergem. Assume-se que o alcance no modelo exponencial seja o ponto no qual o modelo inclui $95 \%$ do patamar $(\mathrm{C}+\mathrm{Co}) . \mathrm{O}$ modelo linear descreve um variograma em linha reta. Portanto, não há patamar neste modelo. Todos os alcances apresentados na Tabela 13 foram calculados pelo programa GS+ e correspondem ao alcance no maior eixo (Gamma Design Software, 1998).

$\mathrm{Na}$ área PD10PG o modelo exponencial ajustou-se ao semivariograma calculado razoavelmente bem $\left(\mathrm{R}^{2}=60\right.$ e $\left.64 \%\right)$ para $\mathrm{MO}$ e $\mathrm{K}$ na camada $0-0,10 \mathrm{~m}$ e a proporção de estrutura espacial $(\mathrm{C} /(\mathrm{Co}+\mathrm{C}))$ foi 0,72 e 0,71 respectivamente (Tabela 13).O modelo linear foi o que melhor se ajustou para $\mathrm{pH}, \mathrm{Ca}, \mathrm{P}$ e $\mathrm{Mg}$. Para $\mathrm{pH}$ e $\mathrm{Ca}$ a variância total quase se iguala a variância inicial (variância pepita), portanto o modelo linear apresenta uma inclinação próxima de zero (efeito pepita puro). Neste caso, as variáveis não são correlacionadas à distâncias iguais ou maiores que o menor intervalo de distância (Cambardella e Karlen, 1999). Para P e Mg, a semivariância aumenta a medida que a distância entre duas amostras aumenta, logo, neste caso, o modelo linear descreve variáveis que são espacialmente correlacionados em todos os intervalos de distância maiores que o espaçamento da grade de amostragem. Entretanto, o $\mathrm{R}^{2}$ do modelo ajustado foi 3,5 e 4,0 respectivamente e os valores das semivariâncias iniciais (efeito pepita ou nugget) foram altos, indicando baixa dependência espacial. Em geral a dependência espacial dos parâmetros analisados foi baixa na camada de $0,10-0,20 \mathrm{~m}$.

$\mathrm{Na}$ área PD10FN, com exceção do $\mathrm{Ke} \mathrm{Mg}$ trocável na camada de $0,10-0,20 \mathrm{~m}$, que teve o semivariograma experimental melhor ajustado pelo modelo exponencial, o modelo linear foi o que melhor se ajustou a todas as demais variáveis estudadas. Houve elevada dependência espacial para $\mathrm{MO}$ em ambas profundidades e para $\mathrm{K}$ e $\mathrm{Ca}$ na profundidade de $0-0,10 \mathrm{~m}$, levando-se em consideração os valores dos coeficientes de regressão $\left(R^{2}\right)$ dos modelos ajustados e a proporção de estrutura espacial $(C /(\mathrm{Co}+\mathrm{C})$. 
Para a área PD20, a dependência espacial foi relativamente maior na camada de $0-0,10 \mathrm{~m}$ do que na camada de $0,10-0,20 \mathrm{~m}$. A maior dependência espacial foi observada para $\mathrm{MO}, \mathrm{pH}$ (modelo linear) e $\mathrm{Ca}$ (modelo exponencial). $\mathrm{O}$ rendimento do trigo apresentou alguma dependência espacial uma vez que a proporção de estrutura espacial foi 0,80 , mas $o R^{2}$ do modelo linear foi 0,47 (Tabela 14).

Em geral a MO foi a variável que apresentou maior dependência espacial , seguida por $\mathrm{K}$ e Ca. Por outro lado, $\mathrm{pH}$ e $\mathrm{P}$ apresentaram menor dependência espacial. A predominância do modelo linear no ajuste dos semivariogramas sugere que o tamanho das áreas amostradas não foi suficientemente grande para exibir toda a variância espacial.

\subsection{CONCLUSÕES}

1 - A fertilidade do solo foi altamente variável e muito estratificada nas três áreas estudadas.

2 - A recomendação de fertilizantes seria praticamente a mesma na aplicação uniforme ou no gerenciamento localizado mas a distribuição de fertilizantes dentro das áreas seria espacialmente diferente. A ocorrência de áreas sub-adubadas usando o procedimento uniforme seria de: 24\% no PD10PG (P e K), 27 e $34 \%$ no PD20 (P e K respectivamente) e 20 e 33 \% na área PD10FN (P e K respectivamente);

3 - As zonas de manejo de fertilizantes criadas pelo programa Fuzme indicaram dependência espacial na demanda de $\mathrm{P}$ e $\mathrm{K}$ nas três áreas de estudo, mostrando uma tendência de concentração de nutrientes nas posições mais elevadas das vertentes cultivadas no sistema PD;

4 - As propriedades dos solo mostraram diferenças na dependência espacial. Modelos anisotrópicos lineares foram definidos para a maior parte das variáveis medidas nas três áreas. MO foi a variável que apresentou maior dependência espacial, seguida por $\mathrm{K}$ e Ca. Por outro lado, $\mathrm{pH}$ e $\mathrm{P}$ foram as variáveis que apresentaram menor dependência espacial 


\section{CONCLUSÕES GERAIS}

O material de origem dos solos e o relevo são responsáveis por importantes diferenças nas característicass dos solos da região dos "Campos Gerais" e estão portanto controlando o comportamento de importantes propriedades no manejo das culturas.

O cultivo de solos no sistema plantio direto (PD) por longo período reduziu a acidez potencial, aumentando o $\mathrm{pH}$ dos solos. Também foi observado aumento na CTC e elevada correlação da CTC com o conteúdo de matéria orgânica (MO) e saturação por bases, suportando a conclusão de que o sistema PD por longo período possa ser importante prática no aumento da fertilidade dos solos desta região. $\mathrm{O}$ aumento da $\mathrm{MO}$, CTC e soma de bases ocorreu principalmente nas posições mais elevadas das vertentes e nas áreas formadas a partir do arenito da formação Furnas e material retrabalhado das formações Furnas e Ponta Grossa, isto é, nas topossequências de solos de textura argiloarenosa e franco argilo-arenosa.

Os resultados deste estudo indicaram correlações significativas entre os atributos dos solos e topográficos. $\mathrm{O}$ uso de equações obtidas através de análises de regressão linear múltipla dos atributos derivados do DEM e atributos dos solos, mostrou-se uma ferramenta útil na geração de modelos de predição de alguns atributos-chave da fertilidade do solo, tais como argila, MO, CTC e densidade do solo, principalmente nos solos formados a partir do arenito Furnas. Este método requer menos amostras de solo do que as técnicas de interpolação, sendo portanto uma promissora alternativa na reducão de custos.

A técnica fuzzy k-means mostrou-se uma ferramenta útil na geração de zonas de manejo de fertilizantes nas topossequências da região dos Campos Gerais.

A fertilidade do solo foi altamente variável e muito estratificada nas três áreas estudadas. Os teores de $\mathrm{MO}, \mathrm{Ca}$ e $\mathrm{Mg}$ trocáveis aumentaram de acordo com o teor de 
argila nas áreas. $\mathrm{O} \mathrm{pH}$ apresentou valores médios $(0-0,10 \mathrm{~m})$ e baixos $(0,10-0,20 \mathrm{~m})$ nas três áreas de estudo mas variou da classe baixa à muito alta. A média dos valores de $\mathrm{P}$ enquadrou-se na classe baixa na área NT10PG mas os valores pontuais variaram da classe muito baixa à média. Nas áreas com menor conteúdo de argila (PD10FN e $\mathrm{PD} 20$ ), os valores médios de $\mathrm{P}$ alcançaram a classe média, porém variando entre as classes baixa e muito alta. A média dos teores de $\mathrm{K}$ foi alta nas três áreas mas os valores variaram da classe baixa a muito alta. Em geral, a maior variabilidade espacial foi observada na área NT20. O rendimento do trigo apresentou variações, porém, neste ano agrícola, houve baixa correlação desta variável com a fertilidade do solo.

A dosagem de fertilizantes recomendada seria praticamente a mesma na aplicação uniforme (convencional) ou no gerenciamento localizado, mas a distribuição de fertilizantes dentro das áreas seria espacialmente diferente. A ocorrência de áreas sub-adubadas usando o procedimento uniforme seria: $24 \%$ no NT10PG (P e K), 27\% e $34,5 \%$ no NT20 (P e K respectivamente) e $20 \%$ e $32,7 \%$ na área NT10FN (P e K respectivamente), representando um potencial de decréscimo no rendimento da cultura de trigo.

As propriedades do solo mostraram diferenças na dependência espacial. Modelos anisotrópicos lineares foram definidos para a maior parte das variáveis medidas nas três áreas. MO foi a variável com maior dependência espacial, seguida por $\mathrm{K}$, e Ca. Em geral pH e P apresentaram menor dependência espacial. 
ANEXO 
Tabela 15. Descrição das variáveis e símbolos .

\begin{tabular}{|c|c|}
\hline Símbolos & Descrição/Unidades \\
\hline $\mathrm{pH}$ & $\left(0,01 \mathrm{M} \mathrm{CaCl}_{2}\right)$ \\
\hline Ac.P. ou $\mathrm{H}^{+}$ & Acidez potencial, $\mathrm{mmol}_{\mathrm{c}} \mathrm{dm}^{-3}$ \\
\hline $\mathrm{Al}^{3+}$ & Alumínio trocável, $\mathrm{mmol}_{\mathrm{c}} \mathrm{dm}^{-3}$ \\
\hline MO & Matéria Orgânica, $\mathrm{g} \mathrm{dm}^{-3}$ \\
\hline $\mathrm{Ca}^{2+}$ & Ca trocável, $\mathrm{mmol}_{\mathrm{c}} \mathrm{dm}^{-3}$ \\
\hline $\mathrm{Mg}^{2+}$ & $\mathrm{Mg}$ trocável, $\mathrm{mmol}_{\mathrm{c}} \mathrm{dm}^{-3}$ \\
\hline $\mathrm{K}^{+}$ & $\mathrm{K}$ trocável, $\mathrm{mmol}_{\mathrm{c}} \mathrm{dm}^{-3}$ \\
\hline $\mathrm{P}$ & $\mathrm{P}$ disponível, $\mathrm{mg} \mathrm{dm}{ }^{-3}$ \\
\hline $\mathrm{SO}_{4}$ & $\mathrm{SO}_{4}$ disponível, $\mathrm{mg} \mathrm{dm}^{-3}$ \\
\hline SB & Soma de bases, $\mathrm{mmol}_{\mathrm{c}} \mathrm{dm}^{-3}$ \\
\hline CTC & Capacidade de troca de cátions, $\mathrm{mmol}_{\mathrm{c}} \mathrm{dm}^{-3}$ \\
\hline Argila & $\mathrm{g} \mathrm{kg}^{-1}$ \\
\hline Silte & $\mathrm{g} \mathrm{kg}^{-1}$ \\
\hline Areia & $\mathrm{g} \mathrm{kg}^{-1}$ \\
\hline Ds ou Dg & Densidade do solo, $\mathrm{g} \mathrm{cm}^{-3}$ \\
\hline Rend & Rendimento de grãos de trigo, $\mathrm{Kg} \mathrm{ha}^{-1}$ \\
\hline U.G. & $\begin{array}{l}\text { Umidade do grão de trigo por ocasião da colheita (usado } \\
\text { como base para transformação do rendimento para } \mathrm{Kg} \mathrm{ha}^{-1}\end{array}$ \\
\hline Alt & Altitude, metros \\
\hline $\mathrm{CN}$ & Campo nativo da região dos "Campos Gerais"-PR \\
\hline PD10PG & $\begin{array}{l}\text { Plantio Direto - } 10 \text { anos - material de origem: folhelho da } \\
\text { formação Ponta Grossa }\end{array}$ \\
\hline PD10FN & $\begin{array}{l}\text { Plantio Direto - } 10 \text { anos - material de origem: arenito da } \\
\text { formação Furnas }\end{array}$ \\
\hline PD20 & $\begin{array}{l}\text { Plantio Direto }-20 \text { anos - material de origem: material } \\
\text { retrabalhado do arenito Furnas e do folhelho Ponta Grossa }\end{array}$ \\
\hline $\mathrm{R}^{2}$ & $\begin{array}{l}\text { Coeficiente de regressão - fornece indicação de como o } \\
\text { modelo ajusta os dados do semivariograma }\end{array}$ \\
\hline $\mathrm{C} /(\mathrm{C} 0+\mathrm{C})$ & Proporção de estrutura espacial \\
\hline $\mathrm{L}$ & Linear \\
\hline S & Esférico \\
\hline E & Exponencial \\
\hline AR & Altitude relativa \\
\hline EXP & Exposição solar \\
\hline DECL & Declividade \\
\hline
\end{tabular}




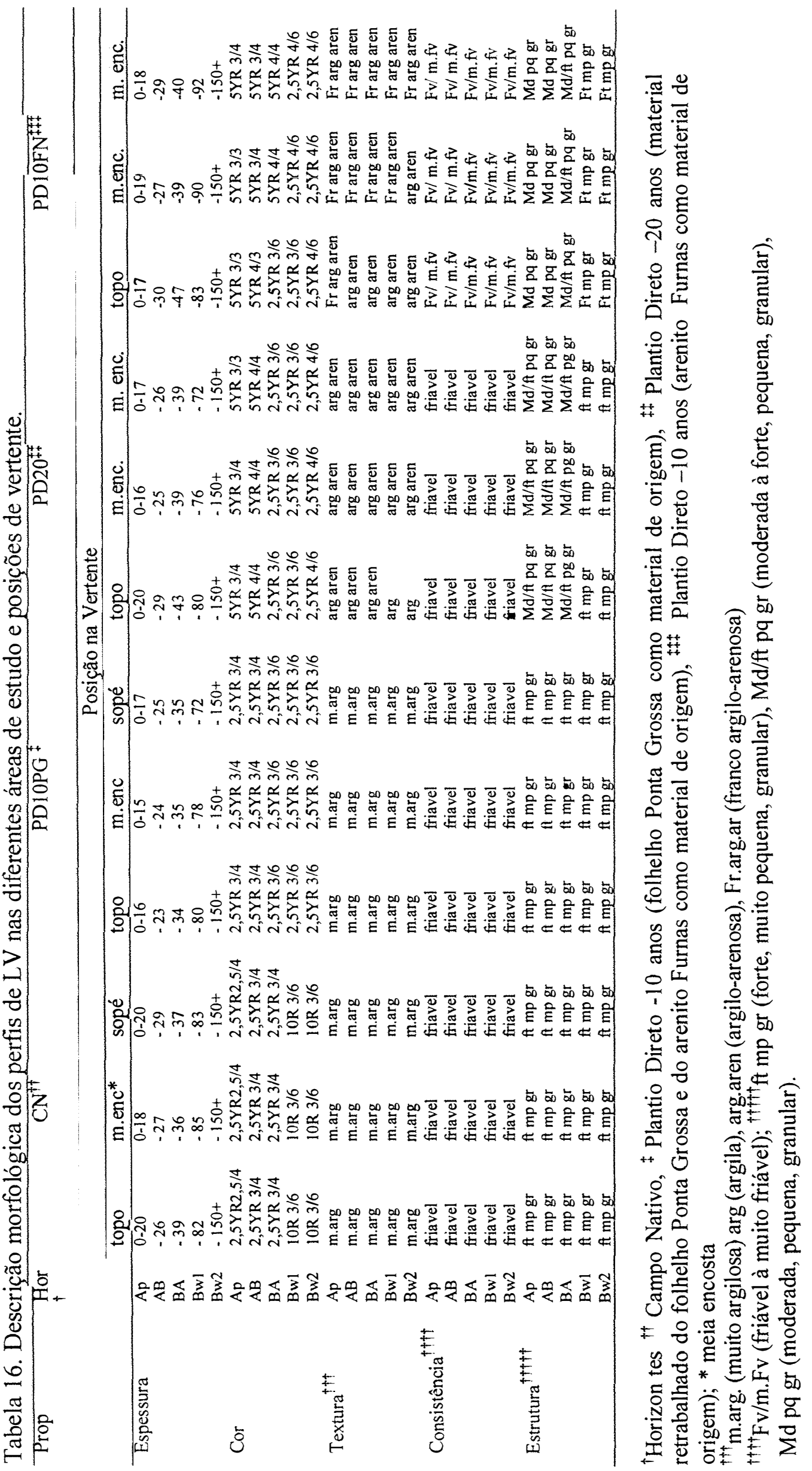




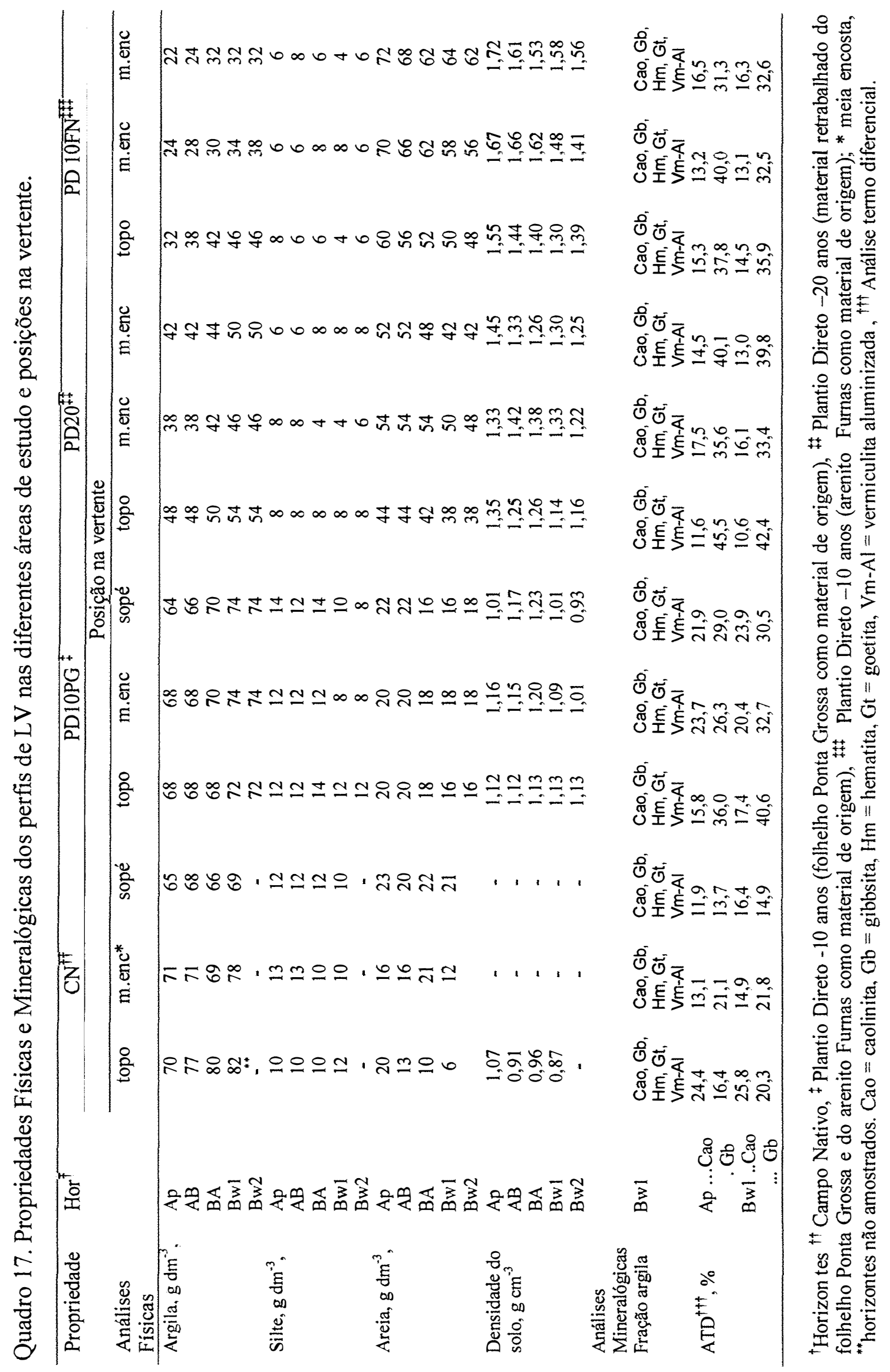


Tabela 18. Propriedades Químicas dos perfis de Latossolos Vermelho nas diferentes áreas e posições da vertente.

\begin{tabular}{|c|c|c|c|c|c|c|c|c|c|c|c|c|c|}
\hline \multirow[t]{3}{*}{ Propriedades } & \multirow[t]{3}{*}{$\mathrm{Hor}^{+}$} & \multicolumn{3}{|c|}{ Campo Nativo } & \multicolumn{4}{|c|}{ PD10PG } & \multicolumn{2}{|l|}{ PD20 } & \multicolumn{3}{|c|}{ PD10FN } \\
\hline & & & & & & Posi & ío na v & tente & & & & & \\
\hline & & Topo & $\begin{array}{l}\text { Meia } \\
\text { enc.* }\end{array}$ & Sopé & topo & $\begin{array}{l}\text { Meia } \\
\text { enc. }\end{array}$ & sopé & topo & $\begin{array}{c}\text { Meia } \\
\text { enc. }\end{array}$ & $\begin{array}{l}\text { Meia } \\
\text { enc. }\end{array}$ & topo & $\begin{array}{l}\text { Meia } \\
\text { enc. }\end{array}$ & $\begin{array}{l}\text { Meia } \\
\text { enc. }\end{array}$ \\
\hline \multirow{5}{*}{$\mathrm{pH}$} & $\mathrm{Ap}$ & 3,9 & 3,7 & 3,6 & 4,8 & 4,9 & 4,6 & 4,8 & 5,3 & 4,6 & 4,8 & 5,5 & 5,3 \\
\hline & $\mathrm{AB}$ & 3,7 & 3,6 & 3,5 & 4,2 & 4,4 & 4,0 & 4,2 & 4,1 & 4,1 & 4,6 & 4,8 & 4,2 \\
\hline & BA & 3,7 & 3,6 & 3,5 & 4,3 & 4,2 & 4,1 & 4,2 & 4,2 & 4,2 & 4,0 & 4,2 & 4,1 \\
\hline & Bwl & 3,9 & 3,7 & 3,7 & 4,5 & 4,4 & 4,1 & 4,5 & 4,2 & 4,2 & 4,4 & 4,4 & 4,2 \\
\hline & Bw2 & 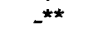 & . & - & 4,7 & 4,6 & 4,4 & 4,6 & 4,5 & 4,4 & 4,3 & 4,8 & 4,2 \\
\hline \multirow{5}{*}{$\begin{array}{l}\text { Ac.P., } \\
\mathrm{mmol}_{\mathrm{c}} \mathrm{dm}^{-3}\end{array}$} & Ap & 166 & 228 & 228 & 64 & 58 & 88 & 58 & 38 & 72 & 42 & 25 & 28 \\
\hline & $\mathrm{AB}$ & 166 & 205 & 253 & 80 & 88 & 150 & 88 & 88 & 88 & 58 & 38 & 58 \\
\hline & BA & 135 & 253 & 228 & 88 & 98 & 109 & 80 & 64 & 72 & 80 & 42 & 52 \\
\hline & Bwl & 98 & 185 & 185 & 52 & 58 & 98 & 52 & 52 & 64 & 52 & 34 & 38 \\
\hline & Bw2 & - & - & - & 42 & 47 & 58 & 47 & 38 & 42 & 42 & 28 & 42 \\
\hline \multirow{5}{*}{$\begin{array}{l}\text { Al trocável, } \\
\mathrm{mmol}_{\mathrm{c}} \mathrm{dm}^{-3}\end{array}$} & Ap & 14 & 20 & 24 & 0 & 0 & 2 & 2 & 0 & 3 & 0 & 0 & 0 \\
\hline & $\mathrm{AB}$ & 16 & 20 & 23 & 5 & 2 & 14 & 4 & 8 & 7 & 2 & 0 & 3 \\
\hline & BA & 13 & 25 & 28 & 6 & 6 & 12 & 5 & 8 & 8 & 8 & 4 & 8 \\
\hline & Bwl & 10 & 20 & 26 & 3 & 4 & 10 & 3 & 4 & 4 & 3 & 3 & 4 \\
\hline & Bw2 & - & 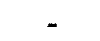 & - & 2 & 2 & 3 & 3 & 3 & 3 & 4 & 0 & 4 \\
\hline \multirow{5}{*}{$\begin{array}{l}\mathrm{MO} \\
\mathrm{g} \mathrm{dm}^{-3}\end{array}$} & $\mathrm{Ap}$ & 47 & 45 & 45 & 29 & 31 & 39 & 33 & 35 & 29 & 30 & 24 & 20 \\
\hline & $\mathrm{AB}$ & 32 & 47 & 36 & 25 & 31 & 24 & 21 & 19 & 20 & 20 & 15 & 15 \\
\hline & BA & 28 & 37 & 33 & 25 & 24 & 27 & 19 & 18 & 17 & 15 & 9 & 13 \\
\hline & Bwl & 18 & 23 & 25 & 13 & 20 & 16 & 13 & 14 & 16 & 11 & 9 & 8 \\
\hline & Bw2 & - & - & - & 9 & 11 & 10 & 12 & 10 & 10 & 11 & 7 & 8 \\
\hline \multirow{5}{*}{$\begin{array}{l}\text { Ca trocável, } \\
\mathrm{mmol}_{\mathrm{c}} \mathrm{dm}^{-3} \text {, }\end{array}$} & Ap & 9 & 9 & 9 & 49 & 55 & 60 & 56 & 58 & 36 & 40 & 44 & 34 \\
\hline & $A B$ & 1 & 8 & 6 & 15 & 21 & 13 & 12 & 11 & 11 & 23 & 11 & 9 \\
\hline & $\mathrm{BA}$ & 1 & 4 & 3 & 6 & 10 & 8 & 10 & 6 & 6 & 4 & 3 & 4 \\
\hline & Bwl & 1 & 1 & 1 & 3 & 7 & 2 & 7 & 4 & 6 & 2 & 2 & 2 \\
\hline & Bw2 & - & - & - & 2 & 2 & 1 & 2 & 2 & 1 & 1 & 3 & 1 \\
\hline \multirow{5}{*}{$\begin{array}{l}\text { Mg trocável, } \\
\text { mmol }_{\mathrm{c}} \mathrm{dm}^{-3}\end{array}$} & Ap & 9 & 11 & 8 & 22 & 26 & 14 & 19 & 25 & 11 & 15 & 17 & 13 \\
\hline & $\mathrm{AB}$ & 2 & 8 & 6 & 9 & 15 & 6 & 6 & 4 & 4 & 14 & 7 & 5 \\
\hline & BA & 1 & 5 & 3 & 5 & 8 & 5 & 5 & 3 & 3 & 3 & 3 & 2 \\
\hline & Bwl & 1 & 1 & 1 & 1 & 6 & 2 & 4 & 3 & 3 & 4 & 3 & 1 \\
\hline & Bw2 & - & - & - & 1 & 2 & 1 & 2 & 3 & 1 & 1 & 2 & 1 \\
\hline & Ap & 3,4 & 4,4 & 2,6 & 4,5 & 1,8 & 2,0 & 4,7 & 2,6 & 1,3 & 3,3 & 3,5 & 3,4 \\
\hline $\mathrm{mmol} \mathrm{dm}^{-3}$ & $A B$ & 1,6 & 3,0 & 2,6 & 2,2 & 2,0 & 1,9 & 2 & 1,9 & 0,5 & 2,2 & 2,1 & 2,4 \\
\hline & BA & 1,3 & 2,5 & 1,8 & 1,4 & 1,2 & 1,5 & 1,7 & 2,2 & 0,7 & 1,2 & 1,8 & 2 \\
\hline & Bwl & 0,6 & 1,1 & 1,2 & 0,3 & 0,4 & 0,6 & 0,8 & 2,6 & 0,5 & 0,5 & 1,5 & 1,1 \\
\hline & Bw2 & - & - & - & 0,2 & 0,2 & 0,2 & 0,9 & 1,7 & 0,2 & 0,2 & 0,5 & 0,2 \\
\hline P disponível, & $\mathrm{Ap}$ & 6 & 6 & 6 & 8 & 11 & 18 & 51 & 43 & 21 & 21 & 35 & 16 \\
\hline $\mathrm{mg} \mathrm{dm}^{-3}$ & $\mathrm{AB}$ & 3 & 5 & 6 & 4 & 5 & 7 & 3 & 5 & 4 & 5 & 4 & 4 \\
\hline & BA & 3 & 4 & 4 & 2 & 3 & 3 & 2 & 2 & 3 & 2 & 2 & 3 \\
\hline & Bwl & 2 & 2 & 2 & 2 & 2 & 2 & 1 & 2 & 2 & 2 & 2 & 2 \\
\hline & Bw2 & - & - & - & $\overline{1}$ & 2 & 1 & 2 & 2 & 2 & 2 & 2 & 2 \\
\hline Soma de & Ap & 21,4 & 24,4 & 19,6 & 75,5 & 82,8 & 76 & 79,7 & 85,6 & 48,3 & 58,3 & 64,5 & 50,4 \\
\hline Bases. & $A B$ & 4,6 & 19,0 & 14,6 & 26,2 & 38,0 & 20,9 & 20,0 & 16,9 & 15,5 & 39,2 & 20,1 & 16,4 \\
\hline Bases, & BA & 3,3 & 11,5 & 7,8 & 12,4 & 19,2 & 14,5 & 16,7 & 11,2 & 9,7 & 8,2 & 7,8 & 8 \\
\hline $\mathrm{mmol}_{c} \mathrm{dm}^{-3}$ & Bwl & 2,6 & 3,1 & 3,2 & 4,3 & 13,4 & 4,6 & 11,8 & 9,6 & 9,5 & 6,5 & 6,5 & 4,1 \\
\hline & Bw2 & - & & - & 3,2 & 4,2 & 2,2 & 4,9 & 6,7 & 2,2 & 2,2 & 5,5 & 2,2 \\
\hline CTC, & Ap & 187 & 252 & 248 & 140 & 141 & 164 & 138 & 124 & 120 & 100,3 & 89,5 & 78,4 \\
\hline $\mathrm{mmol} \mathrm{dm}^{-3}$ & $A B$ & 171 & 224 & 268 & 106 & 126 & 171 & 108 & 105 & 104 & 97,2 & 58,1 & 74,4 \\
\hline & BA & 138 & 265 & 236 & 100 & 117 & 124 & 97 & 75 & 82 & 88,2 & 49,8 & 60 \\
\hline & Bwl & 101 & 188 & 188 & 56 & 71 & 103 & 64 & 62 & 74 & 58,5 & 40,5 & 42,2 \\
\hline & Bw2 & - & - & - & 45 & 51 & 60 & 52 & 45 & 44 & 44,2 & 33,5 & 44,2 \\
\hline $\mathrm{SiO}_{2} \mathrm{~g} \mathrm{~kg}^{-1}$ & Bwl & 160 & 171 & 155 & 145 & 123 & 160 & 68 & 70 & 72 & 75 & 51 & 61 \\
\hline $\mathrm{Al}_{2} \mathrm{O}_{3} \mathrm{~g} \mathrm{~kg}^{-1}$ & Bwl & 226 & 238 & 218 & 283 & 268 & 282 & 201 & 173 & 190 & 177 & 142 & 112 \\
\hline $\mathrm{Fe}_{2} \mathrm{O}_{3} \mathrm{~g} \mathrm{~kg}^{-1}$ & Bwl & 170 & 112 & 86 & 150 & 204 & 153 & 83 & 58 & 68 & 66 & 47 & 35 \\
\hline $\mathrm{TiO}_{2} \mathrm{~g} \mathrm{~kg}^{-1}$ & Bwl & 19,0 & 15,3 & 9,6 & 13,9 & 17,2 & 15,3 & 7,4 & 6,8 & 7,7 & 7,0 & 5,4 & 4,7 \\
\hline $\mathrm{MnO}, \mathrm{g} \mathrm{kg}^{-1}$ & Bwl & 0,6 & 0,2 & 0,2 & 0,3 & 0,3 & 0,2 & 0,1 & 0,1 & 0,1 & 0,1 & 0.1 & 0,1 \\
\hline $\mathrm{Ki}$ & Bwl & 1,20 & 1,22 & 1,21 & 0,87 & 0,78 & 0,97 & 0,58 & 0,69 & 0,65 & 0,72 & 0,61 & 0,92 \\
\hline $\mathrm{Kr}$ & Bwl & 0,81 & 0,94 & 0,96 & 0,65 & 0,52 & 0,72 & 0,45 & 0,57 & 0,52 & 0,58 & 0.50 & 0,77 \\
\hline
\end{tabular}




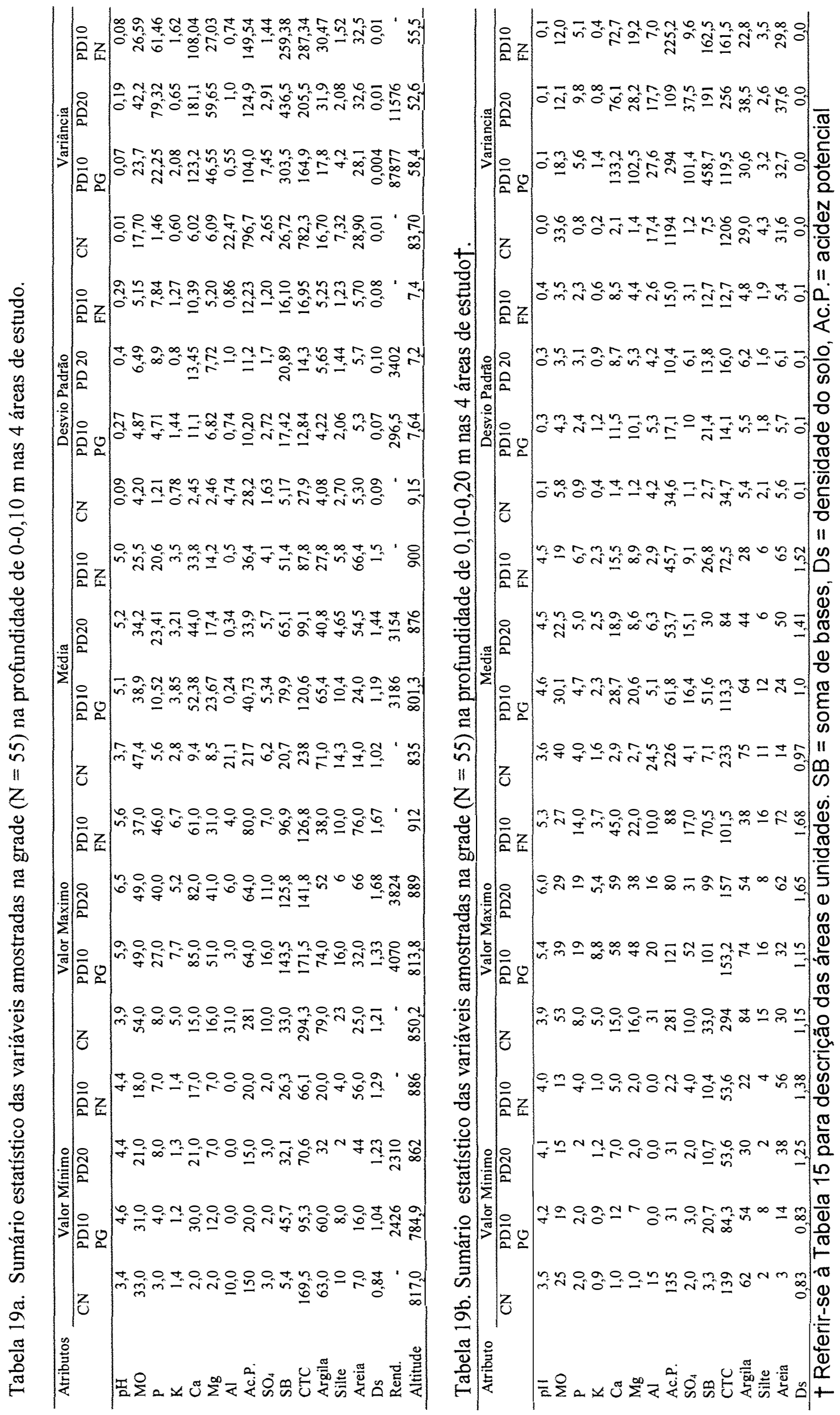


$\mathrm{pH}$
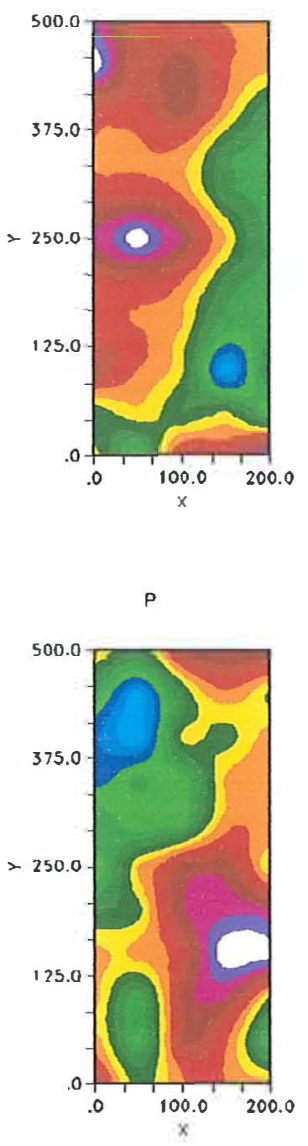

H

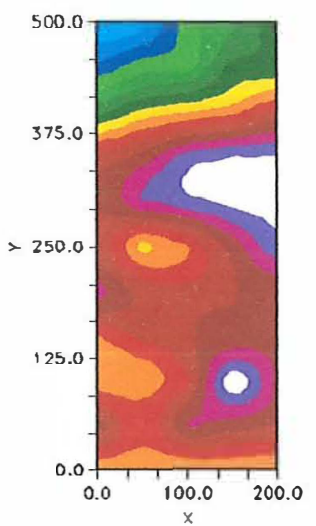

MO
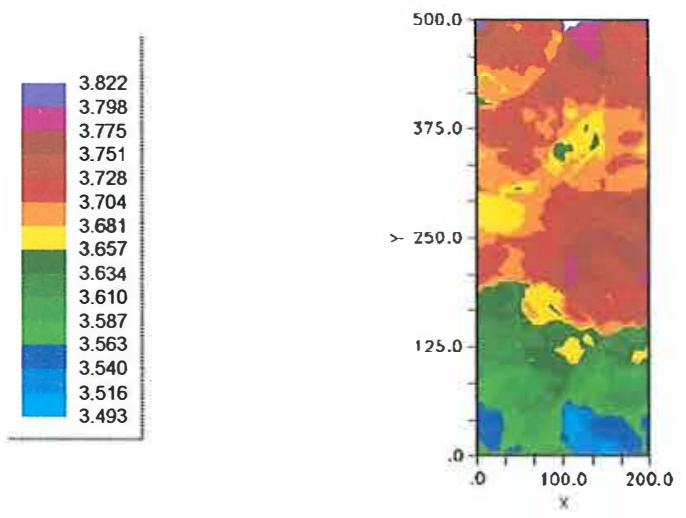

A

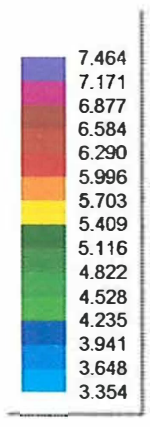

SB
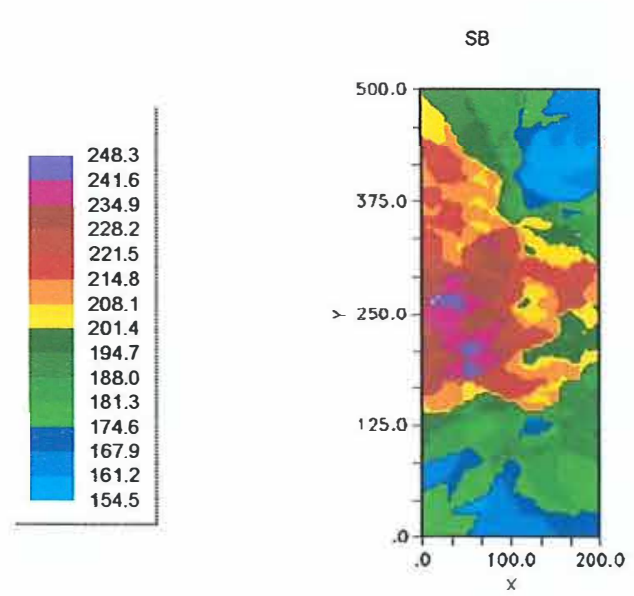

\begin{tabular}{l}
3 \\
6 \\
9 \\
2 \\
5 \\
8 \\
1 \\
4 \\
7 \\
0 \\
3 \\
6 \\
9 \\
2 \\
5 \\
\hline
\end{tabular}
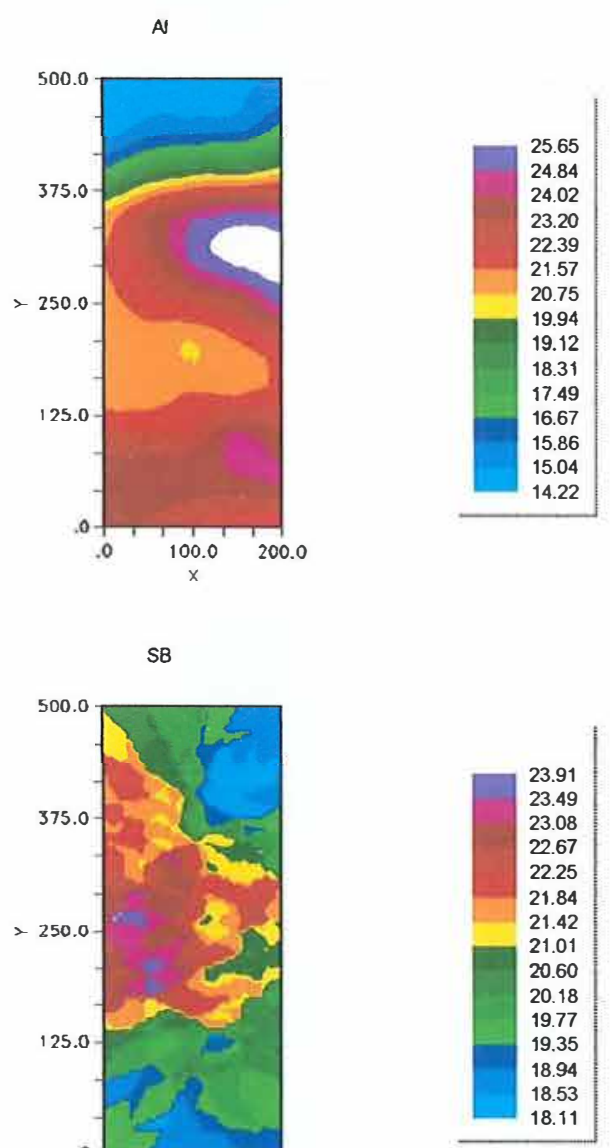

Figura 20a. Mapas de isolinhas de atributos do solo interpolados por krigagem da área de campo nativo (CN), na profundidade de 0-0,10 m. Referir-se à Tabela 15 para descrição da área e unidades. 

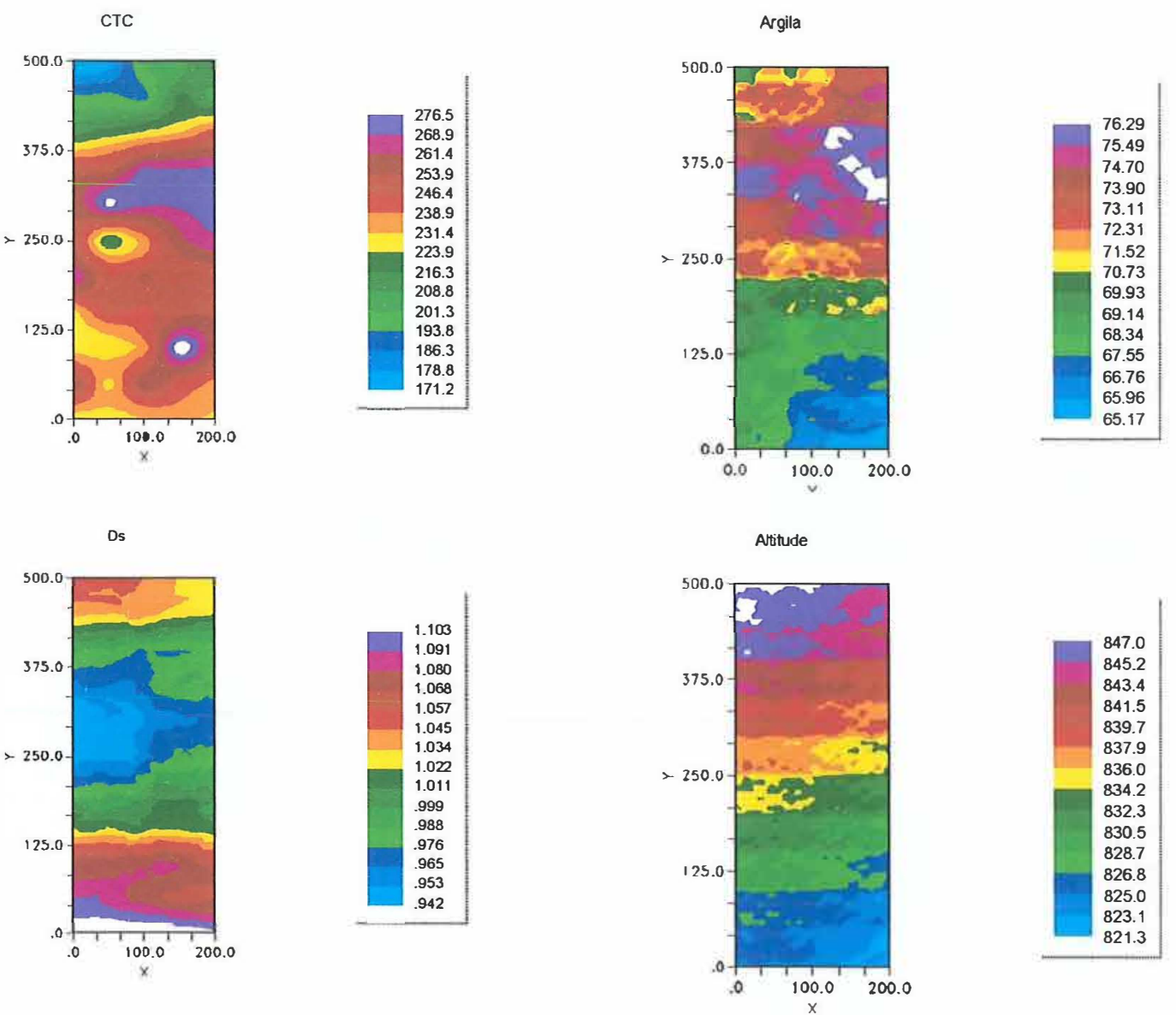

Figura 20b. Mapas de isolinhas de atributos do solo e altitude interpolados por krigagem da área de campo nativo $(\mathrm{CN})$, na profundidade de $0-0,10$ $\mathrm{m}$. Referir-se à Tabela 15 para descrição da área e das unidades. 
$\mathrm{\rho H}$

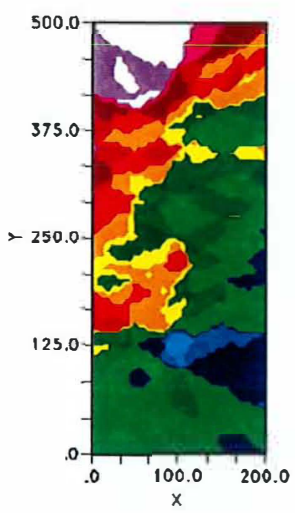

$p$

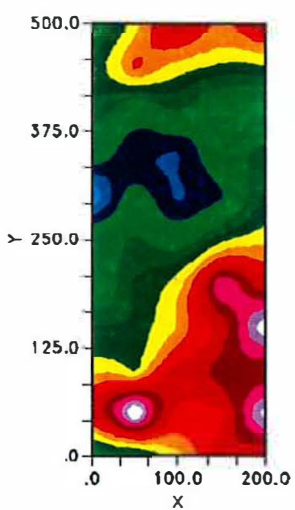

H

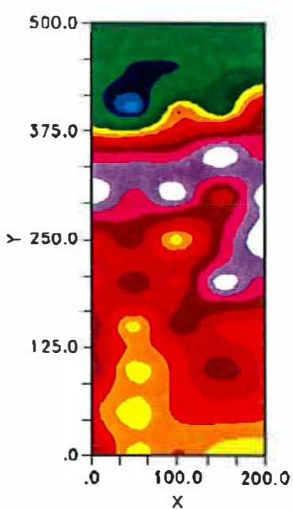

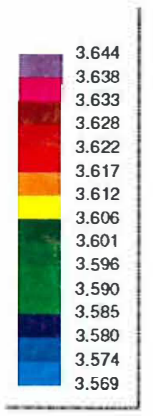
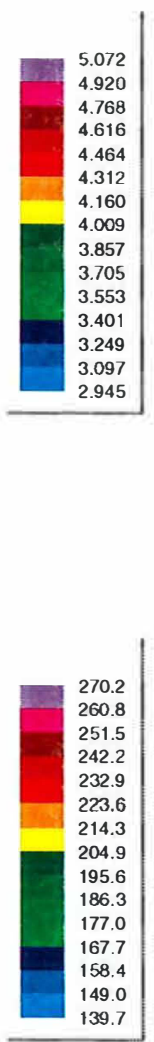

MO
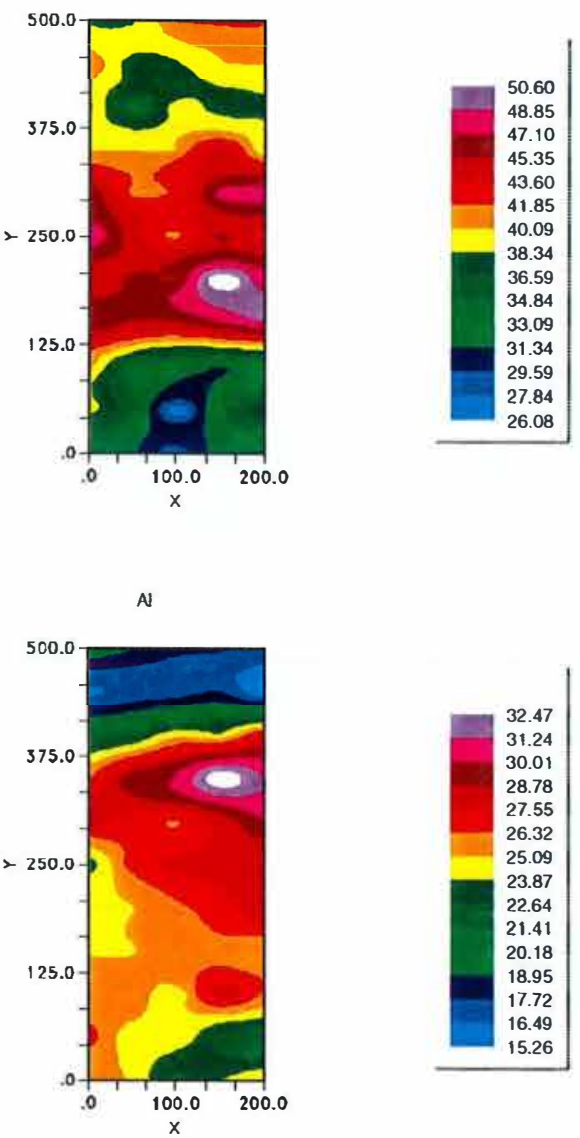

SB

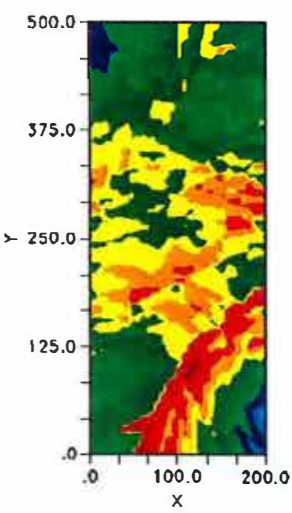

Figura 21a. Mapas de atributos do solo interpolados por krigagem da área de campo nativo $(\mathrm{CN})$, na profundidade de $0,10-0,20 \mathrm{~m}$. Referir-se à Tabela 15 para descriçao da área e das unidades. 

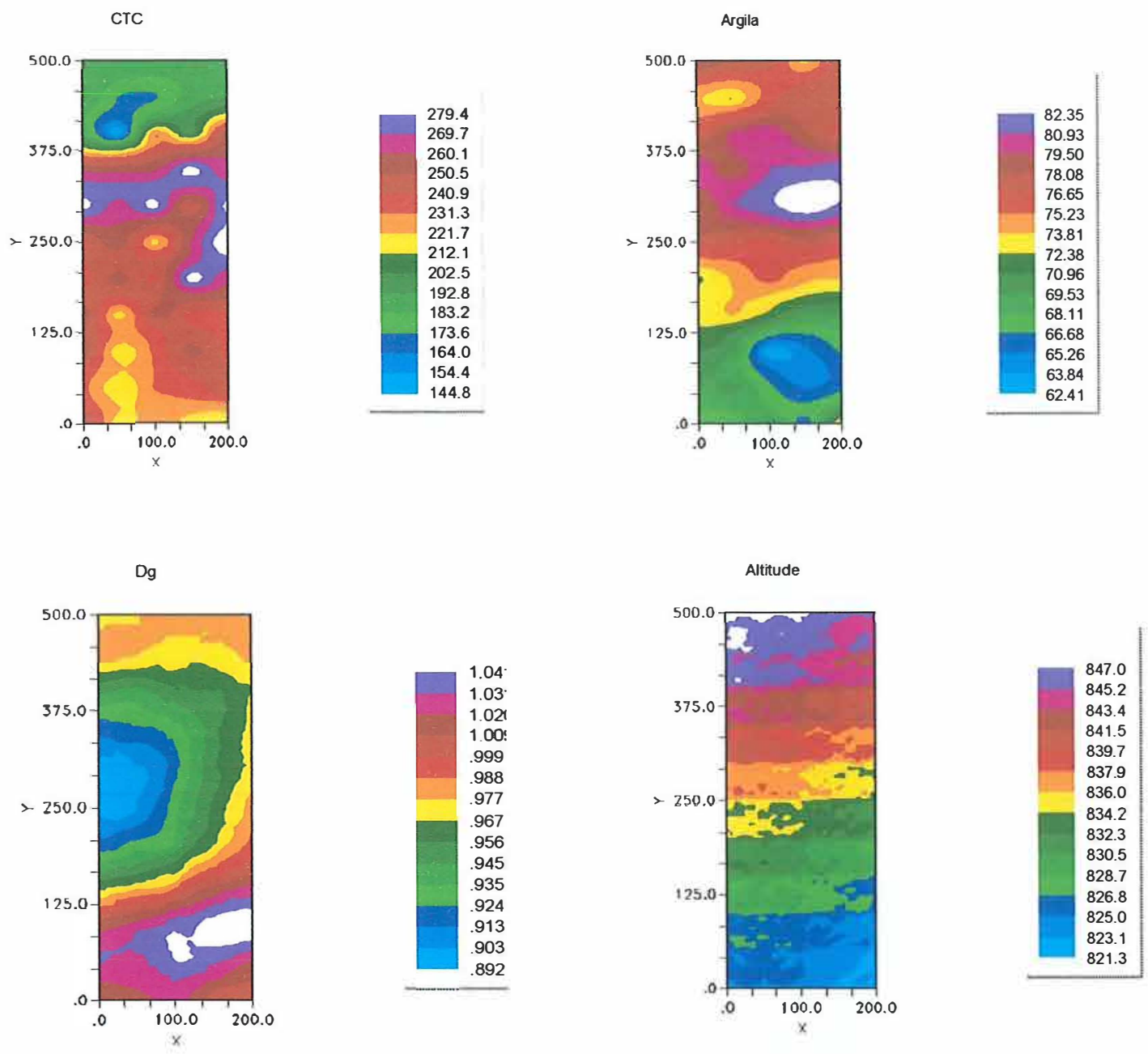

Figura 21b. Mapas de atributos do solo e altitude interpolados por krigagem da área de campo nativo $(\mathrm{CN})$, na profundidade de 0,10-0,20 m. Referir-se à Tabela 15 para descrição da área e das unidades. (cont.) 
$\mathrm{pH}$

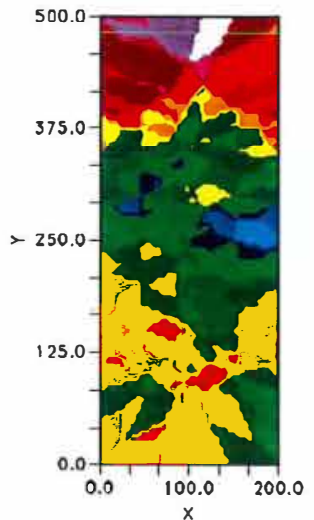

$P$

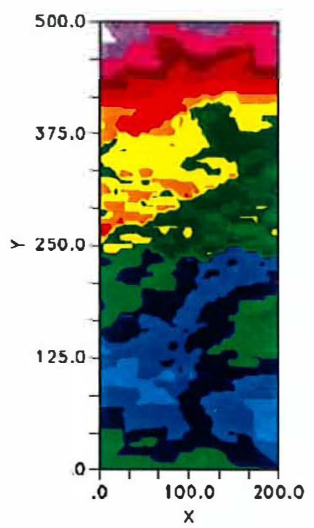

CTC

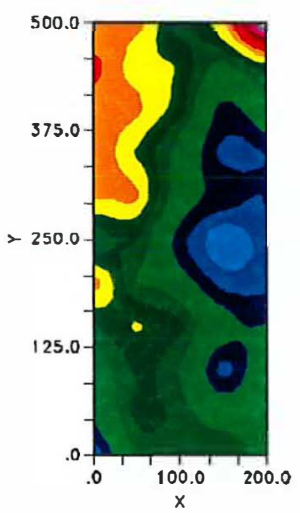

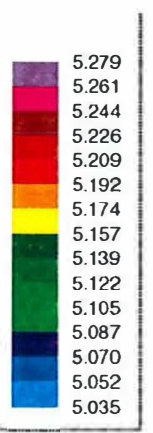
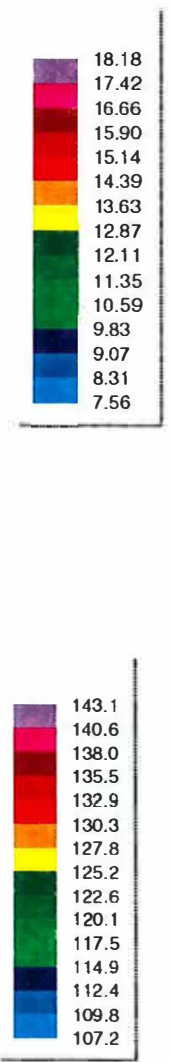

MO
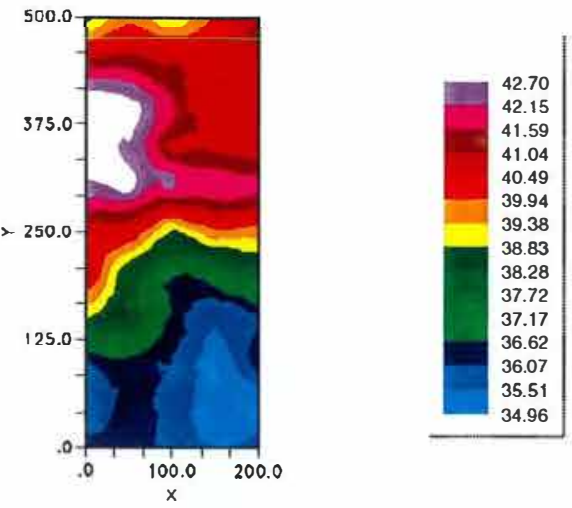

SB
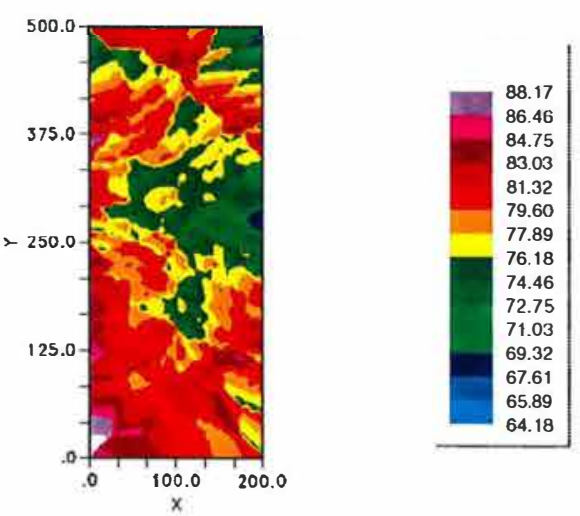
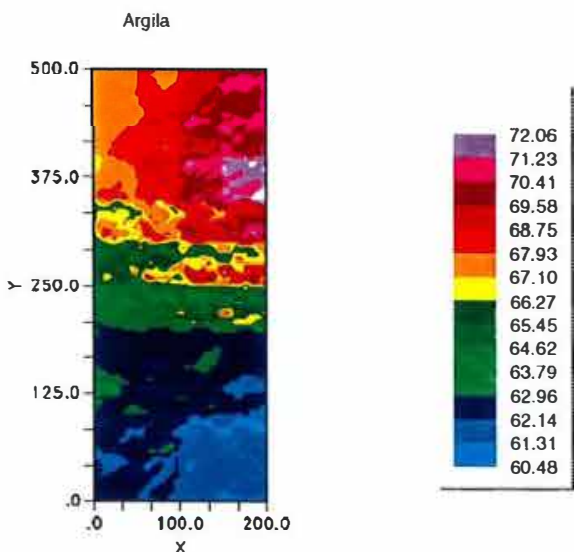

Figura 22a. Mapas de atributos do solo interpolados por krigagem da área PDI0PG, na profundidade de 0-0,10 m. Referir-se à Tabela 15 para descrição da área e das unidades. 

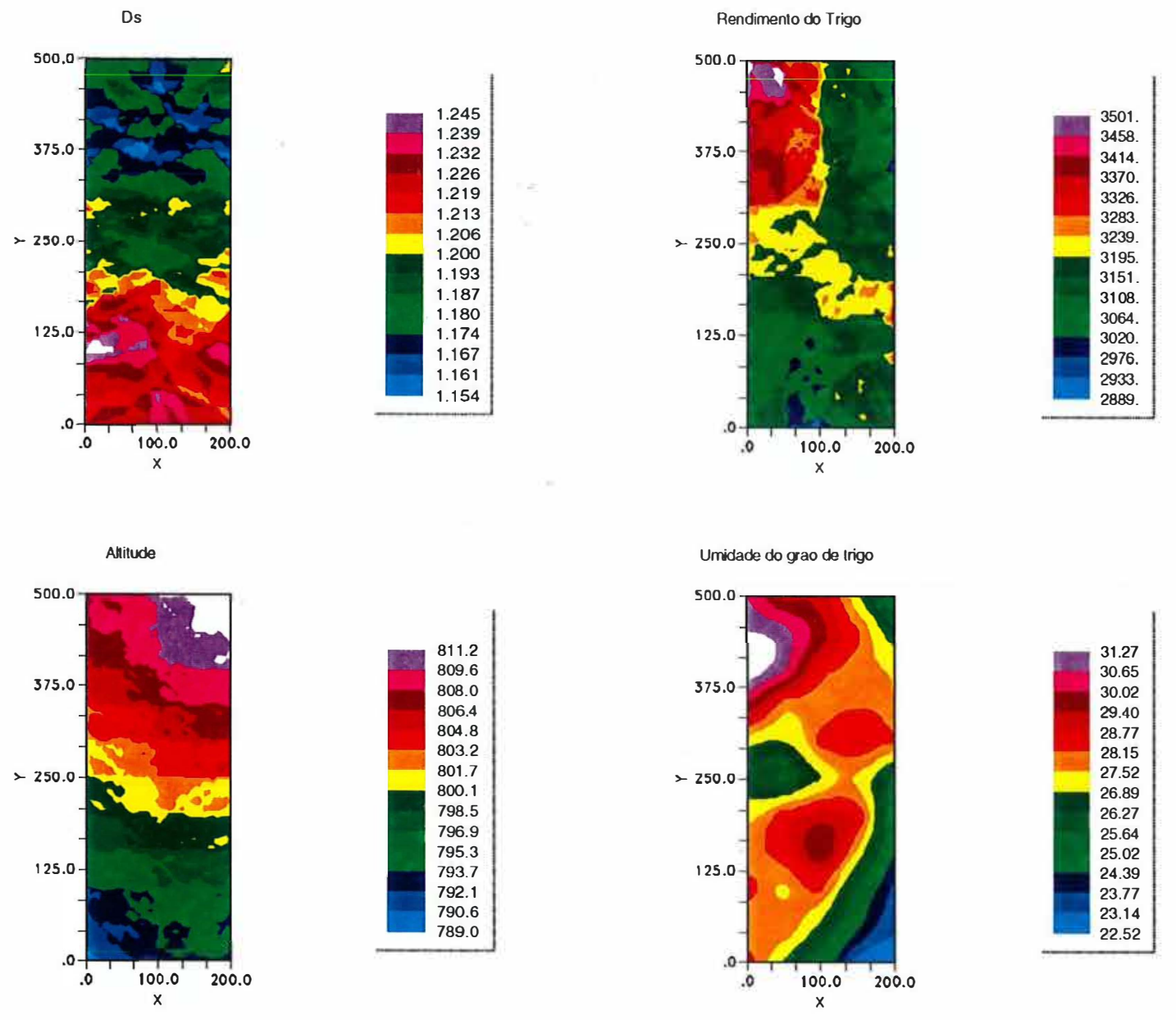

Figura 22b. Mapas de isolinhas de atributos do solo, plantas e altitude interpolados por krigagem da área PD10PG, na profundidade de 0-0,10 m. Referir-se à Tabela 15 para descrição da área e das unidades (cont.). 

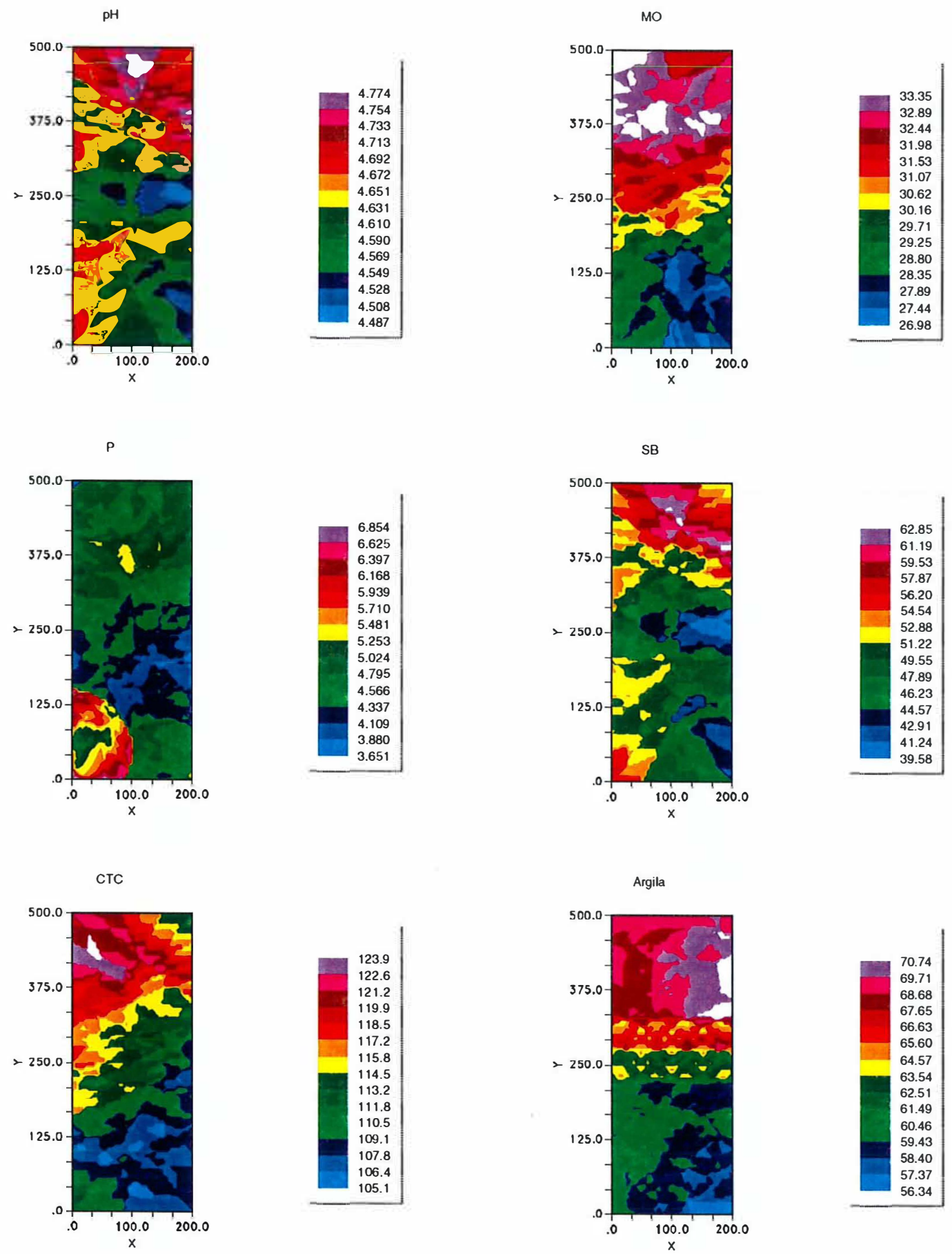

Figura 23a. Mapas de atributos do solo interpolados por krigagem da área PD10PG, na profundidade de 0,10-0,20 m. Referir-se à Tabela 15 para descriçao da área e das unidades. 
Dg

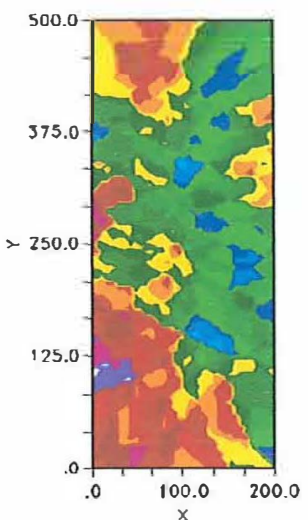

A

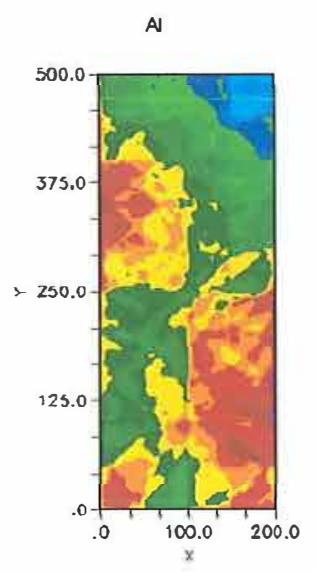

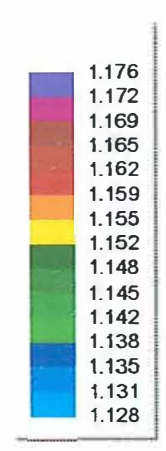

Figura 23b. Mapas de atributos do solo interpolados por krigagem da área PD10PG, na profundidade de 0,10-0,20 m. Referir-se à Tabela 15 para descrição da área e das unidades. (cont.) 

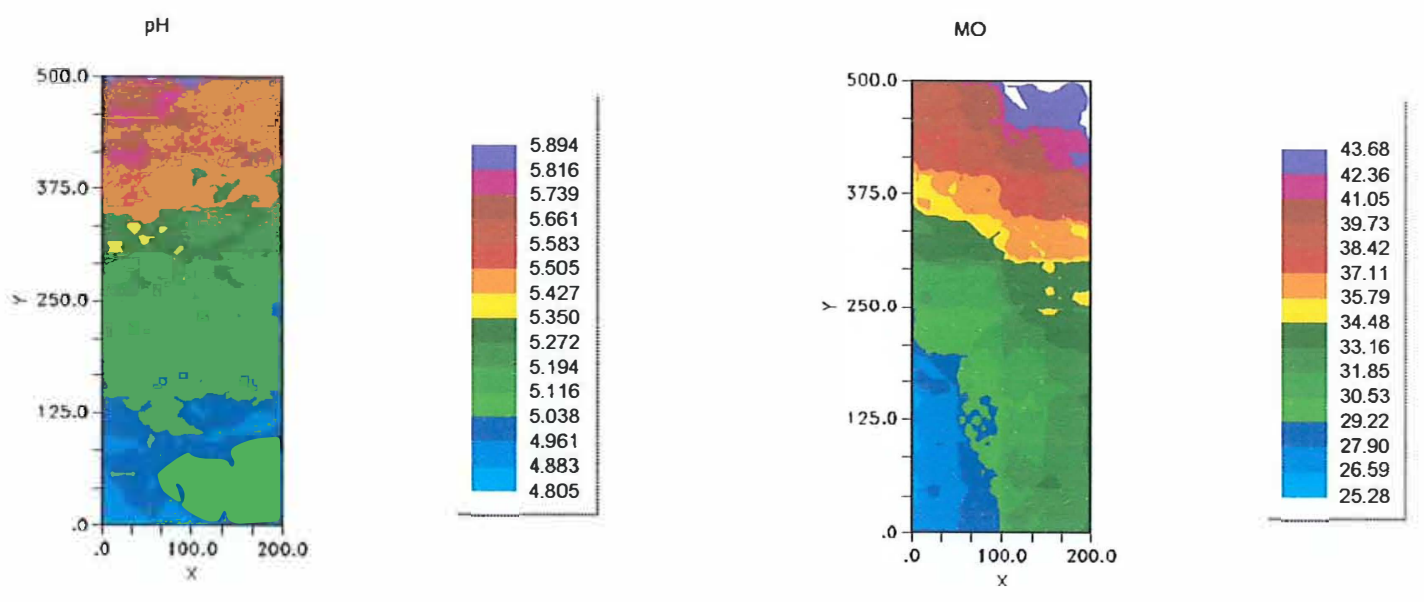

P
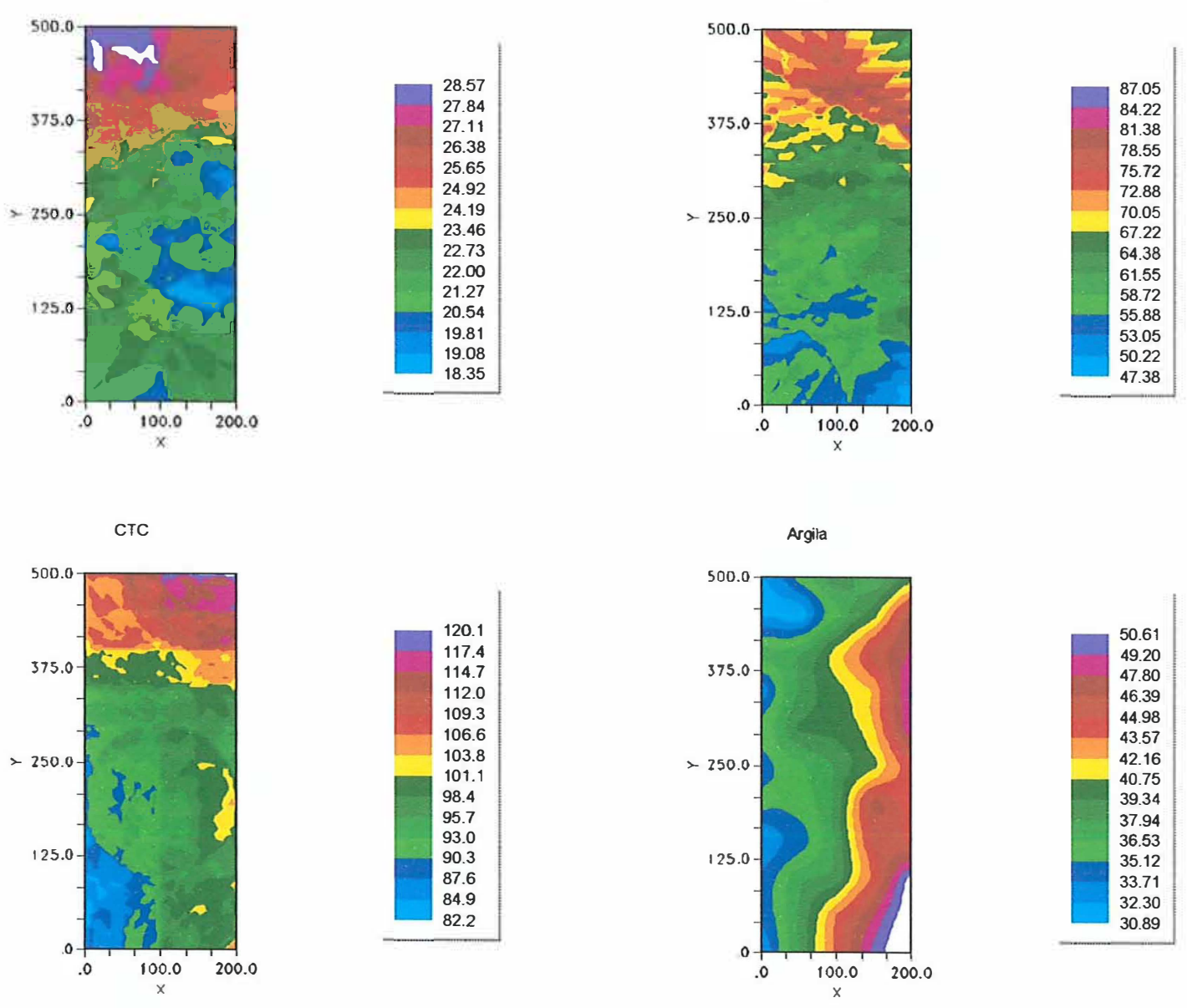

Figura 24a. Mapas de atributos do solo interpolados por krigagem da área PD20, na profundidade de $0-0,10 \mathrm{~m}$. Referir-se à Tabela 15 para descriçao da área e das unidades. 

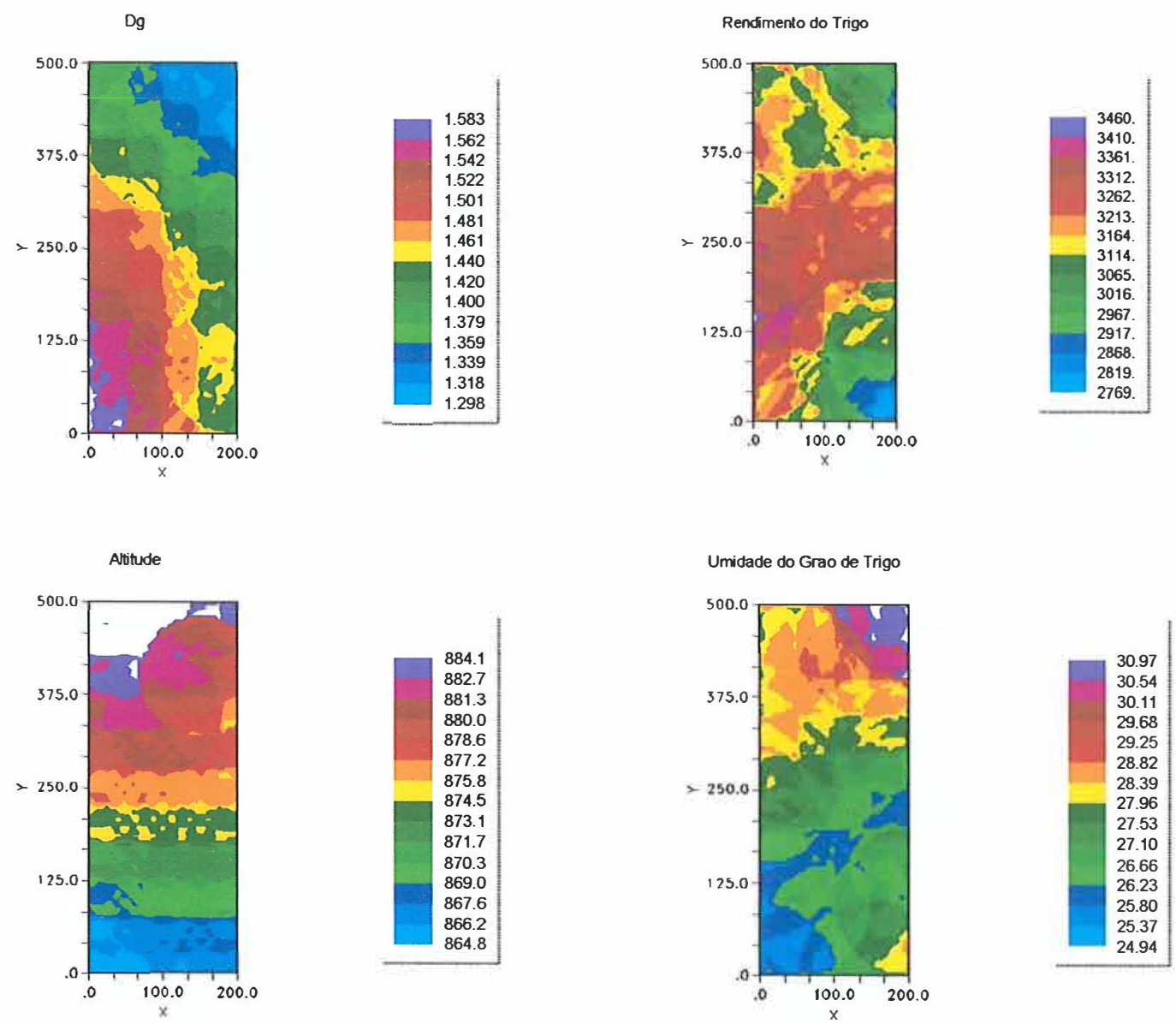

Figura 24b. Mapa de isolinhas de atributos do solo, plantas e altitude, interpolados por krigagem, da área PD20 na profundidade de 0-0,10 m. (cont.) 
$\mathrm{pH}$
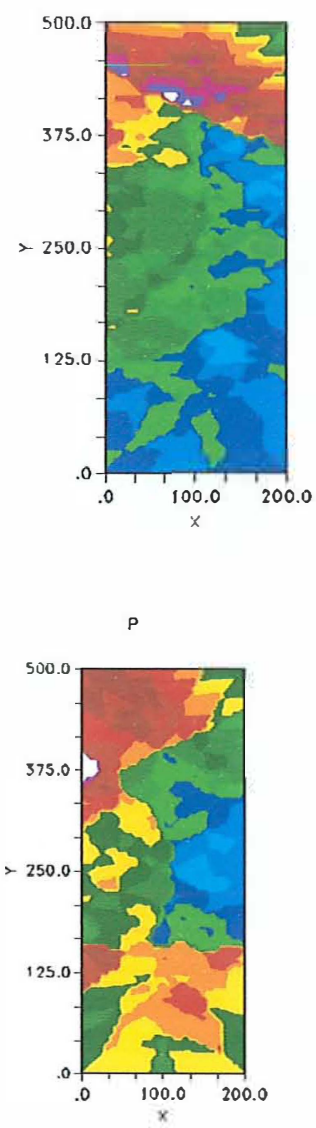

CTC

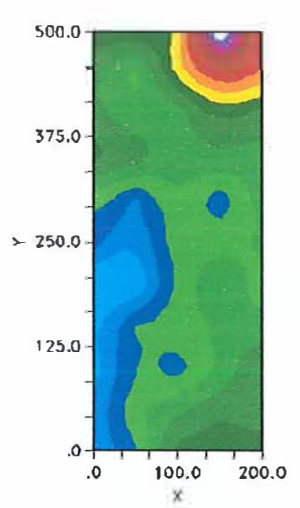

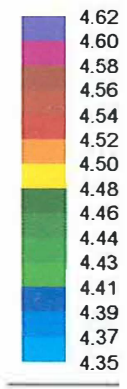
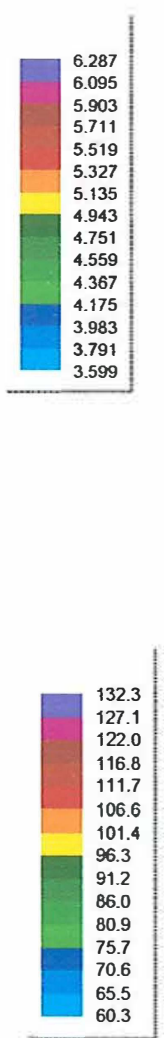

MO

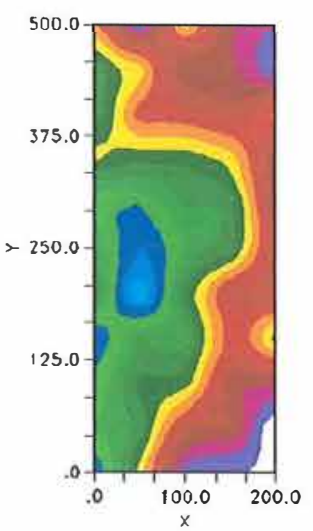

SB
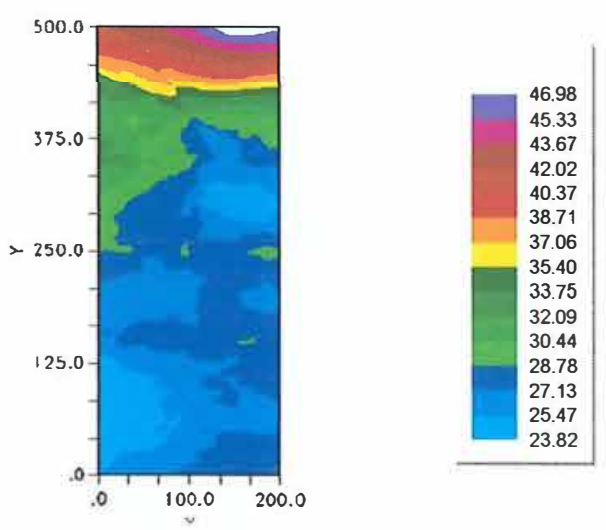

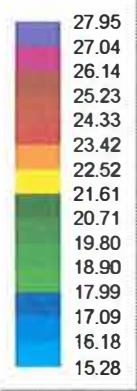

.18
.28
Argila

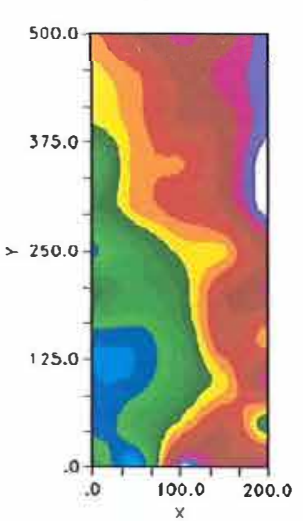

Figura 25a. Mapas de atributos do solo interpolados por krigagem da área PD20, na profundidade de $0,10-0,20 \mathrm{~m}$. Referir-se à Tabela 15 para descriçao da área e das unidades. 

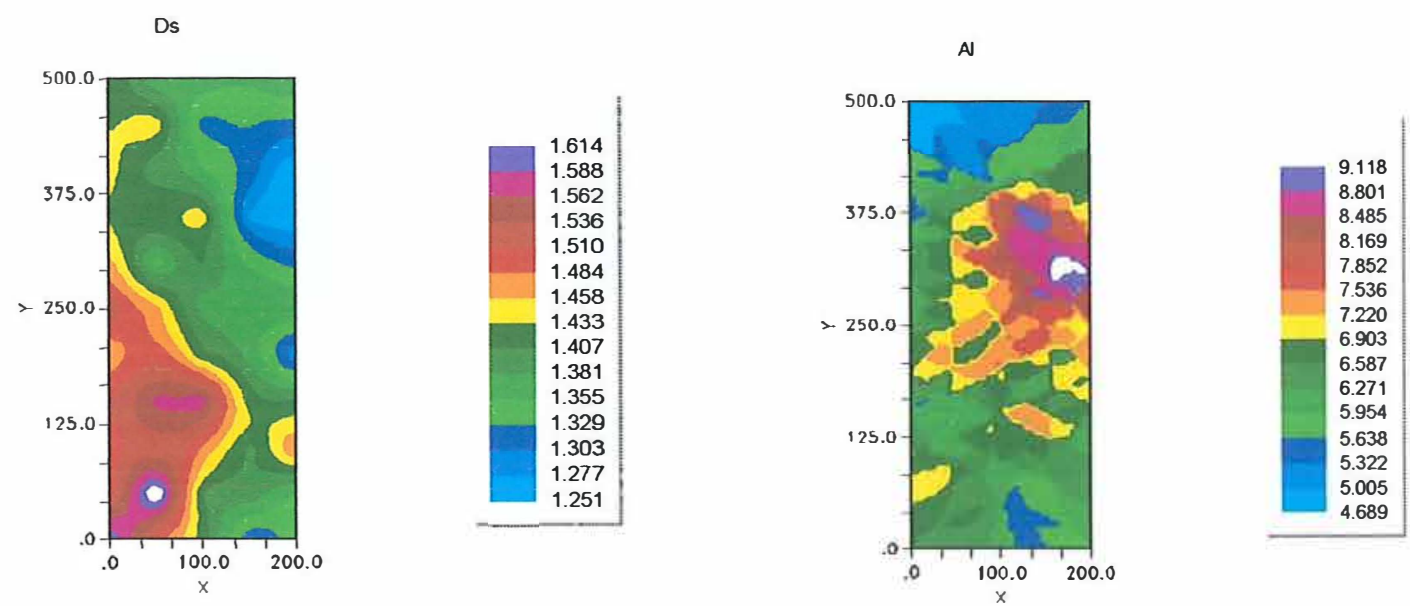

Figura 25b. Mapas de atributos do solo interpolados por krigagem da área PD20, na profundidade de $0,10-0,20 \mathrm{~m}$. Referir-se à Tabela 15 para descrição da área e das unidades. (cont.) 
$\mathrm{pH}$

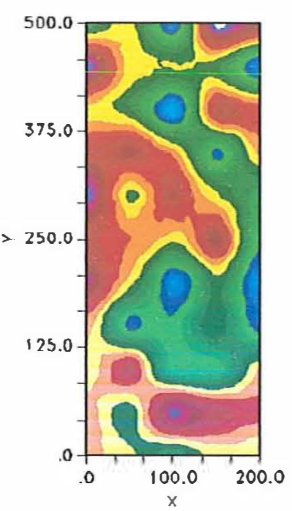

$\mathbf{P}$

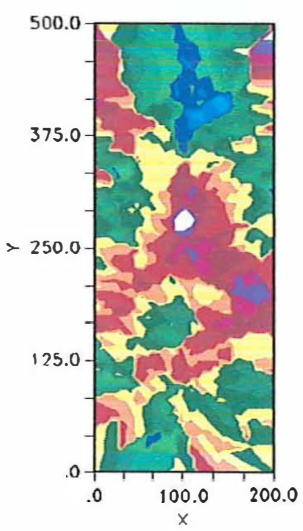

CTC

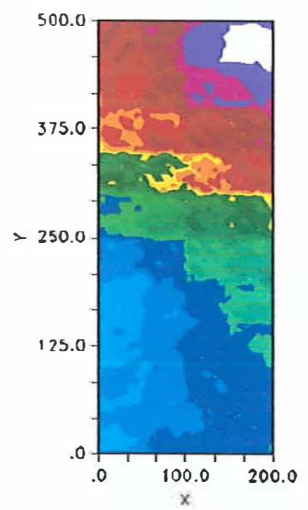

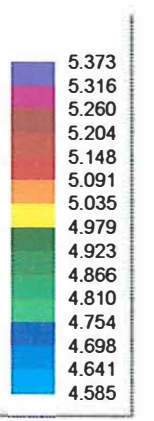

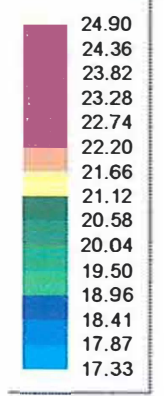

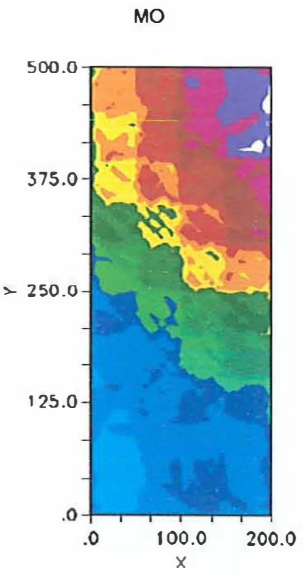

SB

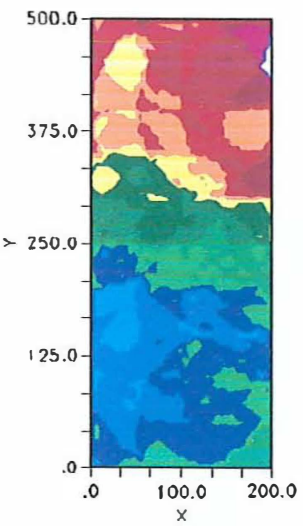

Argila
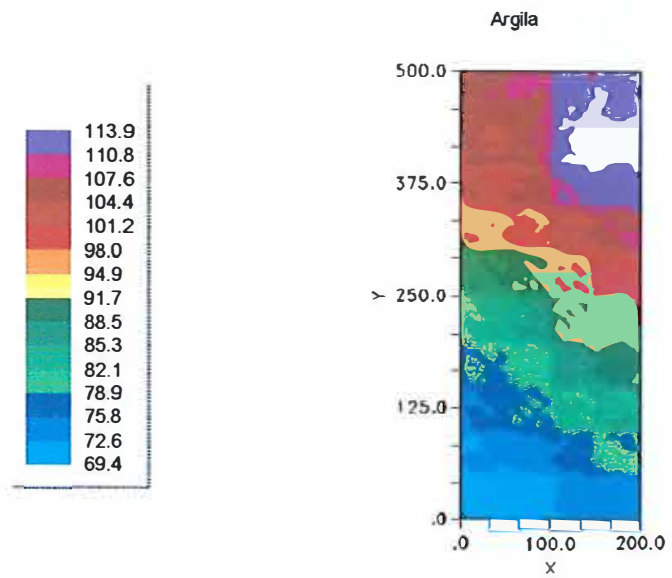

Figura 26a. Mapas de atributos do solo interpolados por krigagem da área PD10FN, na profundidade de $0-0,10 \mathrm{~m}$. Referir-se à Tabela 15 para descrição da área e das unidades. 
Ds

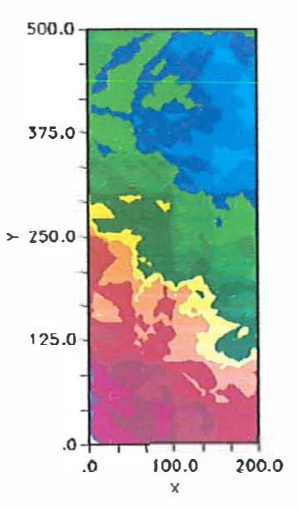

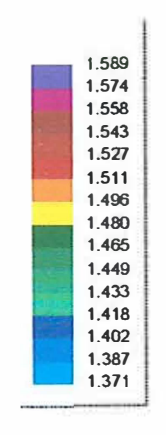

Altitude

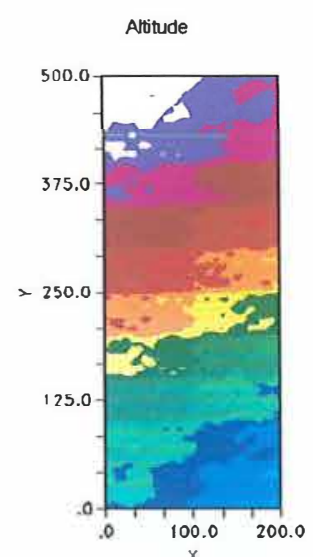

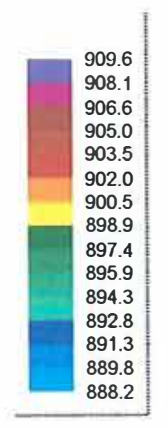

Figura 26b. Mapas de atributos do solo interpolados por krigagem da área PD10FN, na profundidade de $0-0,10 \mathrm{~m}$. Referir-se Tabela 15 para descrição da área e das unidades. (cont.) 

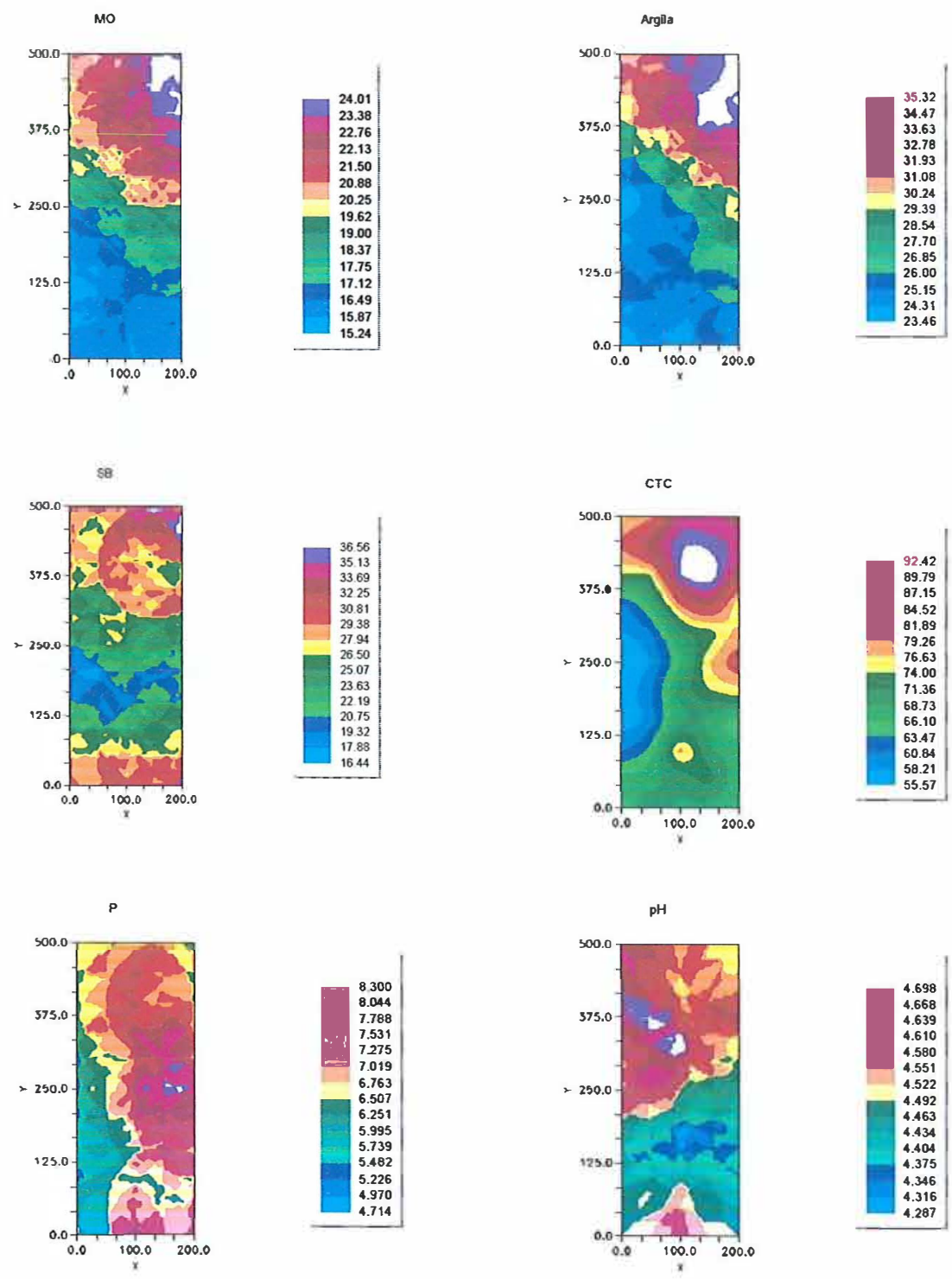

Figura 27. Mapas de atributos do solo interpolados por krigagem da área PD10FN, na profundidade de $0,10-0,20 \mathrm{~m}$. Referir-se à Tabela 15 para descrição da área e das unidades. 


\section{REFERÊNCIAS BIBLIOGRÁFICAS}

ADDISCOTT, T.M.; WAGENET, R.J. Concepts of solute leaching in soils: a review of modelling approaches. Journal of Soil Science, v.36, p.411-424, 1985.

AUERNHAMMER, H.; DEMMEL, M.; MUHR, T.; ROTTMEIER, J.; WILD, K. GPS for yield mapping on combines. Compu ters and Eletronics in Agriculture, v.11, p.54-68, 1994.

AUSTRALIAN CENTER FOR PRECISION AGRICULTURE. Fuzme, Fuzzy kMeans with Extragrades. Sidney, 1999.

BHATTI, A.U.; MULL.A, D.J.; FRAZIER, B.E. Estimation of soil properties and wheat yields on complex eroded hills using geostatistics and thematic mapper images. Remote Sensing Environmental, v.37, p.181-191, 1991.

BLAKE, G.R.; HARTGE, K.H. Bulk density. In: KLUTE A. (Ed.) Methods of soil analysis. 2. ed. Madison: American Society of Agronomy, 1986. pt.1: Physical and mineralogical methods, p.364-367. (Agronomy, 9).

BURGESS, T. M.; WEBSTER, R. Optimal interpolation and isorithmic mapping of soil properties. The semivariogram and punctual kriging. Journal of Soil Science, v.33, p.315-331, 1980.

BURROUGH, P.A. Fuzzy mathematic methods for soil survey and land evaluation. Journal of Soil Science, v.40, p.447-492, 1989. 
BURROUGH, P.A. Soil variability: a late $20^{\text {th }}$ century view. Soils and Fertilizers, v.56, p.529-562, 1993.

BURROUGH, P.A.; BOUMA, J.; YATES, S.R. The state of the art in pedometrics. Geoderma, v.62, p.311-326, 1994.

BURROUGH, P.A.; MCDONNELL, R.A. Principles of Geographical Information Systems. New York: Oxford University Press, 1998, 333p.

BURROUGH, P.A; VAN GANNS, P.F.M; HOOTSMANS, R. Continuous classification in soil survey: spatial correlation, confusion and boundaries. Geoderma, v.77, p.115-135, 1997.

BRUIN, S. de; STEIN, A. Soil-landscape modeling using fuzzy c-means clustering of attribute data derived from a digital elevation model (DEM). Geoderma, v.83, p.17-33, 1998.

CAHN, M.D.; HUMMEL, J.W.; BROUER, B. H. Spatial analysis of soil fertility for site-specific crop management. Soil Science Society of America Journal, v.58, p.1240-1248, 1994.

CAMBARDELLA, C.A.; MOORMAN, T.B.; NOVAK, J.M.; PARKIN, T.B.; KARLEN, R.F.; KONOPKA, A.E. Field-scale variability of soil properties in central Iowa soils. Soil Science Society of America Journal, v.58, p.1501-1511, 1994.

CAMBARDELLA, C.A.; KARLEN, D.L. Spatial Analysis of soil fertility parameters. Precision Agriculture, v.1, p.5-14, 1999. 
CIHA, A.J. Slope position and grain yield of soft white winter wheat. Agronomy Journal, v.76, p.193-196, 1984.

COMISSAO DE FERTILIDADE DO SOLO-RS/SC. Recomendações de adubação e calagem para os Estados do Rio Grande do Sul e Santa Catarina. 3.ed. Passo Fundo, SBCS - Nucleo Regional Sul, 1995. 224p.

CONACHER, A.J.; DALRYMPLE, J.B. The nine unit landsurface model: An approach to pedogeomorphic research. Geoderma, v.18, p.1-154, 1977.

CORA, J.E. The potential for site-specific management of soil and corn yield variability induced by tillage. East Lansing, 1997. 104p. Thesis (Ph D.) - Michigan State University.

CHRISTOPHERSEN, N.; NEAL, C. Linking hydrological, geochemical, and soil chemical process on the catchment scale: An interplay between modeling and field work. Water Resources Research, v.26, p.3077-3086, 1990.

CLINE, M.G. Basic principles of soil classification. Soil Science, v.67, p.81-91, 1949.

CLINE, M.G. The changing model of soil. Soil Science Society of America Proceedings, v.25, p.442-446, 1961.

DANIELS, R.B.; GAMBLE, E.E. Relations between stratigraphy, geomorphology and soils in costal plain areas of southeastern U.S.A. Geoderma, v.21, p.41-65, 1978.

DANIEL, R.B.; GILLIAM, J.W.; KASSEL, D.K.; NELSON, L.A. Soil erosion class and landscape position in North Carolina Piedmont. Soil Science Society of America Journal, v.49, p.991-995, 1985. 
DAVIES, B.E.; GAMM, S.A. Trend surface analysis applied to soil reaction values.

Geoderma, v.3, p.223-231, 1970.

DERPSCH, R.; SIDIRAS, N.; ROTH, C.H. Results of studies made from 1977 to 1984 to control erosion by cover crops and no-tillage techniques in Paraná, Brazil. Soil \& Tillage Research, v.8, p.253-263, 1986.

DIKAU, R. The application of a digital relief model to landform analysis in geomorphology. In: RAPER, J. (Ed.) Three-dimensional applications in geographic information systems. New York: Taylor and Francis, 1989. p.51-77.

DOBERMANN, A.; OBERTHUR, T. Fuzzy mapping of soil fertility - a case study on irrigated riceland in the Philippines. Geoderma, v.77, p.317-339, 1997.

EMPRESA BRASILEIRA DE PESQUISA AGROPECUÁRIA. Centro Nacional de Pesquisa de Solos (Rio de Janeiro, RJ). Manual de métodos de análise de solo. 2. ed. rev. atual. Rio de Janeiro, 1997. 212p.

EMPRESA BRASILEIRA DE PESQUISA AGROPECUÁRIA - EMBRAPA. Centro Nacional de Pesquisa de Solos (Rio de Janeiro, RJ). Sistema Brasileiro de Classificação de Solos. Brasília: Embrapa Produção de Informação; Rio de Janeiro: Embrapa Solos, 1999. 412p.

ENTZ, T.; CHANG. C. Evaluation of soil sampling schemes for geostatistical analyses: A case study for soil bulk density. Canadian Journal of Soil Science, v. 71, p.165-176, 1991.

ENVIRONMENTAL SYSTEMS RESEARCH INSTITUTE. Arc View GIS, version 3.2, Michigan, 1999 
FEDERAÇÃO BRASILEIRA DE PLANTIO DIRETO NA PALHA. Evolução da área de plantio direto no Brasil. http://www.agri.com.br/febrapdp/pd, (25 ago. 2000).

FITZPATRICK, E.A. Soil Horizon Designation and classification. Wageningen: International Soil Reference and Information Center, 1988. 1v.

FREISSINET, C.; ERLICH, M.; VAUCLIN, M. A fuzzy logic-based approach to assess imprecision of soil water contamination modeling. Soil \& Tillage Research, v.47, p.11-17, 1998.

GAMMA DESIGN SOFTWARE. GS+ - Professional geostatistics for the environmental sciences, version 3.1.7. Plainwell, 1998.

GOERING, C.E. Recycling a concept. Agricultural Engineering, Nov., p. 25, 1993.

GOLDEN SOFTWARE INCORPORATION. Surfer - Surface Mapping System, version 7.0, Golden, 1999.

GOOVAERTS, P. Geostatistics for natural resources evaluation. New York : Oxford University Press, 1997, 483p.

GRUIJTER, J.J. de; WALVOORT, D.J.J.; VAN GAANS, P.F.M. Continuous soil maps - a fuzzy set approach to bridge the gap between aggregation levels of process and distribution models. Geoderma, v.77, p.169-195, 1997.

HALL, G.F.; OLSON, C.G. Predicting variability of soils from landscape models. In: SPATIAL VARIABILITY OF SOILS AND LANDFORMS. Madison, 1991. Proceedings. Madison: Soil Science Society of America, 1991, p.9-24. 
HAIRSTON, A. B.; GRIGAL, D. F. Topographic influences on soils and trees within single mapping units on a sandy outwash landscape. Forest Ecology Management v.43, p.35-45, 1991.

HANNA, A.Y.; HARLAN, P.W.; LEWIS, D.T. Soil available water as influenced by landscape position and aspect. Agronomy Journal, v.74, p.999-1004, 1982.

HOLZHEY, S. Soil resources variability: Working group report. In: SOIL SPECIFIC CROP MANAGEMENT: A workshop on research and development issues. Madison, 1992. Proceedings. Madison: American Society of Agronomy,1993, p.69-75.

HOOSBEEK, M.R.; BRYANT, R.B. Towards the quantitative modeling of pedogenesis - a review. Geoderma, v.55, p.183-210, 1992.

HUGGETT, R.J. Soil landscapes systems: A model of soil genesis. Geoderma, v.13, p.1-22, 1975.

IRVIN B.J.; VENTURA, S.J.; SLATER, B.K. Fuzzy and isodata classification of landform elements from digital terrain data in Pleasant Valley, Wisconsin. Geoderma, v.77, p.137-154, 1997.

JACKSON, M.L. Soil chemical analysis: Advanced course. 2. ed. Madison: M.L. Jackson, 1969, 895p.

JEFFREY, L.S.; HALVORSON, J.J.; PAPENDICK, R.I. Using multiple-variable indicator Kriging for evaluating soil quality. Soil Science Society of America Journal , v.57, p.743-749, 1993. 
JENNY, H. Factors of Soil Formation - A system of Quantitative Pedology. New York: McGraw-Hill, 1941. 281p.

JENNY, H. The Soil Resource. Origin and Behavior. New York: Springer-Verlag, 1980. 1v.

JOHNSON, W.M. The pedon and the polypedon. Soil Science Society of America Proceedings, v.27, p. 212-215, 1963.

JOURNEL, A.G.; HUIJBREGTS, C.J. Mining geostatistics. London: Academic Press, 1978. $1 \mathrm{v}$.

KELLOGGS, C. E. Soil interpretation in the soil survey. Washington: USDA-Soil Conservation Service, 1961. 97p.

KINSELLA, J. Improving soil, water and air quality with no-tillage. In: Congresso Nacional de AAPRESID, 5., Mar del Plata, 1997. Anais. AAPRESID, p.91-93.

KIRKBY, M.J. A basis for soil profile modeling in a geomorphic context. Journal of Soil Science, v.36, p.97-121, 1985.

KNOX, E.G. Soil individual and soil classification. Soil Science Society of America Proceedings, v.29, p.79-84, 1965.

KUILENBURG, J. van; GRUIJTER, J.J.de; MARSMAN, B.A.; BOUMA, J. Accuracy of spatial interpolation between point data on soil moisture supply capacity, compared with estimates from mapping units. Geoderma, v.27, p.311-325, 1982. 
LAGACHERIE, P.; CAZEMIER, D.R.; VAN GANNS, P.F.M.; BURROUGH, P.A. Fuzzy k-means clustering of fields in an elementary catchment and extrapolation to a larger area. Geoderma, v.77, p.197-216, 1997.

LARK, R.M. Soil-landscape relationships at within-field scales: an investigation using continuous classification. Geoderma, v.92, p.141-165, 1999.

LEMOS, R.C. de, SANTOS, R.D. dos. Manual de descrição e coleta de solo no campo. 3.ed. Campinas: Sociedade Brasileira de Ciência do Solo, 1996. 83p.

LEPSCH, I.F.; BUOL, S.W.; DANIELS, R.B. Soil landscape relationship in Occidental Plateau of São Paulo State, Brazil: I. Geomorphic Surfaces and Soil Mapping Units. Soil Science Society of America Journal, v.41, p.104-109, 1977.

MAACK, R. Geografia Física do Estado do Paraná. 2 ed. Rio de Janeiro: Livraria Jose Olímpio Editora, 1981. 442p.

MALLARINO, A.P.; OYARZABAL, E.S.; HINZ, P.N. Interpreting within-field relationships between crop yields and soil and plant variables using factor analysis. Precision Agriculture, v.1, p.15-25. 1999.

McBRATNEY, A.B.; WEBSTER, R. Optimal interpolation and isarithmic mapping of soil properties. V. Coregionalization and multiple sampling strategy. Soil Science Society of America Journal, v.34, p.137-162, 1981.

McBRACNEY, A.B.; GRUIJTER, J.J. de. A continuum approach to soil classification by modified fuzzy K-means with extragrades. Journal of Soil Science, v.43, p.159-175, 1992. 
McBRATNEY, A.B.; GRUIJTER, J.J. de; BRUS, D.J. Spatial prediction and mapping of continuous soil classes. Geoderma, v.54, p.39-64, 1992.

McBRATNEY, A.B.; PRINGLE, M.J. Spatial variability in soil-implications for precision agriculture. In: PRECISION AGRICULTURE'97: Spatial Variability in Soil and Crop. Oxford, 1997. Proceedings. Oxford: BIOS Scientific Publishers, 1997. v.1, p.3-31.

McBRATNEY, A.B.; ODEH, I.O.A. Application of fuzzy sets in soil science: fuzzy logic, fuzzy measurements and fuzzy decisions. Geoderma, v.77, p.85-113, 1997.

MACKENZIE, N.J.; RYAN, P.J. Spatial prediction of soil properties using environmental correlation. Geoderma, v.89, p.67-94, 1999.

McSWEENEY, K.; GESSLER, P.E.; SLATER, B.K.; HAMMER, R.D.; BELL, J.; PETERSEN, G.W. Towards a new framework for modeling the soil landscape continuum. In: AMUNDSON, R., SINGER, M.; HARDIN, J. (Eds.) Factors of Soil Formation: A Fiftieth Anniversary Retrospective. Madison: Soil Science Society of America, 1994. p.127-145. (Special Publication 33).

MILLER, M.P.; SINGER, M.J.; NIELSEN, D.R. Spatial variability of wheat yield and soil properties on complex hills. Soil Science Society of America Journal, v.52, p.1133-1141, 1988.

MILNE, G. Some suggested units of classification and mapping particular for East African Soils. Soil Research. v.4, n.3, 1935.

MONDARDO, A. Resultados de pesquisa. In: ENCONTRO NACIONAL DE PESQUISA SOBRE CONSERVAÇÃO DO SOLO. Passo Fundo, 1978. Anais. Passo Fundo: EMBRAPA-CNP Trigo, 1978, p.249-252. 
MOORE, I.D.; GRAYSON, R.B.; LADSON, A.R. Digital terrain modeling: A review of hydrological, geomorphological and biological applications. Hyd rology Processes, v.5, p.3-30, 1991.

MOORE, I.D.; GESSLER, P.E.; NIELSEN, G.A.; PETERSON, G.A. Soil Attribute prediction using terrain analysis. Soil Science Society of America Journal, v.57, p.443-452, 1993a.

MOORE, I.D.; GESSLER, P.E.; NIELSEN, G.A.; PETERSON, G.A. Terrain analysis for soil specific crop management. In: SOIL SPECIFIC CROP MANAGEMENT: A workshop on research and development issues. Madison, 1992. Proceedings. Madison: American Society of Agronomy,1993. p.27-55.

MOORE, G.A.; TYNDALE-BISCOE, J.P. Estimation of the importance of spatially variable nitrogen application and soil moisture holding capacity to wheat productions. Precision Agriculture, v.1, p.27-38, 1999.

MULLA, D.J.; BHATTI, A.U; HAMMOND, M.W; BENSON, J.A. A comparison of winter wheat yield and quality under uniform versus spatially variable fertilizer management. Agriculture Ecosystem Environmental v.38, p.301-311, 1992.

MULLA, D.J.; SCHEPERS, J.S. Key processes and properties for site-specific soil and crop management. In: PIERCE, F.J.; S ADLER, E.J.(Eds.) The state of sitespecific management for agriculture. Madison: ASA Misc. Publ. ASA, CSSA, SSSA, 1997, p.1-18.

NIELSEN, D.R.; ALEMI, M.H. Statistical opportunities for analyzing spatial and temporal heterogeneity of field soils. Plant and Soil, v.115,p.285-296, 1989. 
NIELSEN, D.R.; WENDROTH, O; PARLANGE, M.B. Opportunities for examining on-farm soil variability. In: SITE-SPECIFIC MANAGEMENT FOR AGRICULTURAL SYSTEMS. Minneapolis, 1994. Proceedings. Madison: ASA, CSSA, SSSA, 1995. p.95-131.

ODEH, I. O. A.; CHITTLEBOROUGH, D. J.; MCBRATNEY, A. B. Elucidation of soil-landform interrelationships by canonical ordination analysis. Geoderma, v.49, p.1-32, 1991 .

ODEH, I.O.A.; MCBRATNEY, A.B.; CHITTLEBOROUGH, D.J. Soil pattern recognition with fuzzy c-means: Application to classification and soil-landform interrelationships. Soil Science Society of America Jou rnal, v.56, p.506-516, 1992.

ODEH, I.O.A.; MCBRATNEY, A.B.; CHITTLEBOROUGH, D.J. Spatial prediction of soil properties from landform attributes derived from a digital elevation model. Geoderma, v.63, p.197-214, 1994

OVALLES, F.A.; COLLINS, M.E. Soil-landscape relationship and soil variability in north central Florida. Soil Science Society of America Jou rnal , v.50, p.401-408, 1986.

PENNOCK, D.J.; ZEBARTH, B. J.; DEJONG, E. Landform classification and soil distribution in hummocky terrain, Saskatchewan, Canada. Geoderma, v.40, p.297-315, 1987.

PIERCE, F.J.; WARNCKE, D.D.; EVERETT, M.W. Yield and Nutrient Variability in Glacial Soils of Michigan. In: SITE-SPECIFIC MANAGEMENT FOR AGRICULTURAL SYSTEMS. Minneapolis, 1994. Proceedings. Madison: ASA, CSSA, SSSA, 1995. p.133-151. 
RAIJ, B. van. Capacidade de troca de cations de frações organicas e minerais de solos. Bragantia. v.28, p.85-112, 1969.

RAIJ, B. van ; QUAGGIO, J.A; CANT ARELLA, H.; FERREIRA, M.E.; LOPES, A.S.; BATAGLIA, C.O. Análise química do solo para fins de fertilidade. Campinas: Fundacão Cargil, 1987, 170p.

RAIJ, B. van; CANTARELLA, H;. QUAGGIO, J.A; FURLANI, A.M.G.

Recomendacao de adubacao e calagem para o Estado de Sao Paulo. Campinas: Instituto Agronomico/ Fundacao IAC, 1996. 285p. (Boletim, 100)

RAMOS, M. Sistemas de preparo mínimo do solo: técnicas e perspectivas para o Paraná. Ponta Grossa: Empresa Brasileira de Pesquisa Agropecuária, Representante Estadual do Paraná, 1976. 23p. (Comunicado técnico, 1).

REICHARDT, K.; VIEIRA, S. R.; LIBARDI, P. L. Variabilidade espacial de solos e experimentação de campo. Revista Brasileira de Ciencia do Solo, v.10, p.1-6, 1986.

RETALLACK, G. J. Book review of: Spatial Variability of Soils and Landforms. Geoderma, v.56, p.170-172, 1992.

RUHE, R. V. Geomorphic surfaces and the nature of soils. Journal of Soil Science, v.82, p.441-445, 1956.

RUHE, R. V. Elements of the soil landscape. In: INTERNATONAL CONGRESS OF SOIL SCIENCE, 7., Madison, 1960. Transactions. New York: Elsevier 1960. v.23, p.165-170 
RUHE, R.V.; WALKER, P.H. Hillslope models and soil formation: I. Open systems. In: INTERNATONAL CONGRESS OF SOIL SCIENCE, 9., Adelaide, 1968.

Transactions. New York: Elsevier, 1968. v.4, p.551-560.

RUHE, R.V. Geomorphology. Atlanta: Houghton Mifflin, 1975. 1 v.

SÁ, J.C.M. Plantio direto em campos nativos. In: PEIXOTO, R.T.dos G.; AHRENS, D.C.; SAMAHA, M.J. (Eds.) Plantio direto: o caminho para uma agricultura sustentável. Ponta Grossa: Instituto Agronômico do Paraná, 1997. cap.2, p.53-65.

SÁ, J.C.M. Manejo da fertilidade do solo no sistema plantio direto. In: SIQUEIRA, J.O.; MOREIRA, F.M.S.; LOPES, A.S.; GUILHERME, L.R.G.; FAQUIN, V.; FURTINI NETO, A.E.; CARVALHO, J.G. (Eds.), Soil fertility, soil biology, and plant nutrition interrelationships, Lavras: UFLA, Sociedade Brasileira de Ciência do Solo, 1999. p. 267-320.

SÁ, M.F.M. Influência do material de origem, superfícies geomórficas e posição na vertente nos atributos de solos da região dos Campos Gerais, PR. Curitiba, 1995, 205p. Dissertação (M.S.) - Universidade Federal do Paraná.

SANCHEZ, P.A. Properties and management of soils in the tropics. New York: A Wiley-Interscience, 1976. p. 135-161: Clay mineralogy and ion exchange process.

SAS INSTITUTE. JMP IN - Statistical Discovery Software, version 3,0 forWindows. Belmont , 1997

SCHELLING, J. Soil genesis, soil classification and soil survey. Geoderma, v.4, p.165-193, 1970 
SCHEPERS, J.S. World trend in Precision Agriculture. In: CONGRESSO NACIONAL DE MILHO E SORGO, 23., Uberlândia, 2000. Palestra em CD-Rom., Uberlândia: ABMS, 2000.

SIDIRAS, N., PAVAN,M.A. Influência do sistema de manejo do solo no nível de fertilidade. Revista Brasileira de Ciência do Solo, v.9, p.249-254, 1985.

SILVA, J.E.; LEMANSKI, J.; RESCK, D.V.S. Perdas de matéria orgânica e suas relações com a capacidade de troca catiônica em solos da região de cerrados do oeste baiano. Revista Brasileira de Ciencia do Solo, v.18, p.541-547, 1994.

SIMONSON, R.W.; GARDNER, D.R. Concepts and functions of the pedon In: INTERNATONAL CONGRESS OF SOIL SCIENCE, 7., Madison, 1960. Transactions. New York: Elsevier 1960. v.4, p.127-131.

SIMONSON, R.W. Concept of soil. Advances in Agronomy, v.20, p.1-47, 1968.

SKIDMORE, A.K. A comparison of techniques for calculating gradient and aspect from a gridded digital elevation model. International Journal of Geographical Information Systems, v.3, p.323-34, 1989.

SLATER, B.K. Continuous classification and visualization of soil layers: A soillandscape model of Pleasant Valley Wisconsin. Madison, 1994. 156p. Thesis (Ph. D.) - University of Wisconsin.

STONE, J.R.; GILLIAM, J.W.; CASSEL, D.K; DANIELS, R.B.; NELSON, L.A.; KLEISS, H.J. Effects of erosion and landscape position on the productivity of Piedmont soils. Soil Science Society of America Journal, v.49, p.987-991, 1985. 
TIMLIN, D.J.; PACHEPSKY, YA; SNYDER, V.A.; BRYANT, R.B. Spatial and temporal variability of corn grain yield on a hillslope. Soil Science Society of America Journal , v.62, p.764-773, 1998.

THOMPSON, W. H.; ROBERT, P. C. Evaluation of mapping strategies for variable rate applications. In: SITE-SPECIFIC MANAGEMENT FOR AGRICULTURAL SYSTEMS. Minneapolis, 1994. Proceedings. Madison: ASA, CSSA, SSSA, 1995. p.303-323.

THOMAS, G.T. Labranza zero, resultados en Estados Unidos de la America y observaciones en campos argentinos. Rosario: AAPRESID, 1990. 16p.

TRANGMAR, B.B.; YOST, R.S.; UEHARA, G. Applications of geostatistics to spatial studies of soil properties. Advances in Agronomy, v.38, p.45-94, 1985.

TRANGMAR, B.B.; YOST, R.S.; UEHARA, G. Spatial dependence and interpolation of soil properties in West Sumatra, Indonesia: I. Anisotropic variation. Soil Science Society of America Journal, v.50, p.1391-1395, 1986.

TREIN, E.; FUCK, R.A.; LOPES, J.A.; PALKA, J.; MURATORI, A. Folha Geológica de Tibagi. Curitiba: Comissão da Carta Geológica do Paraná, CODEPAR - UFPR, 1966. Escala 1:50.000.

TROEH, F.R. Landform parameters correlated to soil drainage. Soil Science Society of America Proceedings, v.28, p.808-812, 1964.

UEHARA, G. Management of isoelectric soils of humid tropics. In: LAL, R.; KIMBLE, J.; LEVINE, E.; STEWART, B.A, (Eds). Soil management and greenhouse effect. Boca Raton: CRC Press, 1995. p.271-278. 
UEHARA, G.; KENG, J. Management implications of soil mineralogy in Latin America. In: BORNEMIZA, E.; ALVARADO, A. (Eds.) Soil management in tropical America. Raleigh: North Carolina State University, 1975. p. 351-362.

USERY, E.L.; POCKNEE, S.; BOYDELL, B. Precision farming data management using geographic information systems. Photogram metric Engineering \& Remote Sensing, v.61, n.11, p.1383-1391, 1995.

VIDAL-TORRADO, P. Relacões solo x relevo em Mococa (SP): Influência das características topográficas e posição na vertente nos atributos do solo. Piracicaba, 1989. 205p. Dissertação (Mestrado.) - Escola Superior de Agricultura "Luis de Queiroz", Universidade de São Paulo.

VIEIRA, S. R.; NIELSEN, D.R.; BIGGAR, J.W. Spatial variability of field-measured infiltration rate. Soil Science Society of America Journal , v.45, p.1040-1048, 1981.

VIEIRA, S. R.; HATFIELD, T.L.; NIELSEN, D. R; BIGGAR, W. Geostatistical theory and application to variability of some agronomical properties. Hilgardia, v.51, n.3, p.1-75, 1983.

VISCARRA, R.A.; McBRATNEY, A.B. Preliminary experiments toward a suitable soil sensor for continuous, "on the go" field $\mathrm{pH}$ measurements. In: PRECISION AGRICULTURE' 97, Oxford: BIOS Scientific Publishers, 1997, v.2, p. 493-501.

WAMBEKE, A.R. van. Criteria for classifying tropical soils by age. Journal of Soil Science, v.13, p.124-132, 1962.

WEBSTER, R. Fundamental Objections to the $7^{\text {th }}$ approximation. Journal of Soil Science, v.19, p.354-366, 1968. 
WEBSTER, R.; BURROUGH, P.A. Multiple discriminant analysis in soil survey. Journal of Soil Science, v.25, p.120-134, 1974.

WEBSTER, R. Quantitative and numerical methods in soil classification and survey. Oxford: Oxford University Press, 1977. 1v.

WENDROTH, O.; REYNOLDS, W.D; VIEIRA, S.R.; REICHARDT, K.; WITTH, S. Statistical Approaches to the analysis of soil quality data. In: GREGORICH, E.G.; CARTER, M.R. (Eds.) Soil Quality for crop production and ecosystem health. Amsterdam: Elsevier, cap.1, 1997. p. 247-276.

WILDING, L.P. Spatial variability: its documentation, accommodation and implication to soil surveys. In: NIELSEN, D.R.; BOUMA, J. (Eds.). Soil Spatial Variability. Wageningen: Pudoc, 1985. 195p

WUNCHE, W.A.; DENARDIN, J.E. Perdas de solo por escorrimento de água sob chuva natural em latossolo vermelho escuro nas culturas de trigo e soja. In: ENCONTRO NACIONAL DE PESQUISA SOBRE CONSERVAÇÃO DO SOLO, 2, Passo Fundo, 1978, Anais, Passo fundo, EMBRAPA/CNP-Trigo, 1978. p.289-96.

YAALON, D.H. Conceptual models in pedogenesis: can soil-forming functions be solved? Geoderma, v.14, p.189-205, 1975.

YOST, R.S.; UEHARA, G.; FOX, R.L. Geostatistical analysis of soil chemical properties of large land areas. I. Semivariograms. Soil Science Society of America Journal, v.46, p.1028-1032, 1982.

ZADEH, L.A. Fuzzy sets. Information and Control, v. 8, p.338-353. 1965. 